\title{
Development and evaluation of a school-based organ donation education programme
}

Citation for published version (APA):

Reubsaet, A. (2004). Development and evaluation of a school-based organ donation education programme. [Doctoral Thesis, Maastricht University]. Universiteit Maastricht. https://doi.org/10.26481/dis.20040929ar

Document status and date:

Published: 01/01/2004

DOI:

10.26481/dis.20040929ar

Document Version:

Publisher's PDF, also known as Version of record

\section{Please check the document version of this publication:}

- A submitted manuscript is the version of the article upon submission and before peer-review. There can be important differences between the submitted version and the official published version of record.

People interested in the research are advised to contact the author for the final version of the publication, or visit the DOI to the publisher's website.

- The final author version and the galley proof are versions of the publication after peer review.

- The final published version features the final layout of the paper including the volume, issue and page numbers.

Link to publication

\footnotetext{
General rights rights.

- You may freely distribute the URL identifying the publication in the public portal. please follow below link for the End User Agreement:

www.umlib.nl/taverne-license

Take down policy

If you believe that this document breaches copyright please contact us at:

repository@maastrichtuniversity.nl

providing details and we will investigate your claim.
}

Copyright and moral rights for the publications made accessible in the public portal are retained by the authors and/or other copyright owners and it is a condition of accessing publications that users recognise and abide by the legal requirements associated with these

- Users may download and print one copy of any publication from the public portal for the purpose of private study or research.

- You may not further distribute the material or use it for any profit-making activity or commercial gain

If the publication is distributed under the terms of Article $25 \mathrm{fa}$ of the Dutch Copyright Act, indicated by the "Taverne" license above, 


\title{
Development and evaluation of a school-based organ donation education programme
}

\author{
Astrid Reubsaet
}





\section{Development and evaluation of a school-based organ donation education programme}

\section{PROEFSCHRIFT}

ter verkrijging van de graad van doctor

aan de Universiteit Maastricht,

op gezag van de Rector Magnificus

Prof. Mr. G.P.M.F. Mols,

volgens het besluit van het College van Decanen, in het openbaar te verdedigen

op woensdag 29 september 2004 om 14.00 uur

door

Astrid Reubsaet 


\section{Promotores:}

Prof. dr. H.W. van den Borne

Prof. dr. ir. J. Brug

Prof. dr. J.P. van Hooff

\section{Beoordelingscommissie:}

Prof. dr. N.K. de Vries (voorzitter; Universiteit Maastricht)

Prof. dr. G. Kootstra (academisch ziekenhuis Maastricht)

Prof. dr. T.G.W.M. Paulussen (TNO/PG)

Prof. dr. R.M. Ryckman (University of Maine, USA)

Prof. dr. H. de Vries (Universiteit Maastricht)

ISBN:

Colofon

Printed by: Unigraphic Maastricht

Cover design by: Guus Reubsaet and Kaspar Guyaux

Layout by: Guus Reubsaet

The study presented in his thesis was conducted at the Maastricht Care and Public Health Research Institute (CAPHRI), which participates in the Netherlands School of Primary Care Research (CaRe), acknowledged in 1995 by the Royal Dutch Academy of Science (KNAW).

The study was initiated by the Kidney Patient Organisation Maastricht and was funded by the Dutch Kidney Foundation, the Dutch Ministry of Health, CZ Health Insurances and NIGZ/Donor Education. 


\section{Contents}

General introduction 1

PART 1 Predictors of organ donation registration

Chapter 1 Determinants of the intention of Dutch

adolescents to register as organ donors.

Chapter 2 Predictors of organ donation registration among

Dutch adolescents.

\section{PART 2 Pilot studies}

Chapter 3 The impact and evaluation of two school-based

interventions on intention to register an organ donation preference.

Chapter 4 The effects of practicing registration of organ donation preference on self-efficacy and registration intention: an enactive mastery experience.

\section{PART 3 Effect and Process evaluation}

Chapter 5 The impact of an organ donation registration information programme for high school students in the Netherlands.

Chapter 6 Process evaluation of a school-based education programme about organ donation and registration and the intention for continuance.

\section{Chapter 7 General discussion and conclusions}



General introduction

1

General introduction

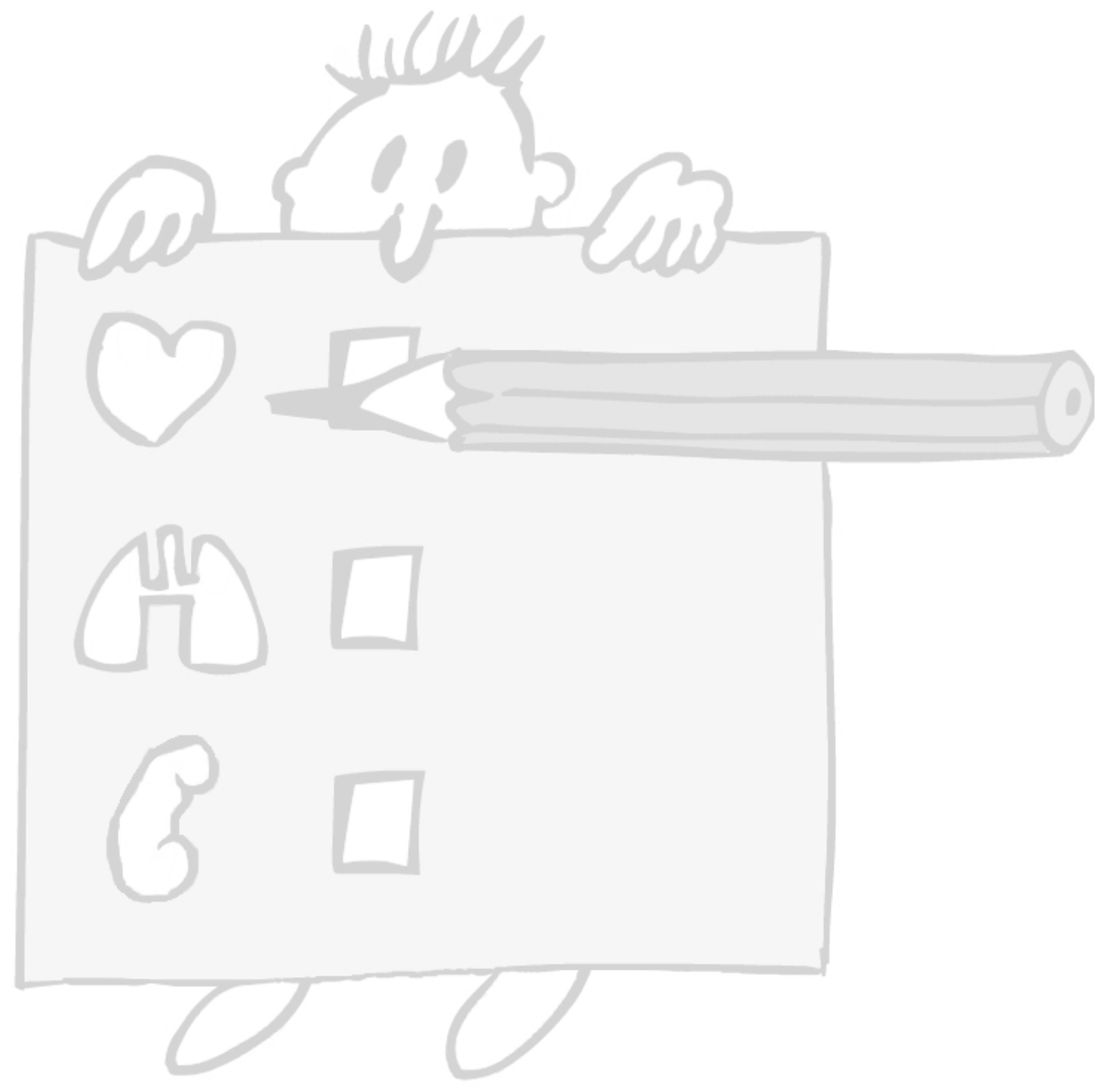




\section{I ntroduction}

With the development of organ transplantation into a more and more effective medical intervention, its success is impeded by a shortage of organs and growing waiting lists. Because of improved technology, better medication to fight physical rejection of donor organs or tissues and more experience with treatments, the eligibility criteria for patients with organ deficiencies or in need of body tissues have enlarged. Consequently, the number of patients requiring a donor organ has increased. For a large group, patients with kidney failure, the costs involved in organ transplantation are much lower than the costs for continued dialysis, while the quality of life is much higher. However, in most countries, the number of patients is growing more rapidly than the number of donors, resulting in an increase in the size of the waiting lists (Cohen, 2001; Kranenburg, Willems, Sieber-Rasch, Geertsma \& Ploeg, 1998; Seldenrijk, 1993; Van 't Hoog, 2001). The Netherlands has one of the lowest numbers of donors per million inhabitants (13 donors p.m.i.) compared to most other WestEuropean countries (e.g., 29.1 donors p.m.i. in Spain) (Coppen, Marquet $\&$ Friele, 2003).

The number of donor organs and tissues that become available is partly dependent on the organ donation legislation and registration system of organ donors (Brug, van Vugt, Van den Borne, Brouwers \& Van Hooff, 2000; Coppen et al., 2003). In 1998, the Dutch government introduced new legislation related to organ donation, Wet Orgaandonatie (WOD), and a new registration system went into effect. The aim of this legislation was fourfold (ZonMW, 2001):

1. Optimise the legal security of both citizens and health care professionals.

2. Increase potentially available organs and tissues.

3. Ensure an equitable distribution of organs and tissues.

4. Prevent the trade in organs and tissues. 
The new organ donation registration system is based on the opting-in principle, which means that each citizen decides voluntarily by virtue of his or her own will and integrity of the body whether he/she wants to be registered as an organ donor. In the Netherlands, this decision is centrally registered in the so-called Donor Register and registration is voluntary. In a one-time action in 1998, all Dutch inhabitants of 18 years and older received information about the new registration system and a registration form for organ donation preferences from the Dutch Ministry of Health. From 1998 onward, every Dutch person who reaches the age of 18 years receives a registration form for completion. Dutch inhabitants of 18 years and older can register their preference according to five alternatives:

1. Registration as a posthumous organ and tissue donor.

2. Registration as a posthumous donor for specific organs and tissues.

3. Registration as a non-donor.

4. Registration to leave the decision to the next of kin.

5. Registration to leave the decision to a specific person.

It was expected that the number of donor organs and tissues would increase as a result of the introduction of the new registration system in 1998. However, data from the Dutch Donor Register and results of a study on the evaluation of the new organ donation law show that the number of available posthumous organ and tissue donors failed to meet expectations and has even decreased from 228 donors in 1995 to 165 donors in 1999 (Van 't Hoog, 2001; ZonMW, 2001). One of the causes for the shortage of donor organs is the fact that only $37.8 \%$ of the adult Dutch population reacted to the invitation of the government to register their organ donation preference, leaving more than 7.5 million unregistered people (Donorregister, 2003b). The new law states that, in cases where deceased persons did not register their donation preference, the next of kin will need to be asked for permission to donate organs and tissues. In such situations, $85 \%$ of the next of kin refuse to give permission for extraction of organs and tissues due to poor communication regarding organ donation wishes within the family (Kokkedee, 1998; NIGZ-Donorvoorlichting, 2003; Van 't Hoog, 2001; ZonMW, 2001). 
In 2000, the large-scale information campaign of 1998 that assisted the introduction of the new organ donation legislation, was evaluated (Ipso Facto, 2000; ZonMW, 2001). The results showed that the generic mass media information had little effect on the number of people who registered an organ donation preference and on the organ donation preferences of the Dutch inhabitants. Based on these results, it was recommended that educational organ donation interventions should be targeted at separate groups with low registration rates. In 2003 , only $33 \%$ of the 18 -year old adolescents responded to the invitation of the Dutch government to register their organ donation preferences in the Dutch registry (Donorregister, 2003a). Each year, on average 190,000 adolescents in the Netherlands reach the age of 18 and, hence, are approached to register an organ donation preference. This group is considered to be the most important target group for encouraging organ donation registration (Donorregister, 2000).

Adolescents should become aware of the topic of organ donation, form an opinion regarding organ donation and subsequently register this organ donation preference (Sanders, 2003). Therefore, a school-based organ donation registration education programme was developed preparing adolescents to make a well-informed decision about organ donation and to encourage them to register their preferences.

In this thesis the development, implementation and evaluation of this organ donation education programme will be presented and discussed. The remaining part of the present introduction provides a description of two organ donation legislation systems, after which the theoretical framework used in the different studies is described. Subsequently, a summary of empirical findings of determinant studies on organ donation among adolescents and a review of different educational programmes on organ donation are presented. The last section stresses the importance of the application of the model for Planned Health Education Interventions and presents an outline of the thesis. 


\section{Organ donation legislation}

In the literature, different legislative systems concerning organ donation are described. In West-European countries, two registration systems are operational. The first system is the opting-in legislation or decision system. Germany and the United Kingdom are based on this opting-in principle, which means that the decision whether a person wants to donate organs and tissues posthumously is registered on a donor card. In case an organ donation will is not available, permission for donation will need to be asked from the next of kin (Cleiren \& Van Zoelen, 1998; Kodde \& Kerkhoff, 1992; Roels, Coosemans, Christiaens, Waer \& Vanrenterghem, 1995). In the United States, health care providers rely totally on the relatives' decision to eventually consent or object to donation (required request) (Cleiren \& Van Zoelen, 1998).

In another frequently used system, the opting-out system or presumed consent legislation, each citizen is a posthumous organ and tissue donor, unless a person indicates during life explicitly (often by registration) to refuse donating organs and tissues posthumously. If no declaration of objection is found, a deceased person is considered to be a donor. Austria, Belgium, France and Poland operate according to the opting-out legislation (Cleiren \& Van Zoelen, 1998; Gnant et al., 1991; Kodde $\&$ Kerkhoff, 1992). Within this system, differences exist with respect to the rights of the next of kin. In Austria and Sweden, a pure opting-out legislation is applied in which citizens who refuse to donate their organs and tissues posthumously are obliged to carry an anti-donor card. Contrary to the situation in Austria, relatives in Belgium, Spain, France and I taly still can object to donation when the deceased did not explicitly indicate donation refusal (i.e., weakened presumed consent). Thus, these legislative organ donation systems also contain elements from the decision system (Cleiren \& Van Zoelen, 1998; Coppen et al., 2003; Roels et al., 1995). 


\section{Determinants of organ donation among adolescents}

An educational programme aimed at influencing organ donation registration behaviour should be based on empirical evidence on possible determinants associated with registration as a potential posthumous organ and tissue donor, as well as with registration of an organ donation preference (Bartholomew, Parcel, Kok \& Gottlieb, 2001). The use of theory is crucial during the different stages of developing, implementing and evaluating educational interventions, since theory explains behaviour and provides insight into how to achieve behaviour change (Glanz, Lewis \& Rimer, 1997).

\section{Social Cognitive Theory}

In the development of health education interventions, Bandura's Social Cognitive Theory (SCT) (1986) is often applied because it addresses psychosocial factors which may influence behaviour as well as intervention tools for behaviour change (Baranowski, Perry \& Parcel, 1990). According to Bandura (1986), (intentions to participate in) a particular behaviour is influenced by three important factors. First, people are more likely to participate in behaviour, which they think will produce positive consequences (positive outcome expectations) and avoid behaviour of which they evaluate the consequences negatively (negative outcome expectations). Second, social outcome expectations refer to the expected social reactions (rewards or disapprovals) certain behaviour may evoke when performing that behaviour. Third, self-efficacy expectations are identified as the most important prerequisites for behavioural intentions and refer to the judgements a person makes about his or her ability to successfully perform a specific behaviour. The more positive a person's self-efficacy expectation with respect to a particular behaviour is, the more motivated and successful he or she is expected to be in performing that behaviour.

The present thesis focuses on changing or solving a social problem (i.e., increasing the number of adolescents who are willing to register an organ donation preference) and consequently may be considered as applied behavioural research. In research with such a focus, often, concepts from multiple theoretical frameworks are used (Kok, Schaalma, De Vries, Parcel $\&$ Paulussen, 1996). Therefore, our main theoretical framework (SCT) was 
extended with concepts from other theoretical models, which have been found to be significantly associated with organ donation (e.g., knowledge about organ donation registration).

\section{Predictors of organ donation registration intention and behaviour}

Various studies have contributed to the understanding of reasons why people may or may not register as potential organ and tissue donors. The present paragraph provides a summary of possible determinants of organ donation registration intentions and behaviour and is structured on the basis of the concepts of SCT extended with factors from other theoretical perspectives. Some of these studies were conducted among adolescents (Anantachoti, Gross \& Gunderson, 2001; Baluch, Randhawa, Holmes \& Duffy, 2001; Birkimer, Barbee, Francis \& Berry, 1994; Brug, van Vugt et al., 2000; Gross, Martinoli, Spagnoli, Badia \& Malacrida, 2001; Horton \& Horton, 1990, 1991; Sanner, 2002; Sherman, Sherman, Smith \& RickertWilbur, 2001; Skowronski, 1997).

Numerous studies have identified positive and negative outcome expectations as predictors of willingness to register as an organ and tissue donor as well as of being a potential donor (i.e., carrying an organ donor card). The most frequently used measurement scale to assess organ donation related outcome expectations is the one developed by Goodmonson and Glaudin (1971). Results from studies using this scale show moderate to very strong relationships between outcome expectations and intention (Horton \& Horton, 1990, 1991; Morgan \& Miller, 2002) and between outcome expectations and behaviour (Goodmonson \& Glaudin, 1971; Morgan \& Miller, 2002; Skumanich \& Kintsfather, 1996). Parisi and Katz (1986) developed a questionnaire to measure positive and negative dimensions of outcome expectations related to organ donation. The absence of negative outcome expectations appeared to be a much stronger correlate of intention to register as organ donor than the presence of positive outcome expectations (Brug, van Vugt et al., 2000; Cacioppo \& Gardner, 1993; Horton \& Horton, 1990; Parisi \& Katz, 1986; Sanner, 2002; Skowronski, 1997). Particularly, people who are scared of being declared dead too soon (Brug, van Vugt et al., 2000; Hessing \& Elffers, 1986; Skowronski, 1997), who think that by being registered as an organ donor, their treatment may be discontinued in an early stage (Nolan \& Spanos, 
1989; Yeung, Kong \& Lee, 2000), or who think that their body may be mutilated after organ donation (Brug, van Vugt et al., 2000; McNamara et al., 1999; Nolan \& Spanos, 1989; Skowronski, 1997) were found to be less willing to register as a posthumous organ and tissue donor.

Social outcome expectations were also found to explain organ donation registration intentions (Brug, van Vugt et al., 2000; Morgan \& Miller, 2002; Morgan, Miller \& Arasaratnam, 2002). Moreover, Morgan and Miller (2002) reported that people who experience greater social normative support for organ donation are more likely to be registered as a potential organ and tissue donor. Kopfman and Smith (1996) found that people who carried an organ donor card received positive support for signing an organ donor card from at least two other people who were important to them.

Few studies have examined the influence of self-efficacy beliefs on the intention to register as a posthumous organ and tissue donor or on actual registration. In one study on psychological factors related to signing an organ donor card, donors reported greater self-efficacy about donating their organs and tissues (Robbins, 1990). Brug and his colleagues (2000) found that self-efficacy was not associated directly with organ donation registration intention among Dutch adolescents but did have an indirect influence via negative and positive outcome expectations.

Knowledge about organ donation refers to the extent to which people are aware of facts related to organ donation (Morgan et al., 2002). Knowledge about organ donation and registration has been identified as a direct, positive correlate of willingness to posthumously donate organs and tissues (Horton \& Horton, 1991; Kopfman \& Smith, 1996; McNamara et al., 1999; Miller \& Hagihara, 1997; Morgan \& Miller, 2002; Schulz, Meier, Clausen, Kuhlencordt \& Rogiers, 2000; Yeung et al., 2000) as well as a predictor of organ donation registration behaviour (Horton \& Horton, 1991; Kopfman \& Smith, 1996; Morgan \& Miller, 2002; Morgan et al., 2002). Few studies did not find a significant effect of knowledge on organ donation intention or registration behaviour (Alden \& Cheung, 2000; Brug, van Vugt et al., 2000; Horton \& Horton, 1990; Radecki \& Jaccard, 1999). 
Further, studies on determinants of organ donation showed that adolescents who had previously thought about organ donation registration (prior thought) were more willing to donate organs and tissues posthumously (Birkimer et al., 1994; Carducci, Deuser, Bauer, Large \& Ramaekers, 1989; Smith, Morrison, Kopfman \& Ford, 1994). Furthermore, communication about organ donation with family members appeared to be positively associated with intention to sign an organ donor card. People who had discussed organ donation registration issues with family members were more likely or willing to register as organ donors (Evers, Farewell \& Halloran, 1988; Gross et al., 2001; McNamara et al., 1999; Nolan \& McGarth, 1990).

Lastly, one study showed that involvement with the subject of organ donation (i.e., the extent to which people believe that organ donation is important or has significant consequences for their own lives) was associated indirectly with the intention to register as a posthumous organ and tissue donor (Skumanich \& Kintsfather, 1996).

\section{The impact of organ donation education programmes}

Several studies have been conducted to assess the impact of organ donation education programmes. However, relatively few studies have been evaluated empirically (Morgan et al., 2002). The literature concerning organ donation campaigns, general organ donation effect studies and school-based effect studies successively are described.

\section{Organ Donation Campaigns}

Few examples of large-scale organ donation campaigns exist. In Sweden, an organ donor-card campaign attempted to increase public awareness of organ donation as well as to increase the number of people who signed an organ donor card (M Sanner, Hedman \& Tufveson, 1995). Results of a quasi-experimental evaluation study among 5600 Swedish inhabitants showed that the distribution of a brochure with two donor cards was most effective in increasing the number of people with donor cards and the number of people who had talked about their organ donation preference with family members, compared to an extensive information package and a 
combination of the brochure and the extensive information package. I mprovement in awareness of organ donation was achieved in all campaign areas.

Cossé and Weisenberger (2000) evaluated a multi-media national promotion campaign for organ donation in the United States. This four-year study consisted of four cross-sectional surveys. Results showed that the number of signed organ donor cards significantly increased in the course of the campaign, whereas no changes in attitude were observed. The absence of a control condition in this study made it impossible to study the success or failure of the campaign.

Results from an evaluation study using a quasi-experimental design of a multi-channel and multi-message worksite organ donation campaign in the United States showed that after the campaign, the number of signed organ donor cards increased significantly, people had more favourable intentions and attitudes toward organ donation, and they were more willing to discuss organ donation within their family. However, knowledge about organ donation facts did not significantly increase because of the campaign (Morgan et al., 2002).

\section{General organ donation effect studies}

Two studies tested the effects of 'bereaved protection motives' on the number of people who registered an organ donation preference (Cleiren \& Van Zoelen, 1999; M Sanner et al., 1995). 'Bereaved protection motives' refer to the concerns that someone may have about the problems or conflicts of interest of relatives because of one's death. The results of these studies showed that education programmes using motives emphasising that family members should be protected from having to make a difficult decision after one's death, resulted in a significant increase of signed organ donor registration forms (Cleiren \& Van Zoelen, 1999) as well as a significant increase in donor card holders (M Sanner et al., 1995).

A technique applied in some studies on organ donation is the socalled 'foot-in-the-door'-technique, in which a small initial request is made with the expectation that compliance with this request results in an increase in compliance with a second larger request (Carducci \& Deuser, 1984; Carducci et al., 1989; Freedman \& Fraser, 1966; Girandola, 2002). Studies on the application of the 'foot-in-the-door'-technique to organ 
donation showed that (Carducci \& Deuser, 1984; Carducci et al., 1989; Girandola, 2002) individuals who were asked to comply with the initial request to complete an organ donation questionnaire were more willing to donate organs and tissues posthumously than individuals not requested to comply with an initial request.

\section{School-based organ donation effect studies}

Although several organ donation interventions or campaigns have been developed and evaluated among adults, there are only a few school-based interventions (Table I) developed to inform adolescents about organ donation registration (Anantachoti et al., 2001; Meier, Schultz, Kuhlencordt, Clausen \& Rogiers, 1999; Slavin, 1993; Weaver et al., 1999). Results of these studies showed that knowledge about organ donation issues significantly increased because of such education programmes. Moreover, Meier et al. (1999) conducted a quasi-experimental study with a pre-post design among German students ranging in age from 17 to 20 years and found a significant increase in the willingness to posthumously donate organs and tissue, and a decrease in transplantation specific fears after exposure to an educational segment. Two studies reported a significantly higher willingness to discuss organ donation with family and/or friends (Anantachoti et al., 2001; Slavin, 1993). 


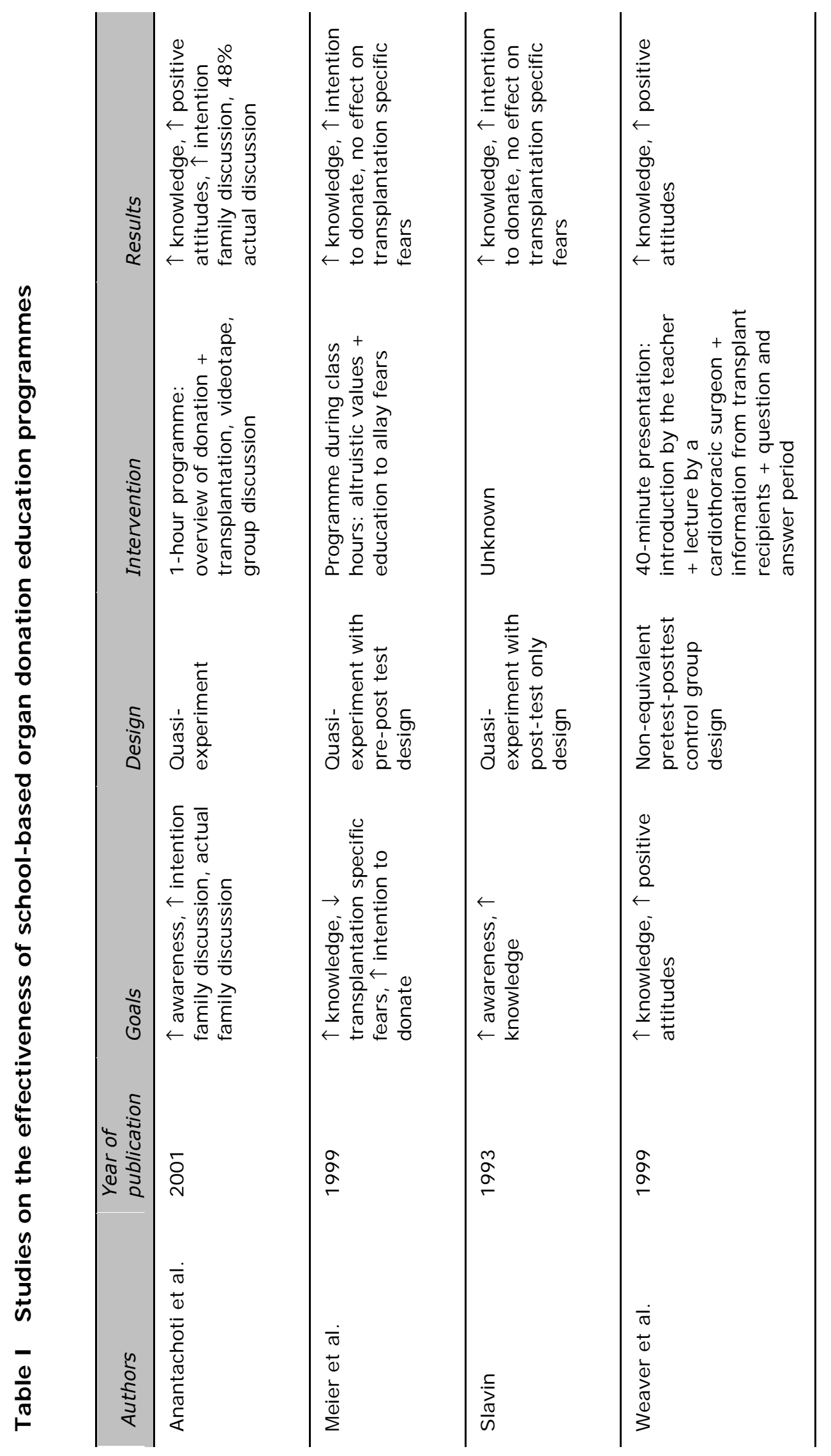




\section{Planned Health Education I nterventions}

Meta-analyses of Health Promotion Intervention revealed that interventions that were developed and implemented in a systematic and planned approach were found to be most effective (Kok, Van den Borne \& Mullen, 1997). Models that effectively have been used in the development of health education interventions are the PRECEED-PROCEDE model (Green \& Kreuter, 1991) and Intervention Mapping (Bartholomew et al., 2001). In such an approach, programme planning and evaluation are performed in sequences of well-defined steps or phases. The model for Planned Health Education Interventions (Brug, Schaalma, Kok, Meertens \& Van der Molen, 2000) identifies five phases in the planning process (Figure I).

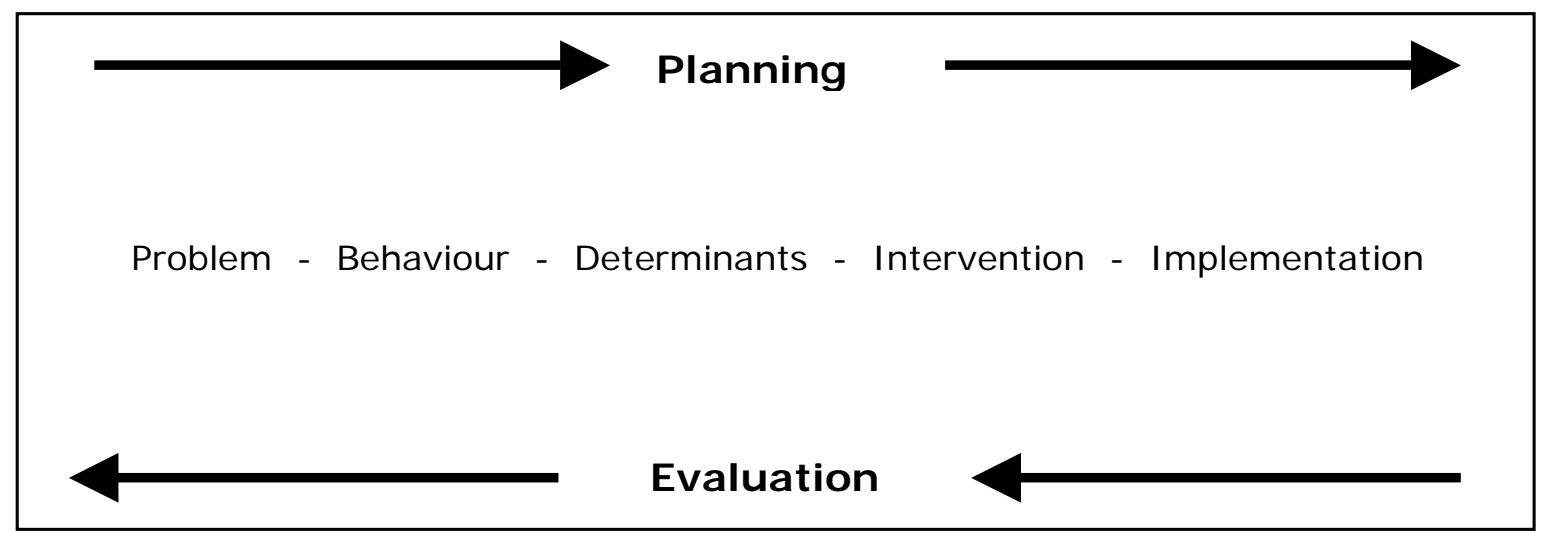

\section{Figure I The model for Planned Health Education I nterventions}

The first phase in the development of a health education intervention is to identify a relevant problem caused by human behaviour. In the second phase, the relevant behaviour that causes the problem should be identified. With regard to organ donation, the problem described in the present thesis is a shortage of potential organ and tissue donors and the behaviour that causes this problem is non-registration of organ donation preferences.

During the third phase, important determinants of the behaviour that causes the problem should be examined. The first part of this thesis describes the determinants of organ donation registration intentions and behaviour among Dutch adolescents. In Chapter 1, important predictors of 
willingness to register as a posthumous organ and tissue donor are presented. A cross-sectional survey was conducted among Dutch adolescents aged 16 to 18 years who had not yet been approached for organ donation registration. Chapter 2 presents the results of a crosssectional survey among Dutch adolescents of 18 and 19 years old, which was conducted in order to study potential determinants of organ donation registration choices.

The fourth phase in the planning model is the actual development of the intervention, which is based on the results of the preceding phases. In the second part of the thesis, the development and testing of the three intervention components is described. Chapter 3 describes two studies on the development and short-term impact of two intervention components in order to encourage adolescents to register their organ donation preferences: a video with group discussion (Study 1) and an interactive computer programme that provided individually tailored information about organ donation registration (Study 2). Chapter 4 describes a Randomised Controlled Trial among Dutch high school students to test whether a registration training session is effective in increasing willingness to register an organ donation preference.

The next phase in the model is the implementation of the intervention, which is followed by the evaluation of the intervention. The last part of this thesis deals with the impact and process evaluation of the implementation of an integrative school-based organ donation education programme. In Chapter 5, the results of a large field study among Dutch high school students are described. It focuses on the short-term impact of the education programme on registration intentions, outcome expectations, knowledge and self-efficacy beliefs. The extent to which teachers implemented the programme as originally planned, the subjective evaluation of the programme and the intention to adopt the programme in the school curriculum are described in Chapter 6.

Chapter 7 provides a summary of the main findings of the studies presented, a discussion on the shortcomings of studies and implications for future research. 


\section{Part 1}

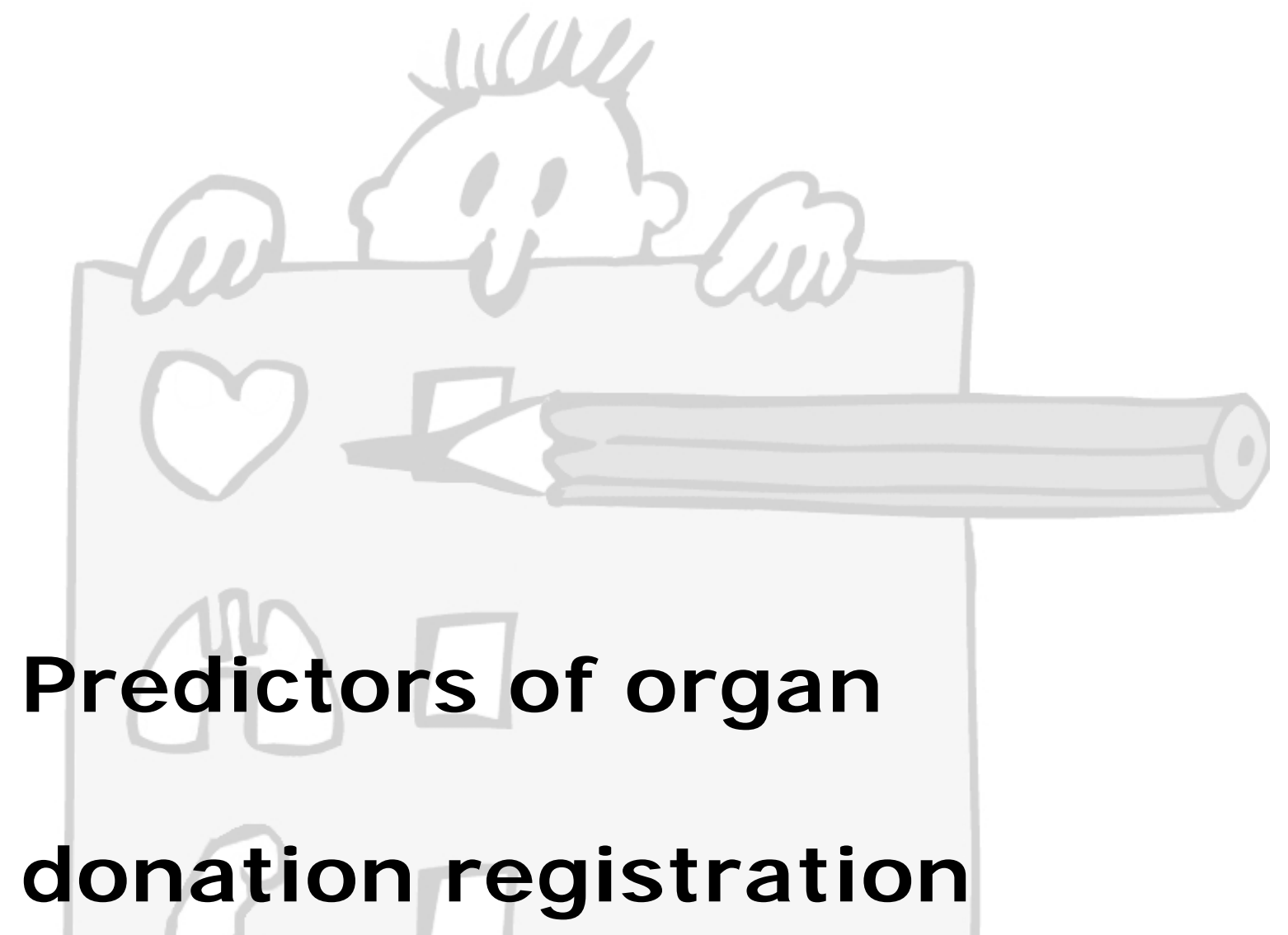





\title{
Chapter 1
}

\section{DETERMI NANTS OF THE I NTENTION OF DUTCH ADOLESCENTS TO REGISTER AS ORGAN DONORS}

\begin{abstract}
This article identifies relevant predictors of willingness among Dutch adolescents to register as posthumous organ and tissue donors. A crosssectional survey was conducted among 1836 Dutch adolescents between 16 and 18 years of age who had not yet been approached for registration. Sixty-seven percent of the participants indicated that they were willing to register as organ donors. In order of greatest association, negative outcome beliefs, anxiety, social outcome expectations, involvement with organ donation issues, positive outcome beliefs, knowledge about organ donation registration, past behaviour and sex were significant predictors of the willingness to register as organ donor. Religion and level of education had a significant bi-variate correlation with intention, but were not significant predictors after controlling for other variables. The results give clear suggestions for tailoring organ donation registration interventions to specific characteristics, beliefs and misconceptions of adolescents.
\end{abstract}

Published as: Reubsaet, A., Van den Borne, H.W., Brug, J., Pruyn, J. \& Van Hooff, J.P. (2001). Determinants of the intention of Dutch adolescents to register as organ donors. Social Science \& Medicine, 53, 383-392. 


\section{Introduction}

In the Netherlands, as in most countries, the demand for organs and tissues exceeds their supply (Brug, van Vugt et al., 2000; Horton \& Horton, 1990; Radecki \& Jaccard, 1997; Van den Driessche, Van Zoelen, Cleiren \& Van Hoorn, 1996). In 1998, almost 1300 people in the Netherlands were waiting for an organ transplantation (Eurotransplant, 1998). The average waiting time for a cadaveric kidney transplantation was about 3.5 years, and for a heart transplantation 0.5 year (Eurotransplant, 1998). The length of the waiting time is dependent on several factors, such as blood group, age and immunization.

Since 1998, all citizens in the Netherlands are explicitly asked at the age of 18 to indicate their preferences with respect to organ donation registration. However, less than one third of these adolescents return the registration form (Kunst \& Witlox, 1999), of whom $54 \%$ in fact register as willing to donate organs posthumously (Rijksvoorlichtingsdienst/DTC, 1999).

To increase the number of potential donors, more adolescents should register as organ donors. Therefore, a school-based education programme will be developed to enable adolescents to make a well-considered decision about registration as organ donors. Such an intervention should be based on a thorough understanding of the motivating determinants to register as an organ donor. The present study was conducted to identify the demographic and psychosocial correlates of willingness to register as an organ donor among a representative sample of Dutch adolescents between 16 and 18 years of age. This information will be used to tailor a schoolbased education programme to the characteristics, information needs and beliefs of Dutch adolescents. 


\section{The New Registration System}

On 1 J anuary 1998, new legislation relating to organ donation (registration) was implemented in the Netherlands (Wet OrgaanDonatie, WOD). The aim of this legislation is, on the one hand, to increase the potential number of available organs and tissues and on the other hand to optimise the rights of citizens and health care professionals. This new law is based on a "decision system", which means that each citizen decides voluntarily by virtue of his/her own will and integrity of his/her body, whether he or she wants to be registered as a potential organ donor. This decision is registered centrally. During a one-time action in 1998, every inhabitant of the Netherlands aged 18 years and older received a registration form with five registration possibilities:

1. Registration as a posthumous organ and tissue donor;

2. Registration as a posthumous donor for specific organs and tissues;

3. Registration as a non-donor;

4. Registration to leave the decision to the next of kin;

5. Registration to leave the decision to a specific person.

Of all inhabitants of 18 years and older ( 12 million), 36\% (4.4 million) returned the registration form (Kunst \& Witlox, 1999). The distribution according to registration preference is presented in Table 1.1 (Rijksvoorlichtingsdienst/DTC, 1999). Most of those who returned their forms, registered as (restricted) organ donor. However, the majority (64\%) did not react to the invitation, leaving more than 7.5 million people whose decision is unknown. According to the new law, these people need to be treated as "category 4", for whom permission will need to be asked from their next of kin, if appropriate. The new system, however, will only work effectively if the organ donation preference of most Dutch people is known. In the present situation, the next of kin will need to be asked for permission in most cases. Past experience has shown that in such a situation, many possible candidates for donation are lost because of logistic and emotional barriers. Health care providers in these circumstances frequently say that they find it difficult to ask such questions, mentioning negative reactions from the next of kin, lack of time, forgetting to ask and confusion about which persons to ask for permission (Cleiren $\&$ Van Zoelen, 1998; Kranenburg et al., 1998). 
Table 1.1 Distribution of Dutch inhabitants over different registration options

\begin{tabular}{lllllll}
\hline & $\begin{array}{l}\text { Organ } \\
\text { donor }\end{array}$ & $\begin{array}{l}\text { Restricted } \\
\text { organ } \\
\text { donor }\end{array}$ & Non-donor & $\begin{array}{l}\text { Decision } \\
\text { to next of } \\
\text { kin }\end{array}$ & $\begin{array}{l}\text { Decision } \\
\text { to a } \\
\text { specific } \\
\text { person }\end{array}$ & Total \\
\hline$N$ & $2,042,525$ & 338,865 & $1,518,475$ & 444,303 & 52,899 & $4,397,067$ \\
$\%$ Registration & 16.45 & 7.71 & 34.53 & 10.10 & 1.20 & 100 \\
$\begin{array}{l}\% \text { Population } \\
(\geq 18)\end{array}$ & 16.72 & 2.77 & 12.43 & 3.64 & 0.42 & 36 \\
\hline
\end{tabular}

This new registration system is based on a decision system (opting-in system). In several other countries this system is also used (for example Germany and in the United States) (Cleiren \& Van Zoelen, 1998; Roels et al., 1995). In general, the decision whether a person wants to be a posthumous organ donor is registered on a donor card. However, in the Netherlands this decision is registered centrally. Therefore, the new Dutch legislation is unique. Austria, Belgium, France and Poland operate according to an 'opting-out' system, which means that each citizen is a posthumous organ and tissue donor, unless a person indicates explicitly (often by registration) to refuse donating organs and tissues posthumously (Cleiren $\&$ Van Zoelen, 1998; Gnant et al., 1991; Kodde \& Kerkhoff, 1992).

Various earlier studies on organ donation have contributed to a basic understanding of why people may or may not register as organ donors (Radecki \& J accard, 1997). In general, these earlier studies were based on expectancy value models. Some of the studies were conducted among adolescents (Birkimer et al., 1994; Brug, van Vugt et al., 2000; Horton \& Horton, 1991). Only one of these studies was conducted in the Netherlands (Brug, van Vugt et al., 2000).

Radecki \& Jaccard (1997) reviewed a number of studies on the willingness to register as an organ donor that were conducted in the United States. They found that religious, cultural, knowledge and altruistic beliefs, as well as social outcome expectations were associated with the intention to register. They further suggested that these beliefs determined a general attitude toward organ donation and that this attitude predicted the willingness to register as a posthumous organ donor. Positive and negative 
outcome beliefs toward registration have also been identified as predictors of the willingness to register as an organ donor. Negative outcome beliefs have been found to have the strongest association with intention (Cacioppo \& Gardner, 1993; Horton \& Horton, 1990; Nolan \& McGarth, 1990; Parisi \& Katz, 1986; Skowronski, 1997). Further, adolescents who were encouraged to spend time thinking about registration as an organ donor reported greater willingness to register as a posthumous tissue and organ donor (Birkimer et al., 1994; Carducci et al., 1989; Smith et al., 1994). Kopfman et al. (1998) found that adolescents who had previously not thought much about organ donation experienced greater anxiety and more negative thoughts and emotions. Knowledge about organ donation and registration was identified as a weak determinant of registration (Horton \& Horton, 1990; Kopfman \& Smith, 1996). Anxiety has also been found to influence the willingness to register as an organ donor (Hessing \& Elffers, 1986; Horton \& Horton, 1990; Kopfman \& Smith, 1996). Adolescents have expressed the fear of being declared dead too soon in a potential organ donation situation. This fear is of course negatively associated with the willingness to register as organ donor.

In a pilot study in the Netherlands, Brug and colleagues (2000) reported that most adolescents reported a positive general attitude towards registration, but various misconceptions about organ donation and registration were identified. They further identified negative outcome expectations, past behaviour, positive outcome expectations and social outcome expectations as significant determinants of willingness to register, while self-efficacy was indirectly associated with motivation to register via outcome expectations. A good understanding of organ donation was not significantly associated with the intention to register as an organ donor. This study, however, was restricted because of the relatively small sample size $(N=145)$. The sample was also school-based and drawn from a specific Dutch region, and may not be representative for Dutch adolescents in general.

The present study was conducted among a large representative sample of Dutch adolescents. This also allows for analysis of a greater number of possible determinants and correlates of willingness to register as an organ donor. 


\section{Theoretical framework}

Two social psychological disciplines can be used in order to study psychosocial determinants (Kok et al., 1996): theory-driven applied social psychology and problem- or action-driven applied social psychology. The main objective of theory-driven applied research is to test the validity of a specific theory. Problem-driven applied social psychology research on the other hand is conducted to tackle a problem. Its primary focus is on problem solving. Often in the last mentioned discipline, concepts from different theories are used instead of the mono-theoretical perspectives used in most theory-driven research. The present study was conducted to identify determinants of willingness to register as posthumous organ donor. It is therefore a problem-focused study, in which the main theoretical framework may be extended using concepts from other theoretical models.

The theoretical starting point of the present study was Bandura's Social Cognitive Theory (SCT) (1986), which has also been used in earlier studies (Brug, van Vugt et al., 2000). SCT identifies two important predictors of intention: outcome expectations and self-efficacy beliefs. Outcome expectations are beliefs about positive and negative consequences that a particular behaviour will produce. One specific category of outcome expectations is social outcome expectations. Social outcome expectations refer to personal experience of external events, such as reward or disapproval. Self-efficacy beliefs are the judgements people make of their capabilities to perform a certain behaviour.

This general SCT-based framework was extended with factors that have been found to be significantly associated with the willingness to register as an organ donor in earlier studies. In the present study, knowledge about organ donation and past behaviour related to organ donation was also included (Horton \& Horton, 1990, 1991). In addition, general interest and the idea that organ donation issues are important were measured. Lastly, anxiety related to organ donation was included, as this was expected to have a negative influence on an individual's behavioural intentions (Dijker, Koomen \& Kok, 1997; Hessing \& Elffers, 1986; Kopfman \& Smith, 1996). 


\section{Methods}

The design of this study was cross-sectional and data were collected by means of self-administered written questionnaires. The questionnaire was based on the one that was used by Brug et al. (2000), with additional items on possible correlates that were not included in the Brug et al. study. The questionnaire consisted of the following parts:

Intention: The first part of the questionnaire included three items that assessed intention to register as an organ donor. The first item was included to describe the distribution of adolescents over the different registration options. Participants were asked to indicate the registration option that they would choose if they were to receive a registration form at that time. In parallel with alternatives in the actual registration procedure, there were five possibilities: (1) registration as an organ donor for specific organs and tissues, (2) registration as an organ donor without restrictions, (3) refusal to register as a posthumous organ and tissue donor, (4) registration as someone who leaves the decision to the next of kin or a specific person and (5) non-registration. Two items were included to assess on a five-point scale the likeliness of respondents to register as organ donors (very unlikely - very likely). The mean score of these last two items was calculated in order to get an overall intention score and this intention score was used in the regression analysis.

Knowledge: Knowledge about organ donation was assessed by means of 27 questions about facts relating to organ donation. Participants could answer the questions with "right", "wrong" and "don't know". Correct answers were coded ' 1 ' and incorrect answers ' 0 '. Questions answered with "don't know" were also scored '0'. The item scores were added up to compute a total knowledge score ranging from 0 to 27 .

Beliefs: A total of 21 propositions reflecting beliefs relating to organ donation (registration) were included. Participants were asked to indicate on five-point scales (fully agree - fully disagree) their agreement with these propositions. High scores $(+2)$ reflected positive beliefs toward registration as an organ donor, while low scores $(-2)$ reflected negative beliefs. The selection and classification of beliefs was based on theories and earlier studies about organ donation (Brug, van Vugt et al., 2000; Horton \& Horton, 1990, 1991; Parisi \& Katz, 1986; Skowronski, 1997). However, this 
classification was provisional because most of the ultimate concepts were determined by means of principal component analyses. Six possible positive outcome beliefs (e.g., "by registration as an organ donor part of my body may survive after my death"; "by registration as an organ donor I can make a good impression on others") and three possible negative outcome beliefs (e.g., " by registration as an organ donor my body may be mutilated after my death"; "by registration as an organ donor my death may be established too soon") were included in the questionnaire. Social outcome expectations were assessed by means of five questions ("I think that most people/people who are important to me/my parents/my friends/my partner would want me to register as an organ donor"). Two items assessed selfefficacy toward donor registration: "it is difficult to register as an organ donor" and "the decision to register as an organ donor is difficult". Based on preliminary research and literature, five items were added to the questionnaire. General interest and the importance of organ donation issues were assessed with three items ("the deficiency of organ donors is an important problem", "problems concerning organ donation don't interest me", "I would like to know more about organ donation"). Finally, two additional items were included, (1) "when it concerns organ donation I have little faith in physicians" and (2) "I would not want to put my family through the ordeal of me being an organ donor".

Anxiety: Two items were included to assess anxiety. Participants were asked how strongly they agreed with two propositions ("being registered as an organ donor would scare me" and "it scares me to think about registration as an organ donor"), from which a mean score was computed after the internal consistency of the two items was established.

Past behaviour: Past behaviour relating to organ donation was assessed with two items. The first question asked participants whether they had ever thought about organ donation. In the second item, participants were asked if they had ever discussed organ donation with other people. Both questions could be answered with No (1) or Yes (2). The mean of these two items was used as a past behaviour score.

Sociodemographic variables: Participants were asked about their sex, education, degree of urbanisation and their religion. 


\section{Participants and study procedure}

A sample of 3318 Dutch adolescents between 16 to 18 years who had not received a registration form yet was drawn from the Dutch General Consumer Survey (de Grote Consumenten Enquête) of 1997. The questionnaires were sent to the participants, who could return them free of charge after completion. Completion of the questionnaire took about 15 to 20 minutes. Of this sample, a total of 1836 adolescents filled in and returned the questionnaire. Non-response analysis among a random sample of non-participants showed that one fifth of the non-participants did not meet the criteria for age. After correction for this, a response rate of $61 \%$ was found. Fifty-nine percent of the sample consisted of female participants. Because of their age, none of the adolescents had received a registration form for organ donation yet. Of all participants, 50\% reported to live in a village or smaller town, $45 \%$ in a larger city, while only $5 \%$ reported that they lived in the country. Most participants $(43 \%)$ reported to be non-religious, 32\% were Roman Catholics, $20 \%$ were members of the Protestant Church and $5 \%$ reported to have another religion.

\section{Statistical methods}

First, in order to detect latent variables in the pattern of beliefs, a principal component analysis with oblique rotation was conducted. The number of scales was determined by ( 1 ) the eigenvalues of the components (greater than one), (2) the extent to which the items in a scale loaded uniquely on that scale, (3) the explained variance of the factors and (4) the interpretability of the scales. Subsequently, internal consistency of the scales was assessed with reliability analysis.

The extracted scales, as well as the knowledge scores, past behaviour scores, anxiety scores, sex, religion and education level were subsequently included in a standard Multiple Linear Regression analysis, in which all independent variables enter into the regression equation at once (Tabachnick \& Fidell, 1996). The intention to register was used as dependent variable, in order to identify important correlates of the intention to register as a posthumous organ and tissue donor. Because religion was a discrete variable, it was converted into a set of dichotomous variables by dummy variable coding with 1 's and 0 's, with non-religious 
adolescent as the reference group (Protestant $=1$ vs. no religion=0; Catholics $=1$ vs. no religion $=0$; other religions $=1$ vs. no religion $=0$ ).

The data matrix was tested for multicolinearity and singularity. Because of multicolinearity, no interactions were entered into the model.

\section{Results}

The structure of beliefs about organ donation

The principal component analysis revealed four factors: social outcome expectations, negative outcome beliefs, positive outcome beliefs and involvement with organ donation. These four factors accounted for $44 \%$ of the total variance. The eigenvalues of the factors were 4.83, 2.29, 1.67 and 1.37, respectively. The four dimensions with the factor loadings are depicted in Table 1.2.

The means, standard deviations and internal consistency data for the four scales measuring the adolescents' beliefs structure and two 2 -item scales measuring anxiety and past behaviour are presented in Table 1.4. The table also presents the mean individual knowledge score with standard deviation. 


\section{Table 1.2 Extracted factors}

\begin{tabular}{|c|c|c|c|c|}
\hline Items & $F 1$ & $F 2$ & $F 3$ & $F 4$ \\
\hline $\begin{array}{l}\text { I think that my friends would want me to register as an organ } \\
\text { donor }\end{array}$ & 0.86 & & & \\
\hline $\begin{array}{l}\text { I think that my parents would want me to register as an organ } \\
\text { donor }\end{array}$ & 0.86 & & & \\
\hline $\begin{array}{l}\text { I think that most people would want me to register as an organ } \\
\text { donor }\end{array}$ & 0.82 & & & \\
\hline $\begin{array}{l}\text { I think that my partner would want me to register as an organ } \\
\text { donor }\end{array}$ & 0.82 & & & \\
\hline $\begin{array}{l}\text { I think that people who are important to me would want me to } \\
\text { register as an organ donor }\end{array}$ & 0.71 & & & \\
\hline The decision to register as an organ donor is difficult & & 0.72 & & \\
\hline When it concerns organ donation I have little faith in physicians & & 0.69 & & \\
\hline It is difficult to register as an organ donor & & 0.62 & & \\
\hline $\begin{array}{l}\text { By registration as an organ donor my death may be established } \\
\text { too soon }\end{array}$ & & 0.61 & & \\
\hline $\begin{array}{l}\text { I wouldn't want to put my family through the ordeal of me being } \\
\text { an organ donor }\end{array}$ & & 0.57 & & \\
\hline $\begin{array}{l}\text { By registration as an organ donor my body may be mutilated } \\
\text { after my death }\end{array}$ & & 0.46 & & \\
\hline $\begin{array}{l}\text { By registration as an organ donor I run the risk that my organs } \\
\text { may be traded }\end{array}$ & & 0.39 & & \\
\hline $\begin{array}{l}\text { By registration as an organ donor part of my body may survive } \\
\text { after my death }\end{array}$ & & & 0.58 & \\
\hline $\begin{array}{l}\text { By registration as an organ donor I can make a good impression } \\
\text { on others }\end{array}$ & & & 0.54 & \\
\hline $\begin{array}{l}\text { By registration as an organ donor I may learn more about organ } \\
\text { donation }\end{array}$ & & & 0.54 & \\
\hline $\begin{array}{l}\text { By registration as an organ donor I can decide what happens to } \\
\text { my organs after my death }\end{array}$ & & & 0.49 & \\
\hline $\begin{array}{l}\text { By registration as an organ donor I have more right to receive a } \\
\text { transplant, should I need one }\end{array}$ & & & 0.49 & \\
\hline $\begin{array}{l}\text { By registration as an organ donor, death may at least have } \\
\text { something positive }\end{array}$ & & & 0.49 & \\
\hline I would like to know more about organ donation & & & & 0.72 \\
\hline Problems concerning organ donation do not interest me & & & & -0.72 \\
\hline The deficiency of organ donors is an important problem & & & & 0.49 \\
\hline
\end{tabular}

Note: All loadings $>.35$ are depicted. $\mathrm{F} 1=$ social outcome expectations; $\mathrm{F} 2$ = negative outcome beliefs; $\mathrm{F} 3$ = positive outcome beliefs; $\mathrm{F} 4$ = involvement with organ donation. 
Intention to register as a posthumous organ and tissue donor Of all participants, $46 \%$ reported their willingness to register as an organ donor without restrictions and $21 \%$ as a posthumous organ donor for specific organs and tissues. Refusal to register as an organ donor was indicated by $14 \%$, while $16 \%$ of the participants wanted to leave the decision to their next of kin or a specific person. Only three percent reported that they would not return the registration form.

\section{Knowledge}

On average, sixty-three percent of the 27 knowledge questions (Mean= 16.9, $\mathrm{SD}=3.3$ ) were answered correctly, with a range of 0-27. All knowledge items with the rate of correct answers are presented in Table 1.3.

Almost every respondent knew correctly that the heart (\#19b), kidneys (\#19a) and liver (\#19d) can and brain tissue (\#19c) cannot be transplanted. Fewer participants knew correctly that lungs (\#19e) are and the spinal cord (\#19f) is not a potential transplant, while a great majority thought incorrectly that bones (\#19i) and intestines (\#19g) cannot be and the cornea (\#19h) can be transplanted. Half of the participants knew that donation can start when the potential donor is brain dead (\#14), that the funeral does not have to be postponed (\#13) and that different physicians are responsible for the organ donor and the recipient (\#15). A small proportion answered correctly that the ideal donor is a young person who died from a head injury (\#17), that organ donation does not increase medical and health costs (\#16) and that nearly all western religions are in favour of organ donation (\#18). About half of the participants incorrectly thought that the family of organ donors can receive a financial reward $(\# 11)$ and that the family or their insurance is responsible for the costs of organ donation (\#12). 
Predictors of the willingness to register as an organ donor

Negative outcome beliefs, anxiety, social outcome expectations and involvement correlated highly with intention. Correlations of the other variables with intention were significant, but smaller. Further, negative outcome beliefs had a significant high correlation with anxiety. Table 1.4 presents the results of the multiple linear regression on intention. The independent variables that entered the model explained $55 \%$ of the variance in intention, with negative outcome beliefs being the strongest predictor of willingness. Adolescents with negative outcome beliefs had less intention to register as organ donors. Furthermore, anxiety, social outcome expectations, involvement with organ donation, positive outcome beliefs, knowledge, past behaviour and sex were all significantly associated with the willingness to register as an organ donor. A high level of anxiety was significantly associated with low intention and adolescents who perceived a stronger positive outcome expectation towards organ donation were more willing to register as organ donors. It also appeared that adolescents who were already feeling involved with organ donation issues had stronger intentions to register as posthumous organ donors. The more correct knowledge a person had, the more willing he/she was to register as an organ donor. Adolescents who had previously thought about organ donation and had discussed organ donation issues with other people appeared to be more willing to register as donors. Lastly, female participants reported a higher intention to register as posthumous organ and tissue donors than males. 
Table 1.3 Proportion of participants who answered each question correctly

\begin{tabular}{|lc}
\hline Knowledge items (all items were multiple choice or true/false) (\#) & $\begin{array}{c}\text { Correct } \\
\text { answer (\%) }\end{array}$
\end{tabular}

1. For most organs, the demand for transplants is higher than the 93 availability

2. Smokers can also be organ donors 86

3. If a deceased is registered as an organ donor, one cannot have an 83 open casket funeral

4. When you are registered as an organ donor, it is not possible to 82 withdraw when you change your mind

5. Older people are not suitable for organ donation $\quad 78$

6. Donor organs should be extracted before the donor is truly deceased 71

7. Only people who are completely healthy are suitable as organ donors 70

8. When an organ donor dies, the bereaved have less opportunity to be 69 with the deceased

9. Organs should be fully grown $\quad 67$

10. If you are registered as an organ donor, your family cannot stop organ 66 donation

11. The family of organ donors can receive a financial reward 58

12. The family of the donor or their insurance policy is not responsible for 58 organ donation costs

13. If a deceased is registered as an organ donor, the funeral has to be 48 postponed

14. In which situation can organs be extracted from a donor?

15. Different physicians should be responsible for the organ donor and the 47 recipient

16. Organ donation increases medical and health costs 36

17. The ideal donor is a young person who died from head injury 34

18. Nearly all western religions are in favour of organ donation 29

19. Is transplantation of the following organs possible?

a. Kidneys 98

b. Heart 95

$\begin{array}{lr}\text { C. Brain } & 94\end{array}$

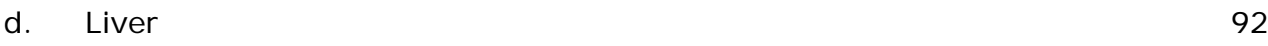

e. Lungs 73

f. Spinal cord 51

g. Intestines 24

h. Cornea 23

i. Bones 22 
Table 1.4 Potential determinants of intention, internal consistency, mean scores (SD) and beta-weights

\begin{tabular}{lcccc}
\hline Predictors (possible range) & $\begin{array}{c}\text { Number of } \\
\text { items }\end{array}$ & $\begin{array}{c}\text { Internal } \\
\text { consistency }\end{array}$ & Mean (SD) & $\beta$-weights \\
\hline Negative outcome beliefs $(-2 /+2)$ & 7 & $\alpha=0.74$ & $-0.84(0.86)$ & $-0.29^{* *}$ \\
Anxiety $(-2 /+2)$ & 2 & $r=0.70$ & $-1.04(1.26)$ & $-0.25^{* *}$ \\
Social outcome expectations (-2/+2) & 5 & $\alpha=0.88$ & $0.27(1.04)$ & $0.18^{* *}$ \\
Involvement (-2/+2) & 3 & $\alpha=0.57$ & $1.13(0.84)$ & $0.17^{* *}$ \\
Positive outcome beliefs (-2/+2) & 6 & $\alpha=0.55$ & $-0.23(0.80)$ & $0.14^{* *}$ \\
Knowledge (0-27) & 27 & - & $16.90(3.30)$ & $0.08^{* *}$ \\
Past behaviour (1/2) & 2 & $r=0.55$ & $1.84(0.32)$ & $0.07^{* *}$ \\
Sex & - & - & - & $0.07^{* *}$ \\
Level of education & - & - & - & $0.04^{*}$ \\
Roman Catholic vs. no religion & - & - & - & -0.03 \\
Protestant vs. no religion & - & - & - & 0.01 \\
Other religions vs. no religion & - & - & - & -0.02 \\
\hline
\end{tabular}

$* \mathrm{p}<0.05 \quad * * \mathrm{p}<0.001$

\section{Discussion}

The present study shows that two-thirds of the adolescents between 16 and 18 years of age were willing to register as posthumous organ and tissue donors. Only three percent reported that they would not return the registration form. Thirty-nine percent of the sample did not participate in the present study. We expect that a truer estimate of willingness to donate would be less than $67 \%$ since people not willing to donate may be overrepresented among non-responders. However, non-response analysis showed that only one percent of the non-responders refused to participate in the present study on grounds of principle.

A relatively high percentage of variance (55\%) in the intention to register as a posthumous organ donor could be explained by the variables that were identified as potential determinants based on behaviour theory and earlier empirical research. The most important predictors of intention were negative outcome beliefs, social outcome expectations and anxiety related to registration as an organ donor. Other significant predictors of 
willingness to register were involvement with organ donation issues, positive outcome beliefs, knowledge about organ donation, past behaviour, sex and level of education. Religion was not a significant predictor of the intention to register as a posthumous organ donor.

The fact that the absence of negative outcome expectations was found to be a much stronger predictor of the intention to register as an organ donor than the presence of positive outcome expectations has been found in previous studies (Brug, van Vugt et al., 2000; Cacioppo \& Gardner, 1993; Horton \& Horton, 1990; Parisi \& Katz, 1986; Skowronski, 1997). Particularly, adolescents who believe being registered as an organ donor may cause their death to be declared too soon, who have little faith in physicians with regard to organ donation and who believe that their body will be mutilated after death, have a much lower intention to register as potential organ donors. Social outcome expectations also appear to be a relevant predictor. Adolescents who think that their partner, their parents, their friends or other people who are important to them would like them to register as an organ donor have a much higher intention to register in the future. In addition to negative outcome beliefs and social outcome expectations, anxiety contributes to the explanation of intention to register as an organ donor. Adolescents who admitted that being registered as an organ donor would scare them and who admit that even thinking about registration makes them anxious were significantly less likely to have an intention to register.

Although Brug et al. (2000) reported that correct knowledge was not significantly associated with the intention to register as organ donor, the present study supports the findings of previous studies that correct knowledge is a significant, albeit weak predictor of the intention to register (Horton \& Horton, 1990, 1991; Kopfman \& Smith, 1996; Radecki \& Jaccard, 1999). It is possible that adolescents who have certain misconceptions (e.g., adolescents who think that an open casket funeral is not possible after registration as an organ donor or that donor organs can be extracted before the donor is truly deceased), experience more fear and hold more negative outcome beliefs than adolescents who have correct knowledge about organ donation (registration) procedures (Kopfman \& Smith, 1996). Indeed, secondary analyses showed a substantial correlation between knowledge and negative outcome expectations and knowledge and anxiety. 
Increasing adolescents' level of knowledge about organ donation (registration) procedures by supplying factually correct information, may alleviate the level of anxiety, turn negative outcome beliefs into more positive ones and hence may increase willingness to register as an organ donor.

Furthermore, adolescents who had previously thought about organ donation or who had discussed this topic with other people were more likely to register as organ donors. The current study supports the positive association with the intention to register that was found in previous studies (Birkimer et al., 1994; Brug, van Vugt et al., 2000; Carducci et al., 1989; Nolan \& McGarth, 1990; Smith et al., 1994). Bandura (1986) suggested that through past experience, people gain increasing knowledge about organ donation issues, which has a predictive value for screening and guiding their behaviour.

The present study was conducted among a large, representative sample of Dutch adolescents and the results are therefore representative for Dutch adolescents in general. It also gave us the possibility to study differences in the willingness to register according to a number of sociodemographic variables. Our results identify only small differences in willingness between specific groups of adolescents. Sex and level of education were the only sociodemographic variables that were significant correlates. The finding that women were more willing to register may be explained by the fact that women are generally more altruistic than men (Sabini, 1995). The fact that the level of education appeared to be relevant to willingness to register shows that adolescents with a lower level of education were generally less willing to register as organ donors than adolescents with a high level of education. However, although statistically significant, level of education is only weakly associated with willingness. The lack of influence of religion may reflect the fact that most religions in the Netherlands support organ donation registration (Pranger, 1998). Furthermore, the majority of Dutch adolescents, even though they are registered as belonging to certain religions, are not active churchgoers or otherwise religiously active. Yuen et al. (1998) found no differences between racial groups in the support for donating organs. The present study did not examine racial differences in organ donation support. 
Although the registration system used in the Netherlands resembles other opting-in systems, it is a unique system in its registration style. Therefore, the results of this study cannot easily be generated to other countries. However, the Dutch registration system is a serious alternative for organ donation registration and the present study may help to identify possible benefits and barriers related to the specific system.

The findings of this study have important implications for the development of a school-based education programme to encourage adolescents to register as organ donors. Firstly, the results imply that refutational messages will have to be developed to counteract negative outcome beliefs and consequently reduce feelings of anxiety in order to encourage adolescents to register as organ donors when they reach the age of 18. These messages should emphasise the care that is being put into preparing a body for organ donation and the brain death protocol that is used in the Netherlands before organs can be abstracted from a donor.

Secondly, since the results suggest that adolescents who had previously thought about or talked with other people about organ donation issues were more willing to register as posthumous organ donors, strategies should be developed that encourage adolescents to spend time thinking about organ donation (registration) procedures (e.g., "foot-in-thedoor" technique) (Carducci et al., 1989). Kopfman et al. (1998) emphasised that it is important to think about the issue of prior thought, because persons who have given organ donation little prior thought have different thoughts and emotions in response to education messages than people who have given significant prior thought to the subject. Adolescents should also be encouraged to discuss issues relating to organ donation and registration with their parents and friends.

Lastly, there were various misconceptions about organ donation registration among large proportions of the participants (e.g., by registration as an organ donor, the funeral has to be postponed and one physician is responsible for the organ donor and the recipient). This suggests that in order to persuade adolescents to register posthumously as organ donors, correct knowledge about organ donation registration should be increased. 
In summary, a school-based education programme aimed at encouraging adolescents to register should stimulate adolescents to think and talk about organ donation issues and should consist of both refutational messages to counteract negative outcome beliefs and additional information to confirm positive outcome beliefs. Cleiren and Van Zoelen (1999) also suggested that it is important to combine refutational with additional outcome belief based messages. Lastly, in order to increase correct knowledge about organ donation registration, factual information about procedures and the most prominent misconceptions found in this study should be provided. Moves such as these may result in a larger proportion of posthumous organ donors. 



\section{Chapter 2}

\section{PREDICTORS OF ORGAN DONATION REGISTRATION AMONG DUTCH ADOLESCENTS}

\section{Abstract}

In 1998, a new organ donor registration scheme was implemented in the Netherlands in order to increase the number of potential donors and to facilitate decisions and procedures concerning organ donation. However, registration rate and registration choices failed to meet the expectations. A cross-sectional survey among a random sample of 1,731 Dutch adolescents of 18 and 19 years was conducted to study potential determinants of organ donor registration choices. Almost one fifth of the adolescents indicated that they did not return their organ donation registration form. Among subjects who registered, $57 \%$ was willing to donate their organs or tissues posthumously. More positive social influences, fewer negative outcome beliefs and a low level of organ donation anxiety were significant predictors of returning a completed registration form and registration as an organ donor. In addition, religion was a significant predictor of returning a completed registration form and positive outcome beliefs contributed to the prediction of registration as an organ donor. The results give clear suggestions for tailoring organ donation registration interventions to specific characteristics, beliefs and misconceptions of adolescents. The results also suggest that it is important to encourage adolescents to discuss issues related to organ donation with their parents and friends in order to increase donor registration.

Published as: Reubsaet, A., Brug, J., Van den Borne, H.W. \& Van Hooff, J.P. (2001). Predictors of organ donation registration among Dutch adolescents. Transplantation, 72, 51-56. 


\section{Introduction}

In most countries, a vast disparity exists between the demand for organs and tissues and the supply of available organs and body tissues (Brug, van Vugt et al., 2000; Horton \& Horton, 1990; Radecki \& Jaccard, 1997; Van den Driessche et al., 1996). In order to increase the availability of donor organs, on January 1, 1998, new legislation related to organ donation (registration) was implemented in the Netherlands. The goal of this legislation was twofold. In addition to increasing the number of potential donor organs and tissues, the new law should optimise the rights of citizens and health care professionals who may be involved in the organ donation procedure. This new law is based on a "decision system", which means that each citizen decides by virtue of his/her own will and integrity of his/her body whether he or she wants to be registered as a potential organ donor or not. In order to create clarity for both health care professionals and the family of a deceased person, this decision is centrally registered. However, registration is voluntary. In March and April of 1998, all Dutch citizens of 18 years and older received a letter from the Dutch Ministry of Health, containing information about the new registration system and a registration form with five registration options:

1. Registration as a posthumous organ and tissue donor;

2. Registration as a posthumous donor for specific organs and tissues;

3. Registration as a non-donor;

4. Registration to leave the decision to the next of kin;

5. Registration to leave the decision to a specific person.

From 1998 onwards, every Dutch person who reaches the age of 18 will receive a registration form for completion. In the first registration round, among inhabitants of 18 years and older, 36\% returned the registration form, of whom almost $55 \%$ did register as a posthumous organ and tissue donor (Kunst \& Witlox, 1999; Rijksvoorlichtingsdienst/DTC, 1999). However, less than one third of the adolescents sent back their completed forms (Kunst \& Witlox, 1999), of whom 54\% registered to be willing to donate their organs or tissues posthumously (Rijksvoorlichtingsdienst/DTC, 1999). The majority of Dutch citizens (64\%) did not react to the invitation, leaving more than 7.5 million unregistered people. The new law states that, 
for these people, the next of kin will need to be asked for permission for donation, when appropriate. This means that, in the present situation, the next of kin will need to be asked for permission in most cases. From past experience, it is known that, in such a situation, many possible candidates for donation are missed because of logistic and emotional barriers. Health care providers in these circumstances often say that the next of kin interprets nonregistration as a refusal of posthumous organ donation. They also find it too difficult to ask such questions, meeting with negative reactions from the next of kin, lack of time, forgetting to ask and not knowing which persons to ask for permission (Cleiren \& Van Zoelen, 1998; Kranenburg et al., 1998). It is therefore important that the number of registrants increases to a vast majority of the Dutch adult population.

Various earlier studies on organ donation have contributed to an understanding of the reasons why adolescents may or may not register as organ donors (Birkimer et al., 1994; Brug, van Vugt et al., 2000; Horton \& Horton, 1991; Radecki \& J accard, 1997). Religious beliefs, cultural beliefs, knowledge beliefs, altruistic beliefs and social outcome expectations have been identified as possible predictors of intention to register (Radecki \& Jaccard, 1997). Positive and negative outcome beliefs toward organ donation registration have also been found to be associated with the intention to register (Cacioppo \& Gardner, 1993; Horton \& Horton, 1990; Parisi \& Katz, 1986; Skowronski, 1997). Adolescents with a high score on prior thoughts about organ donation and who were encouraged to spend time thinking about registration as an organ donor reported a greater willingness to register as a posthumous organ donor (Birkimer et al., 1994; Carducci et al., 1989; Smith et al., 1994). Correct knowledge about organ donation and registration was found to be a significant, although weak, predictor of registration in various studies (Horton \& Horton, 1990; Kopfman \& Smith, 1996). Finally, anxiety has been found to have a negative influence on the intention to register as an organ donor (Hessing \& Elffers, 1986; Horton \& Horton, 1990).

Because of the low donor registration rate following the new legislation, the first priority of the Dutch health authorities in the years to come is to increase the number of adolescents who return a completed registration form. Additionally, these registrants should be encouraged to register as willing to posthumously donate their organs and/or tissues. 
Therefore, a school-based education programme will be developed, enabling adolescents to make a well-considered decision about registration and encouraging them to register their will in this respect. Such an intervention should be based on empirical evidence on determinants of registration behaviour. The present study was conducted to identify demographic and psychosocial correlates of two specific organ donation registration behaviours: (1) returning a completed registration form and (2) the registration choice that was made on this form. The findings of the current study can be used to tailor school-based organ donation education programmes to the characteristics, information needs and beliefs of adolescents.

\section{Methods}

The design of the study was cross-sectional and data were collected by means of self-administered written questionnaires, based on Bandura's Social Cognitive Theory (1986). The questionnaire was similar to the one used by Brug et al. (2000) in a preliminary study on correlates of motivation to register among younger children.

\section{Participants and procedure}

A sample of 1731 adolescents of 18 and 19 years old, who had received registration forms according to the new Dutch procedure, was derived from a representative sample from the Dutch General Consumer Survey (de Grote Consumenten Enquête) of 1997. The questionnaires were sent out and recipients were asked to return the questionnaire free of charge after completion. Completion of the questionnaire took about 15 to 20 minutes. A total of 937 adolescents responded. An additional telephone survey was conducted among a sample of nonresponders $(N=100)$ in order to study reasons for nonresponse. The measurements consisted of the following parts:

Registration behaviour: Registration behaviour was measured according to the official Netherlands registration procedure. Participants were asked to select a registration option from a list of six possible types: (1) registration as an organ donor without restrictions; (2) registration as 
an organ donor for specific organs and tissues; (3) refusal to register as a posthumous organ and tissue donor; (4) registration to leave the decision to the next of kin; (5) registration to leave the decision to a specific person; and (6) nonregistration. On the basis of this choice, two dichotomous behaviour variables were computed, to be used as dependent variables in the present study. A dichotomous registration variable was computed to compare registrants (registration choice $=1-5$ ) with nonregistrants (registration choice $=6$ ) and a dichotomous registration as donor variable was computed to compare subjects who indicated that they would register as potential donors (registration choice $=1$ or 2 ) to other subjects ( registration choice $=3-6$ ).

Knowledge: Correct knowledge about organ donation was assessed by means of 27 questions about relevant facts related to organ donation and procedures. The questions could be answered with "true", "false", or "don't know". A correct answer was coded ' 1 ', an incorrect one or "don't know" answer was coded as ' 0 '. To compute an overall correct knowledge score (range 0-27), the item scores were added up.

Beliefs: Participants were asked to indicate on five-point scales (fully agree to fully disagree) their agreement with the 21 propositions reflecting possible relevant beliefs relating to organ donation registration. High scores $(+2)$ reflected positive beliefs toward registration as an organ donor, while low scores (-2) reflected negative beliefs (see Table 2.2). On the basis of preliminary research and a literature review, five items that were expected to reflect measures of general interest to organ donation issues were added to the questionnaire.

Anxiety: Two items were included to assess anxiety, asking participants how strongly they agreed with two propositions ("being registered as an organ donor would scare me" and "it scares me to think about registration as an organ donor"). A mean anxiety score was computed after the internal consistency of the two items was established.

Past behaviour: Past behaviour relating to organ donation was assessed by asking participants whether they had ever thought about organ donation before and if they had ever discussed organ donation with others. The mean of these two dichotomous items was used as a past behaviour score. 
Sociodemographic variables: Finally, participants were asked about their sex, level of education, degree of urbanisation and their religion.

\section{Statistical analyses}

Data were analysed using the 'Statistical Package for Social Science' (SPSS) 8.0 for Windows. In order to detect latent variables in the pattern of beliefs, a principal component analysis followed by oblique factor rotation was conducted. We determined the number of scales on the basis of the eigenvalues of the components (greater than one), the extent of unique loading of items on one scale, the explained variance of the factors and the interpretability of the scales. Subsequently, internal consistency of the scales was assessed with a reliability analysis.

The extracted scales, knowledge scores, past behaviour scores, anxiety scores, sex, religion and education level were subsequently included in two multivariate logistic regression analyses, using forced entry, with the registration score and the donor score as dependent variables. Because religion was a discrete variable, it was first converted into a set of dichotomous variables by dummy variable coding, with Roman Catholics as the reference group.

For predictors that were significant in the multivariate logistic regressions, further analyses with specific beliefs as predictors and registration choice as a dependent variable, were conducted in order to investigate which specific beliefs were specifically relevant. This information can help to tailor organ donation registration education to specific beliefs. 


\section{Results}

\section{Participants}

After correction for failing the inclusion criterion for age, based on the nonresponse analysis, a response rate of $60 \%$ was found. Of all participants, $61 \%$ was female, $51 \%$ reported to live in a village or a smaller town, $45 \%$ in a larger city and only $4 \%$ reported that they lived in the country. Most participants (43\%) reported to be nonreligious, 33\% were Roman Catholic, almost one fifth of the participants were members of the Protestant Church and 5\% reported to have another religion.

Structure of beliefs about organ donation

The principal component analysis of beliefs about organ donation registration revealed four factors: social outcome expectations, negative outcome beliefs, involvement with organ donation and positive outcome beliefs. These four factors accounted for $48 \%$ of the total variance. The eigenvalues of the factors were $5.54,2.59,1.88$ and 1.40 , respectively. The specific beliefs of these four dimensions with the factor loadings are shown in Table 2.1. 


\section{Table 2.1 Extracted factors}

\begin{tabular}{|c|c|c|c|c|}
\hline Items & $F 1$ & $F 2$ & F3 & F4 \\
\hline $\begin{array}{l}\text { I think that my partner would want me to register as an organ } \\
\text { donor }\end{array}$ & 0.84 & & & \\
\hline $\begin{array}{l}\text { I think that my parents would want me to register as an organ } \\
\text { donor }\end{array}$ & 0.84 & & & \\
\hline $\begin{array}{l}\text { I think that my friends would want me to register as an organ } \\
\text { donor }\end{array}$ & 0.83 & & & \\
\hline $\begin{array}{l}\text { I think that most people would want me to register as an organ } \\
\text { donor }\end{array}$ & 0.83 & & & \\
\hline $\begin{array}{l}\text { I think that people who are important to me would want me to } \\
\text { register as an organ donor }\end{array}$ & 0.66 & & & \\
\hline The decision to register as an organ donor is difficult & & 0.78 & & \\
\hline $\begin{array}{l}\text { When it concerns organ donation, I have little faith in } \\
\text { physicians }\end{array}$ & & 0.73 & & \\
\hline It is difficult to register as an organ donor & & 0.71 & & \\
\hline $\begin{array}{l}\text { By registration as an organ donor, my death may be } \\
\text { established too soon }\end{array}$ & & 0.69 & & \\
\hline $\begin{array}{l}\text { I wouldn't want to put my family through the ordeal of me } \\
\text { being an organ donor }\end{array}$ & & 0.57 & & \\
\hline $\begin{array}{l}\text { By registration as an organ donor, I run the risk that my } \\
\text { organs may be traded }\end{array}$ & & 0.56 & & \\
\hline $\begin{array}{l}\text { By registration as an organ donor, my body may be mutilated } \\
\text { after my death }\end{array}$ & & 0.46 & & \\
\hline Problems concerning organ donation do not interest me & & & 0.75 & \\
\hline I would like to know more about organ donation & & & 0.62 & \\
\hline The deficiency of organ donors is an important problem & & & 0.58 & \\
\hline $\begin{array}{l}\text { By registration as an organ donor, I can make a good } \\
\text { impression on others }\end{array}$ & & & & 0.67 \\
\hline $\begin{array}{l}\text { By registration as an organ donor, part of my body may } \\
\text { survive after my death }\end{array}$ & & & & 0.66 \\
\hline $\begin{array}{l}\text { By registration as an organ donor, I may learn more about } \\
\text { organ donation }\end{array}$ & & & & 0.58 \\
\hline $\begin{array}{l}\text { By registration as an organ donor, death may at least have } \\
\text { something positive }\end{array}$ & & & & 0.51 \\
\hline $\begin{array}{l}\text { By registration as an organ donor, I have more right to receive } \\
\text { a transplant, should I need one }\end{array}$ & & & & 0.50 \\
\hline $\begin{array}{l}\text { By registration as an organ donor, I can decide what happens } \\
\text { to my organs after my death }\end{array}$ & & & & 0.43 \\
\hline
\end{tabular}

Note: All loadings $>0.40$ are depicted. F1, social outcome expectations; F2, negative outcome beliefs; F3, involvement with organ donation; F4 positive outcome beliefs. 
Table 2.2 presents the means, standard deviations and internal consistency for the four belief factors and the two 2 -item scales measuring anxiety and past behaviour related to organ donation. It also presents the mean individual knowledge score with standard deviation.

Table 2.2 Potential correlates of registration (as an organ donor), internal consistency and mean scores (SD)

\begin{tabular}{|c|c|c|c|}
\hline Scale (possible range) & $\begin{array}{c}\text { Number of } \\
\text { items }\end{array}$ & Internal consistency & Mean (SD) \\
\hline Social outcome expectations $(-2 /+2)$ & 5 & $\alpha=0.88$ & $0.17(1.07)$ \\
\hline Negative outcome beliefs $(-2 /+2)$ & 7 & $\alpha=0.74$ & $-0.90(0.90)$ \\
\hline Positive outcome beliefs $(-2 /+2)$ & 6 & $\alpha=0.55$ & $-0.33(0.82)$ \\
\hline Involvement $(-2 /+2)$ & 3 & $\alpha=0.57$ & $1.09(0.83)$ \\
\hline Anxiety $(-2 /+2)$ & 2 & $r=0.73$ & $-1.07(1.27)$ \\
\hline Past behaviour ( $1 / 2)$ & 2 & $r=0.55$ & $1.91(0.25)$ \\
\hline Knowledge (0-27) & 27 & - & $17.60(3.40)$ \\
\hline
\end{tabular}

\section{Registration choice}

A total of $45 \%$ of the adolescents reported that they were willing to donate their organs and tissues posthumously without any restrictions, whereas $12 \%$ were prepared to do so with restrictions. Thirteen percent wanted to leave the decision of donation to the next of kin $(11 \%)$ or to a specific person ( $2 \%$ ). Refusal to register as an organ donor was reported by $13 \%$ of the sample and $17 \%$ indicated that they did not return their registration form. 


\section{Knowledge}

A mean knowledge score of 17.6 ( $S D=3.4$; range $0-27$ ) was found, suggesting that more than half of all knowledge questions (65\%) were answered correctly. Table 2.3 presents the specific knowledge items with the proportion of respondents that answered each question correctly.

In line with earlier studies (Brug, van Vugt et al., 2000), a large majority of the respondents knew correctly that kidneys (question 19a), the heart (question 19b) and the liver (question 19d) can be and brain tissue (question 19c) cannot be transplanted posthumously. Fewer participants knew correctly that lungs (question 19e) are a potential transplant and half of the participants thought incorrectly that the spinal cord (question 19f) was also a transplantable tissue. A large majority thought incorrectly that bones (question 19g) and intestines (question 19h) cannot be and that the retina (question 19i) can be transplanted. Half of the participants thought incorrectly that the funeral has to be postponed after donation (question 14) and that cardiac arrest, lack of breathing or a state of coma were situations in which a donation procedure can start (question 15). Relatively large proportions had misconceptions about who is a suitable organ donor (question 17) and how Western religions think about organ donation (question 18). A large majority knew correctly that one can have an open casket funeral after donation (question 4), that smokers are also potential organ donors (question 3 ) and that it is always possible to change your mind when your are registered as an organ donor (question 2 ). 


\section{Table 2.3 Proportion of participants who answered each question correctly}

\begin{tabular}{lc}
\hline Knowledge items (all items were multiple choice or true/false) & $\begin{array}{c}\text { Correct } \\
\text { answer (\%) }\end{array}$ \\
\hline
\end{tabular}

1. For most organs, the demand for transplants is higher than their 93 availability.

2. When you are registered as an organ donor, it is not possible to withdraw when you change your mind.

3. Smokers can also be organ donors. 91

4. If a deceased is registered as an organ donor, one cannot have an open 87 casket funeral.

5. Older people are not suitable for organ donation.

6. Only people who are completely healthy are suitable organ donors. 75

7. Donor organs should be extracted before the donor is truly deceased. 72

8. The family of organ donors can receive a financial reward. 70

9. Organs should be fully grown. 69

10. When an organ donor dies, the bereaved have less opportunity to be 68 with the deceased.

11. If you are registered as an organ donor, your family cannot stop organ 64 donation.

12. The family of the donor or their insurance policy is not responsible for organ donation costs.

13. Different physicians should be responsible for the organ donor and the recipient.

14. If a deceased is registered as an organ donor, the funeral has to be postponed.

15. In which situation can organs be extracted from a donor? 52

16. Organ donation increases medical and health costs. 43

17. The ideal donor is a young person who died from a head injury. 32

18. Nearly all Western religions are in favour of organ donation. 31

19. Is transplantation of the following organs possible?
a. Kidneys
b. Heart
94
c. Brain
d. Liver
e. Lungs
f. Spinal cord
g. Bones
h. Intestines
i. Retina 


\section{Predictors of registration}

The results of the multivariate logistic regression analysis are presented in Table 2.4. Multivariate logistic regression analysis concerning registration showed that stronger negative outcome beliefs and feelings of anxiety were associated with not returning a completed registration form. Social outcome expectations were positive associated with registration. Finally, adolescents with a Protestant background were less inclined to return their registration form.

Further in-depth analysis showed specifically that adolescents who feel that they are encouraged by their parents and close friends more often return their registration cards.

\section{Predictors of registration as an organ donor}

The results of the multivariate logistic regression analysis with registration as an organ donor as a dependent variable showed that social outcome expectations, negative and positive outcome beliefs and anxiety were significantly related to registration as a posthumous organ donor. Adolescents who have higher social outcome expectations and have more positive outcome beliefs about organ donation more often registered as a posthumous organ and tissue donor. The more negative outcome beliefs a person had, the more likely was the registration as a nondonor. Anxiety related to organ donation also had a significant negative relation with registration as an organ donor, which means that the more feelings of anxiety adolescents had, the less chance there was that they were registered as organ donors.

In-depth analysis again showed that adolescents who were encouraged by their parents were more likely to register as posthumous organ donors. Adolescents who think that part of them may survive if they donate organs and tissues were also more inclined to register as donors.

Adolescents who admit that being registered as an organ donor would scare them, who think that it is difficult to register as organ donor, or who think that the decision to register as a posthumous organ donor is difficult, more often registered as nondonors. 
Table 2.4 Odds ratios of the independent variables of the comparison of registrants vs. nonregistrants and registration as donor vs. registration as nondonor ${ }^{1}$

\begin{tabular}{llllc}
\hline \multirow{2}{*}{ Outcome variable } & \multicolumn{2}{c}{ Nonregistrant vs. registrant } & \multicolumn{2}{c}{ Nondonor vs. donor } \\
\cline { 2 - 5 } & \multicolumn{1}{c}{ OR } & $95 \%$ CI & OR & $95 \%$ CI \\
\hline Social outcome expectations & $1.30^{*}$ & $1.05-1.61$ & $1.66^{* *}$ & $1.37-2.01$ \\
Negative outcome expectations & $0.52^{* *}$ & $0.40-0.68$ & $0.28^{* *}$ & $0.21-0.37$ \\
Positive outcome expectations & 1.09 & $0.83-1.43$ & $1.68^{* *}$ & $1.30-2.17$ \\
Involvement & 0.86 & $0.66-1.12$ & 1.18 & $0.92-1.52$ \\
Anxiety & $0.70^{* *}$ & $0.58-0.83$ & $0.63^{* *}$ & $0.52-0.75$ \\
Past behaviour & 0.62 & $0.27-1.43$ & 1.33 & $0.62-2.83$ \\
Knowledge & 0.95 & $0.89-1.01$ & 1.06 & $0.99-1.12$ \\
Sex & 0.99 & $0.64-1.52$ & 0.84 & $0.57-1.24$ \\
Level of education & 0.99 & $0.89-1.10$ & 0.99 & $0.90-1.09$ \\
No religion & 0.62 & $0.38-1.01$ & 1.02 & $0.67-1.54$ \\
Protestant & $0.46 * *$ & $0.26-0.80$ & 0.88 & $0.52-1.48$ \\
Other religion & 0.69 & $0.27-1.78$ & 1.65 & $0.66-4.17$ \\
\hline
\end{tabular}

${ }^{1} \mathrm{OR}$, odds ratio; $\mathrm{Cl}$, confidence interval.

A significant $O R>1.0$ means that the variable has a positive relation with the outcome variable, whereas a significant $O R<1.0$ means that the variable has a negative relation with the outcome variables.

* $\mathrm{P}<0.05 ; * * \mathrm{P}<0.01$

\section{Discussion}

The present study was conducted in order to identify demographic and psychosocial correlates of both returning a completed registration form and registration as an organ donor. We first discuss the results for registration, i.e., returning completed registration forms regardless of the specific registration choice, after which we discuss the results for registration as an organ donor. Finally, the implications of these results for organ donation education will be discussed.

\section{Predictors of registration}

One fifth of the respondents who received a registration form reported that they did not return a completed registration form. We identified social outcome expectations, anxiety and negative outcome beliefs as important predictors of returning a completed organ donation registration form. 
Protestantism also had a significant relation with actual registration. Positive outcome beliefs, involvement with organ donation issues, correct knowledge, past behaviour, sex and level of education had no significant relation with returning the registration forms. The registration rate found in the present study was substantial and higher than the one found in the official registration figures ( $36 \%$ registration rate). This difference is most probably the result of a response bias. On average, people who returned their registration forms will be more likely to be willing to answer questions about registration. Nevertheless, the number of nonregistrants in our study was large enough to study possible predictors of registration.

First of all, social outcome expectations were associated with returning a completed registration form. Adolescents who think that especially their parents and their friends, but also their partners or other people who are important to them, would like them to return the registration form are much more likely to do so. The fact that registration among adolescents is strongly influenced by their social environment has been found before. Radecki and Jaccard (1997), as well as Brug et al. (2000), support this finding. Adolescents with more negative outcome beliefs were less likely to return a completed registration form. It is not surprising that people, who expect more negative outcomes from a given behaviour, will be less likely to enact that behaviour. The fact that a decisional balance in outcome expectations is a strong determinant of behaviour has been well documented (Prochaska \& Velicer, 1997). It may be that adolescents who have more negative beliefs are more uncertain about their registration choice and therefore postpone this choice, resulting in not returning the form. Anxiety also contributes to the explanation of returning the registration form. Fear about making a specific choice again seems to lead to not making a choice at all.

In contrast to the findings of previous studies (Horton \& Horton, 1990, 1991; Kopfman \& Smith, 1996), we found that a higher level of correct knowledge about organ donation possibilities and procedures did not lead to a higher registration choice. The main target in organ donation education programmes is often increasing this knowledge, but the results of our study indicate that we may not expect effects of knowledge education on completing and returning an organ donation registration form. Adolescents who are members of the Protestant denominations appear to 
be less likely to return a completed registration form. This may be the result of an existing belief among Protestants in the preservation of the integrity of life, which for some Protestant groups in the Netherlands means that the body of a deceased should not be desecrated because it is a gift of God. On the other hand, Protestants also believe in the duty of seeking for possibilities to save one's own life and the lives of other people (Pranger, 1998). Because of interpretation problems of these two considerations, Protestant adolescents may become uncertain and decide not to return their registration forms. No other differences in registration probability were found according to sociodemographic variables.

\section{Predictors of registration as an organ donor}

We found that almost $60 \%$ of the adolescents who returned their registration forms were willing to donate their organs and tissues posthumously. This proportion is about the same as the national figures $(57 \%)$, which is an indicator for the validity of the present study. The determinants of registration as a posthumous organ donor were often similar but not identical to the determinants of returning the registration form. Again, social outcome expectations, expectations about negative outcomes and anxiety were important. However, expectations about positive outcomes of registration as organ donor were also important. The fact that positive outcomes are not relevant for the decision to register, but do predict the specific registration choice, may require further study. A possible explanation may be that the presence of negative outcome expectations at first prevents adolescents from making a decision, whereas possible positive outcomes become relevant after they have made the choice to register in order to decide what registration choice will be made.

The finding that negative, positive and social outcome beliefs were associated with the decision to register as a posthumous organ donor was also found in earlier studies (Brug, van Vugt et al., 2000; Cacioppo \& Gardner, 1993; Horton \& Horton, 1990; Parisi \& Katz, 1986; Radecki \& Jaccard, 1997; Skowronski, 1997). These studies further found, in line with the present study, that negative outcome beliefs had the strongest association with organ donation registration. Similar to the decision to register, social outcomes are also important in the decision to register as an organ donor. 
Despite the fact that various misconceptions about organ donation registration were present among large proportions of the participants, correct knowledge about organ donation registration was again not a significant predictor of registration as an organ donor. This result supports the findings of the Brug et al. study (2000), although some studies reported that knowledge was a significant, but weak predictor of the willingness to register as a donor (Horton \& Horton, 1990, 1991; Kopfman $\&$ Smith, 1996). In contrast to the results of previous research, our study did not find a significant association between prior thought and later organ registration behaviour and present registration choice (Birkimer et al., 1994; Carducci et al., 1989; Smith et al., 1994).

The findings of the current study can be used to tailor school-based education programmes to encourage adolescents to register, and to encourage them to register as willing to be a posthumous organ donor. First, the results implicate that it is important to develop refutational messages in order to counterargue negative outcome beliefs and hence reduce feelings of anxiety. Further, in addition to these refutational messages (e.g., "much care is put into preparing a body for organ donation", "the brain death protocol is systematically and consistently used before organs can be abstracted from the donor"), it is advisable to develop messages that confirm and enhance positive outcome beliefs (e.g., "by registration as an organ donor, part of my body may survive after my death"). It is important to develop education that facilitates the decision process concerning registration.

Second, because social outcome expectations are important with a special emphasis on parents and friends, it is important to involve these close friends and relatives in any programme that is designed to encourage decisions about organ donor registration. Encouraging adolescents to discuss their beliefs, anxieties, or thoughts with these important others, as well as a peer education approach, may result in higher registration prevalence and in more adolescents registering as willing to donate their organs and tissues. 


\section{Part 2}

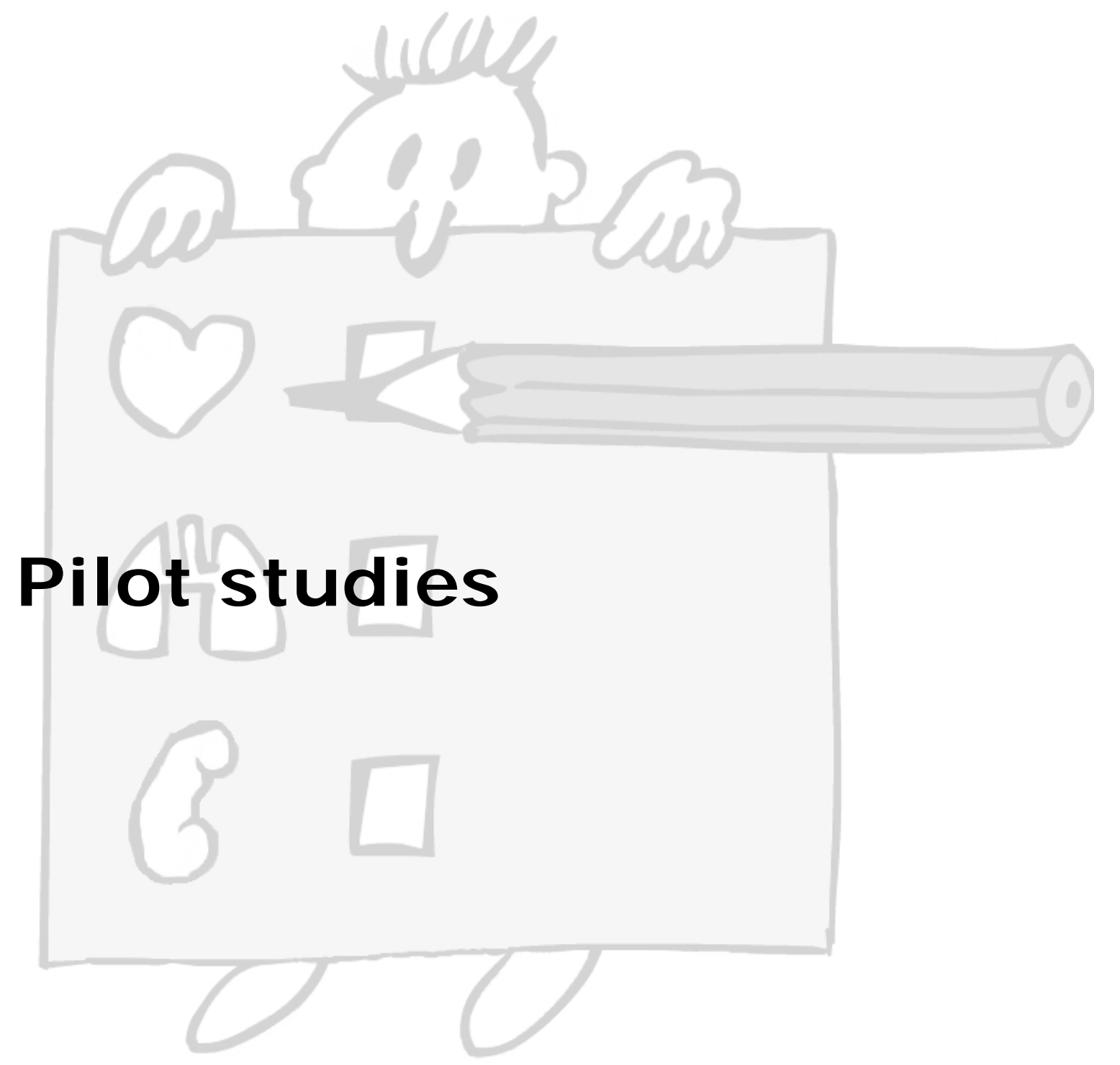





\title{
Chapter 3
}

\section{THE IMPACT AND EVALUATION OF TWO SCHOOL-BASED INTERVENTIONS ON INTENTION TO REGISTER AN ORGAN DONATION PREFERENCE.}

\begin{abstract}
The present chapter describes the impact and evaluation of two intervention components, a video with group discussion and an interactive computer-tailored programme, in order to encourage adolescents to register their organ donation preference. Studies were conducted in school during regular school hours.

The video with group discussion in class had a positive impact on the intention to register an organ donation preference as well as on the intention to register as a posthumous organ donor. The computer-tailored programme had no surplus value when compared to reading an extensive brochure with general information on organ donation. However, participants appreciated the tailored information more than the brochure. It may be that having provided general information before exposure to the tailored programme, the tailored intervention will be more effective. This needs to be tested in a further experiment.
\end{abstract}

Published as: Reubsaet, A., Brug, J., Kitslaar, J., Van Hooff, J.P. \& Van den Borne, H.W. (2004). The impact and evaluation of two school-based interventions on intention to register an organ donation preference. Health Education Research, 19(4), 447-456. 


\section{Introduction}

In most countries, there is a lack of available donor organs and tissues, resulting in loss of quality of life and premature death among people in need of donor organs and tissues (Horton \& Horton, 1990; Radecki \& Jaccard, 1997). This is also the case in the Netherlands (Van den Driessche et al., 1996). In order to increase the number of potential organ and tissue donors, the Dutch government changed donation legislation in 1998, implementing a new opting-in system in which a central registration system for organ donation preferences was established to replace the use of donor cards. From 1998 on, all Dutch citizens - within a year after reaching the age of 18 - receive an organ donation registration form on which they can indicate their organ donation preference. All preferences are centrally registered at the Donor Register. One can be registered as:

1. A posthumous organ and tissue donor;

2. A posthumous organ donor for specific organs and tissues;

3. Non-donor;

4. Leaving the decision to the next of kin;

5. Leaving the decision to a specific person.

In 1998, all 12 million Dutch inhabitants of 18 years and older were asked to indicate their preferences with regard to organ donation. However, $63 \%$ of these inhabitants did not complete and return their registration form, which means that for a majority the preference is unknown (Kunst \& Witlox, 1999). When a potential donor has not registered his or her desire, permission for donation will need to be asked from their next of kin. In order to create clarity and to prevent next of kin from taking a difficult decision on a very emotional moment, it is important that people register their organ donation will and that the number of registrants increases to a majority of the Dutch adult population. As each year, on average, 190,000 adolescents in the Netherlands reach the age of 18, this group is considered to be the most important target group for encouraging organ donation registration (Donorregister, 2000). A school-based education programme is being developed, to enable adolescents to make a wellconsidered decision about organ donation and to encourage them to register their decision (registration option 1 to 5 ). 
This chapter describes and discusses two studies on the development and short-term impact of two intervention components to encourage adolescents to register their preferences with regard to organ donation, specifically developed for that programme: a video with group discussion (Study 1) and an interactive computer-tailored programme (Study 2 ).

\section{Preliminary Research}

Planned health education should be based on a careful analysis of the determinants of the behaviour change or attitude change, which the intervention is intended to achieve. Three studies were conducted to investigate the determinants of organ donation registration among Dutch adolescents (Brug, van Vugt et al., 2000; Reubsaet, Brug, Van den Borne \& Van Hooff, 2001; Reubsaet, Van den Borne, Brug, Pruyn \& Van Hooff, 2001), based on Bandura's Social Cognitive Theory (SCT) (1986). In brief, these studies showed that negative outcome beliefs (e.g., "by registration as an organ donor, death may be established too soon"), positive outcome beliefs (e.g., "by completing and returning the registration form, I can decide what happens with my organs and tissues after my death"), social outcome expectations (e.g., "I think that my parents would want me to register as an organ donor") and anxiety related to organ donation registration, were all significantly associated with the adolescents' willingness to register as a posthumous organ donor (registration option 1 or 2). Reubsaet et al. (2001) also found that involvement with organ donation issues, past behaviour (e.g., "having discussed organ donation registration with other people"), knowledge, sex and level of education were significantly associated with the willingness to register as a posthumous organ donor. Based on these preliminary studies, it was concluded that interventions should be aimed at increasing involvement, communicating correct facts and information about outcomes related to organ donation registration. 


\section{General methods}

Both studies were conducted in a school environment during school hours. In each school, classes were selected and randomly assigned to either an experimental group or a control group.

All students received written information about the study and two informed-consent forms. The first form was to state their personal agreement with participation in the study. The second form was for their parents to fill out (in the Netherlands agreement of participants as well as their parents is required for people between 12 and 18 years old). The informed consent forms were distributed and collected by the teachers. After written agreement of both students and parents was documented, the experiment was carried out.

Data were collected with self-administered questionnaires. Post-test questionnaires were developed to assess the impact of the interventions. These post-tests assessed the willingness to complete and return an organ donation registration form and donation preference. Additional questions about participants' reactions to the computer-tailored programme and the video with group discussion were included. Questions were included in order to assess how many participants read or saw the information and to rate the information on interest, understandability, credibility and personal relevance. The questions could be answered on five-point scales, varying from "not at all" to "very much". Finally, questions about the participants" age, sex and level of education were included in the post-test questionnaires. 


\section{Study 1: Video with group discussion}

\section{I ntroduction}

The kind of intervention that should be used in health education varies and depends on the situation and end-users of the intervention (Bartholomew et al., 2001). In a school-based education programme, group discussion is a method often used by teachers for learning and cognitive development (Ahern, Peck \& Laycock, 1992; Bartholomew et al., 2001). An advantage of group discussions is the interaction between students, giving adolescents the opportunity of expressing different points of view and to explore new concepts. Furthermore, better understanding and more thorough absorption of information can be achieved (Ahern et al., 1992; Beckman, 1952). A video may be a useful education tool to trigger a classroom group discussion and thus encourage involvement among adolescents (O'Donnell, Doval, Duran \& O'Donnell, 1995; Wetzel, Radtke \& Stern, 1994). Furthermore, students may learn more easily from visual media. A video combines more ways of providing information than other media, such as text, allows learning through both verbal and visual means (Wetzel et al., 1994) and, may be better able to capture students' attention (Ferland, Ladouceur \& Vitaro, 2002). Furthermore, videotape players are nowadays available in all school settings and under the direct control of teachers. Teachers have the possibility of previewing a tape, to introduce it at any time that is convenient for them, to stop it for discussion and to rewind it at any time (Wetzel et al., 1994). Finally, a video-based intervention is time- and cost-effective and can be used repeatedly (Ferland et al., 2002; Torabi, Crowe, Rhine, Daniels \& Jeng, 2000).

We developed a video to encourage group discussion about organ donation and registration in order to increase involvement, to encourage positive beliefs and to counterargue negative outcome beliefs in order to increase intentions towards organ donation and registration. 


\section{Methods}

A quasi-experiment with a Solomon four-group design was conducted in seven secondary schools in the Netherlands. We expected that a pre-test questionnaire could make participants more sensitive to the intervention. In order to examine pre-testing effects, two groups ( $E 1$ and $\mathrm{C} 1$ ) received a pre-test questionnaire for completion two weeks before the intervention started. Each class was randomly assigned to one of the experimental groups E1 $(N=57)$ or $E 2(N=69)$ or one of the control groups $C 1(N=66)$ or $\mathrm{C2}(\mathrm{N}=60)$. Students in the experimental groups (E1 and E2) watched a video concerning organ donation and registration. After watching the video, students discussed these episodes among each other in the class, supervised by their teacher. The control groups ( $\mathrm{C} 1$ and $\mathrm{C} 2)$ did not receive any intervention. I mmediately after the intervention, students in all groups received a post-test questionnaire.

The videotape consisted of four episodes in which positive and negative outcome expectations concerning organ donation and registration were discussed. The different episodes of the video were aimed at eliciting a class discussion among adolescents of these different positive and negative outcome expectations.

The first episode dealt with the concept of "brain death" from the perspective of the parents and brother of a deceased 16-year old boy. Participants were encouraged to think about and discuss what brain death means and who decides when a person is diagnosed as brain dead. The second episode addressed common beliefs that by registering as a posthumous organ donor, one may be able to help a person who is in need of a donor organ. Although many adolescents agree with this outcome expectation, some may not, and participants were encouraged to discuss their opinions on this topic. In the third episode, a family discussed some of the pros and cons of registration and non-registration of an organ donation preference. This episode is aimed especially at encouraging adolescents to discuss organ donation and registration within their families. In the last episode, the importance of registering an organ donation preference was discussed again, this time from the perspective of a physician and the parents of a deceased boy. 
After each part of the video, participants were encouraged by their teacher to discuss their opinions and beliefs. The group discussion took about 50 minutes.

\section{Participants}

In total, 252 secondary-school students participated in the study. Due to privacy reasons, schools were not allowed to provide any information on non-responders. Twenty-four percent of the participants were educated at higher general secondary education and $77 \%$ at university preparation school. The mean age of the participants was 15.88 ( $S D=0.75$; range 14-19 years) and $59 \%$ were female.

\section{Results}

First, Chi-square tests showed that there was no impact of the pre-test questionnaire on the intention to register an organ donation preference at post-test, nor on the intention to register as an organ donor at post-test. Direct logistic regression analysis, showed that more female participants were assigned to the experimental group than to the control group (OR= $2.31 ; \mathrm{Cl}=1.02-5.27 ; \mathrm{p}<.05)$ and that participants who were assigned to the groups with a pre-test questionnaire were significantly younger ( $O R=$ 1.75; $\mathrm{Cl}=1.21-2.54 ; \mathrm{p}<.005)$. Therefore, further tests were adjusted for sex and age.

In order to test the impact of the video with group discussion on the willingness to register (as a posthumous organ donor), one-sided direct logistic regression analyses were performed, using study group (E/C), pretest/no pre-test, interaction between study group and pre-test/no pre-test, age and sex as independent variables (Table 3.1). Because of one-sided logistic regression analyses, $90 \%$ confidence intervals are reported. The results show that participants in the experimental group were more likely to be willing to register their organ donation preference $(\mathrm{OR}=3.42 ; \mathrm{Cl}=$ 1.22-9.60), and were more likely to intend to register as a posthumous donor ( $\mathrm{OR}=1.85 ; \mathrm{Cl}=1.02-3.34)$ after watching the video and discussing the scenes with their classmates than participants in the control group. 
Further, male participants were less likely to be willing to register their organ donation preference than female participants $(\mathrm{OR}=0.46 ; \mathrm{Cl}=0.23$ $0.95)$.

Table 3.1 Odds ratios (OR) and $90 \%$ confidence intervals for potential predictors of the willingness to register organ donation preference

\begin{tabular}{llrrr}
\hline Outcome variable & \multicolumn{2}{c}{$\begin{array}{c}\text { Intention to register an organ } \\
\text { donation preference }\end{array}$} & $\begin{array}{r}\text { Intention to register as an } \\
\text { organ donor }\end{array}$ \\
\cline { 2 - 5 } & \multicolumn{1}{c}{$O R^{a}$} & $90 \% C I^{a}$ & $O R^{a}$ & $90 \% C I^{a}$ \\
\hline Video with discussion & $3.42^{*}$ & $1.22-9.60$ & $1.85^{*}$ & $1.02-3.34$ \\
Pre-test/ No pre-test & 0.62 & $0.25-1.51$ & 0.62 & $0.34-1.16$ \\
Interaction (study group*pre-test) & 0.43 & $0.10-1.95$ & 0.48 & $0.20-1.16$ \\
Age & 1.13 & $0.68-1.89$ & 1.10 & $0.81-1.49$ \\
Sex (1=female; $2=$ male) & $0.46^{*}$ & $0.23-0.95$ & 0.94 & $0.60-1.47$ \\
\hline
\end{tabular}

$* p<0.05$ (one-sided)

a OR, Odds Ratio; $\mathrm{Cl}$, Confidence Interval

Of the participants in the experimental group, 71\% thought that it was (very) good to discuss different outcome expectations concerning organ donation and registration, while $57 \%$ found the discussion (very) interesting. Half of the participants thought that the discussion was (very) easy and only $12 \%$ found it difficult. With respect to the novelty of the information they received, $17 \%$ indicated that they learned (very) much, $39 \%$ of the participants indicated that they received a fair amount of new information (neither a lot of new information nor only a little bit of new information) and $46 \%$ indicated that they did not learn much nor less from the video and group discussion. 


\section{Discussion}

Study 1 was conducted to test the impact and subjective evaluation of a video followed by a group discussion in the class. The results demonstrate that the video-based intervention followed by a group discussion is effective in increasing both the intention to register an organ donation preference and the intention to register as a posthumous organ donor.

As mentioned before, videos are used frequently in school-based education programmes addressing various behaviours such as unsafe sex (O'Donnell et al., 1995; Torabi et al., 2000) and gambling (Ferland et al., 2002). These studies also demonstrated positive effects of video-based interventions. Further, O'Donnell et al. (1995) and Ferland et al. (2002) found that the efficacy of a video was increased substantially by using the video as a trigger for an interactive discussion.

\section{Study 2: An interactive computer-tailored intervention}

\section{I ntroduction}

Because of the size of the target group of 18-year olds, a mass media approach is a likely choice to encourage 18-year olds to register. However, generic mass media interventions are more effective in drawing attention to a specific issue than in initiating specific actions (Van den Ban \& Hawkins, 1996). The generic information that is communicated in these interventions is usually unspecific and not personally relevant for most individuals targeted with the intervention (De Vries \& Brug, 1999; M Kreuter, Farell, Olevitch \& Brennan, 2000). By tailoring interventions to the characteristics, education needs and beliefs of individuals, it is possible to provide information that is personally relevant and therefore more specific and less redundant. It has been proven that personally tailored information is more likely to be read, comprehended, processed more intensively and appreciated more, which makes the desired behaviour (change) more likely (see Brug \& De Vries, 1999 and Kreuter et al., 2000 for overviews of empirical evidence). A relatively new approach in health education computer-tailoring - combines the individualised approach of interpersonal counselling with the opportunity to reach larger population groups against relatively low costs per person (Brug, 1999). 
Computer-tailoring was expected to be a useful approach in teaching adolescents about organ donation (registration), because many misconceptions exist about organ donation and these misconceptions differ among individuals. The misconceptions are important predictors of the willingness to register (Reubsaet, Van den Borne et al., 2001). Furthermore, interactive computer-tailored interventions may be especially suitable for this target group since using computers has become a favourite leisure time activity for adolescents and computers are used more and more in school-based activities (Lieberman, 1997).

\section{Methods}

A computer-tailored intervention was developed and tested in a post-test design against a control group who received information about organ donation through a brochure. Because of the results found in Study 1, we used in this study a more simple two-group design. Five schools (14 classes) participated, and in each school the classes were randomly assigned to either an experimental group $(\mathrm{N}=86)$ or a control group ( $\mathrm{N}=$ 100). Students in the experimental classes individually started and completed the programme. Since in Study 2 we wanted to test whether computer-tailored information would be more effective than existing brochures with information on organ donation, the control group received an 11-page brochure from the Dutch Foundation of Donor Education. Students in both groups received a post-test questionnaire immediately after completion of the tailored programme or reading the brochure.

For the generation of a computer-tailored intervention, four elements are required (Figure 3.1): (1) a theory-based and empirically validated inventory of variables that are important determinants of the willingness to register as a posthumous organ donor, (2) a screening instrument which performs a 'diagnosis' at the individual level of these characteristics, (3) a message library that contains educational messages tailored to all possible screening results and (4) a computer programme that evaluates the diagnosis and selects and generates relevant messages tailored to the specific needs of each participating adolescent (Brug, Steenhuis, Van Assema \& De Vries, 1996; Dijkstra \& De Vries, 1999). 
An interactive computer-based screening questionnaire was developed. Completion of the questionnaire took 15 to 20 minutes and adolescents could feed their answers directly into the computer by mouse clicks. All answers on the screening questions were automatically coded and read into a data file. The screening questionnaire included questions on positive and negative outcome expectations, social outcome expectations, anxiety related to organ donation registration, involvement with organ donation issues, past behaviour and knowledge. Most questions could be answered on four-point (fully agree-fully disagree) scales with a "don't know" option. The two past behaviour questions were answered with "Yes" or "No", and the knowledge statements were answered with "right", "wrong" or "don't know".

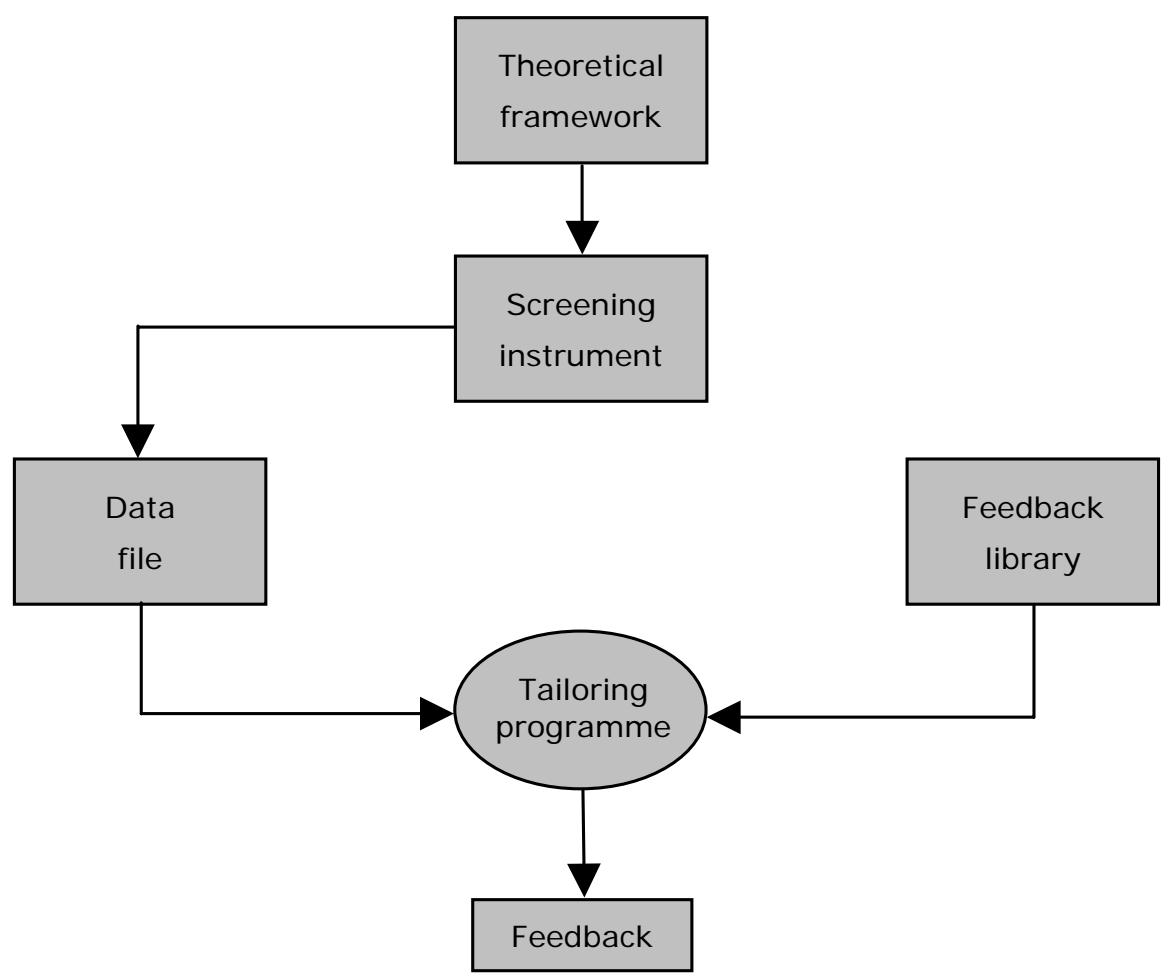

Figure 3.1 Computer-tailored intervention 
The messages library file consisted of 226 different feedback messages, which were tailored to different beliefs, knowledge scores, anxiety levels and general interest. Different feedback messages were written for each item of the screening questionnaire. The messages were written by professional health educators in association with a physician and representatives of the Dutch Foundation of Donor Education. The feedback messages were pre-tested among a small group of adolescents and were rewritten according to the results from the pre-test. Each feedback message was provided with a unique code.

Figure 3.2 gives an example of one of the possible feedback pages in the programme. A professional designer enriched the messages with illustrations and a clear and attractive layout.

A computer programme written in Visual Basic, read and analysed the screening results and selected relevant messages from the library. The tailored feedback was on screen and consisted of a series of interlinked web pages. Participants could also print the feedback.

Six topics related to organ donation and registration were presented (advantages of organ donation and registration; what do other people think about organ donation and registration; is organ donation scary?; what do you think about organ donation and registration?; the organ donation knowledge test; do you want to receive more information about organ donation and registration?). By clicking on a topic, the screening questions related to that particular topic appeared on the screen. Feedback was provided immediately after all questions on a topic were completed. After reading the information on a topic, participants could continue with one of the other topics. For the present study, subjects were instructed to go through all six topics. 
Proposition: Funerals have to be postponed in the case of organ donation.

True or false?: This is false.

What did you think?: You thought that this was true.

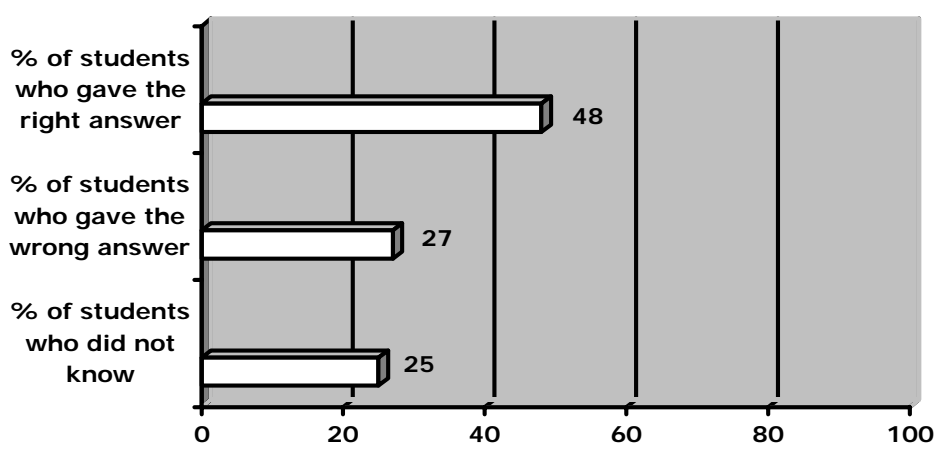

If a person is an organ donor, the funeral proceeds normally without delay.

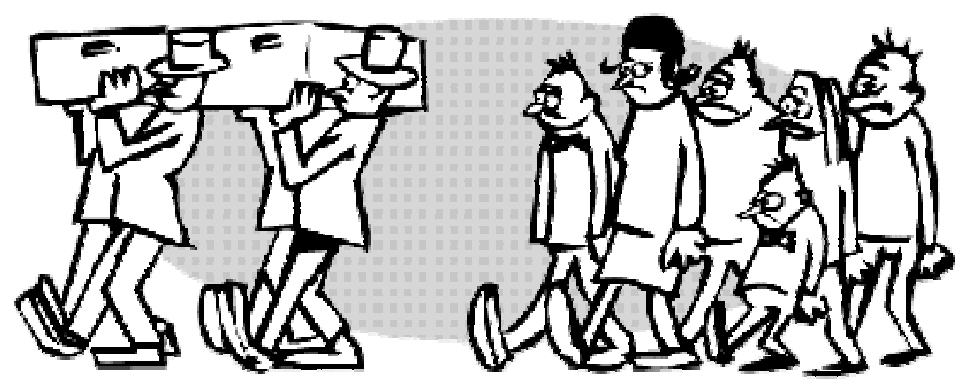

You thought, like many people, that a funeral has to be postponed in the case of organ donation. However, it is legally determined that a funeral has to take place within five days. Organ donation does not change that.

Figure 3.2 An example of a feedback page in the computer-tailored intervention.

\section{Participants}

A total of 186 secondary-school students participated. Again, two different school levels (comparable to the UK secondary-school system) were included in the study: higher general secondary education $(\mathrm{N}=136)$ and university preparation school education $(\mathrm{N}=50)$. Mean age was $16.02(\mathrm{SD}=$ .65; range $15-18$ ) and $53 \%$ were female. 


\section{Results}

Direct logistic regression analyses were performed with the intention to register and the intention to register as an organ donor as dependent variables and study group, age, sex and school type as independent variables. The results showed that the intervention had no significantly stronger impact on either the intention to register an organ donation preference or the intention to register as a posthumous organ and tissue donor than the control condition, in which students studied the (extensive) brochure (Table 3.2).

Table 3.2 Odds ratios (OR) and $95 \%$ confidence intervals for potential predictors of the willingness to register organ donation preference

\begin{tabular}{lcccc}
\hline \multirow{2}{*}{ Outcome variable } & \multicolumn{2}{c}{ Intention to register } & \multicolumn{2}{c}{ Intention to register as organ donor } \\
\cline { 2 - 5 } & $O R^{a}$ & $95 \% C I^{a}$ & $O R^{a}$ & $95 \% C I^{a}$ \\
\hline Computer-tailored intervention & 1.11 & $0.39-3.19$ & 1.09 & $0.60-1.97$ \\
Age & 0.89 & $0.37-2.13$ & 0.89 & $0.54-1.45$ \\
Sex (1=female; 2=male) & 2.44 & $0.78-7.59$ & 1.49 & $0.82-2.70$ \\
School type & 0.35 & $0.11-1.09$ & 1.08 & $0.53-2.21$ \\
\hline
\end{tabular}

a OR, odds ratio; $\mathrm{Cl}$, confidence interval

Table 3.3 shows that the computer-tailored information was more often read than the general information $(T=2.72, d f=184, p<0.01)$. Furthermore, t-tests showed significant differences between the experimental group and the control group in the extent to which the information was found to be interesting $(T=3.13, d f=184, p<0.01)$ and personally relevant $(T=2.88$, $\mathrm{df}=183, \mathrm{p}<0.01)$. However, participants in the general information group perceived to have learned more from the information they received ( $T=$ $-2.54, d f=183, p<0.05)$. No differences in credibility, comprehensibility, quality and novelty of the information were found. 
Table 3.3 Participants' reactions to computer-tailored interactive information and general information (mean scores (SD))

\begin{tabular}{|c|c|c|c|}
\hline Items (possible range) & $\begin{array}{c}\text { Computer- } \\
\text { tailored } \\
\text { information }\end{array}$ & $\begin{array}{c}\text { General } \\
\text { information } \\
\text { (brochure) }\end{array}$ & $p<.05$ \\
\hline Did you read the information? (1/3) & $2.73(0.52)$ & $2.51(0.59)$ & $\mathrm{T}>\mathrm{G}$ \\
\hline How interesting was the information? $(-2 /+2)$ & $0.93(0.65)$ & $0.60(0.79)$ & $\mathrm{T}>\mathrm{G}$ \\
\hline How credible was the information? $(-2 /+2)$ & $1.06(0.62)$ & $1.09(0.51)$ & ns \\
\hline How understandable was the information? $(-2 /+2)$ & $1.17(0.83)$ & $1.17(0.53)$ & ns \\
\hline How good was the information? $(-2 /+2)$ & $1.21(0.58)$ & $1.19(0.69)$ & ns \\
\hline How personally relevant was the information? $(-2 /+2)$ & $0.59(0.89)$ & $0.24(0.77)$ & $\mathrm{T}>\mathrm{G}$ \\
\hline How much new information did you read? $(-2 /+2)$ & $0.41(0.85)$ & $0.64(0.86)$ & ns \\
\hline How much did you learn? $(-2 /+2)$ & $0.26(0.79)$ & $0.54(0.72)$ & $\mathrm{T}<\mathrm{G}$ \\
\hline
\end{tabular}

$\mathrm{T}=$ Tailored information; $\mathrm{G}=$ General information

\section{Discussion}

Study 2 showed that the computer-tailored intervention was appreciated better than general information, but did not result in stronger intentions to register or in differences in preference for registration as an organ donor.

Earlier studies showed positive effects of computer-tailored education over a range of health-related behaviours, such as dietary change (Brug, Campbell \& Van Assema, 1999) and smoking cessation (Dijkstra, De Vries \& Rooijakkers, 1998; Strecher, 1999). However, Kreuter et al. (MW Kreuter, Oswald, Bull \& Clark, 2000) showed that the impact of tailoring may be completely dependent on the (lack of) variation in beliefs and other determinants of the target behaviour in the study population. In a study on weight loss, it was shown that among people for whom non-tailored materials (by chance) fitted their beliefs, non-tailored materials were equally effective or even more effective than tailored information. In the present study, the control group received fairly specific information on organ donation and registration through a brochure and this may have been as well fitting and, therefore, as influential as the computer-tailored information. Because we wanted to test if computer-tailored information would do better than generic information, a control group that received no information on organ donation and registration was not included in the study. 
It may also be that, because organ donation and registration is a relatively new topic for adolescents and because for many students it was the first time they discussed this topic, it could be that in such situations tailored information has no additional impact and that initially generic information is sufficient. Also, because of their age, adolescents often do not regard organ donation as a highly relevant topic.

Finally, in most computer-tailored interventions that have been evaluated to date, computer technology was used very sparsely and participants may not even realise that computer technology was used to give them personal advice. In these studies, participants completed written questionnaires and received written feedback while the feedback generating process was done at an intervention centre (De Vries \& Brug, 1999). But the present study used an interactive computer programme, so there could be no doubt that a computer generated the feedback. Hardly anything is known yet about how trustworthy web-based information is perceived to be. As in earlier studies (Brug, Glanz, Van Assema, Kok \& Van Breukelen, 1998; De Bourdeauduij \& Brug, 2000), the tailored information was read more often and was evaluated as more interesting and personally relevant than the general information on organ donation and registration.

\section{General conclusions}

In the Netherlands, the educational curriculum pays little or no attention to organ donation and registration. In order to increase the number of registered adolescents in the Netherlands, interventions activities were developed that could be incorporated in a school-based education programme. The present chapter described the development, rationale and efficacy tests of these activities: a video-based intervention with group discussion and an interactive computer-tailored programme. Efficacy testing is generally regarded as important before implementing a programme in which different activities are combined. Pre-test research is often restricted to very brief qualitative research. In the present study, we presented a more extensive, experimental - and therefore quantitative pre-test. 
The video with group discussion had a positive effect on the intention to register an organ donation preference as well as on the intention to register as an organ donor, and participants evaluated the group discussion as good and interesting. Although the computer-tailored programme did not show more effects than reading an extensive brochure on organ donation, participants did appreciate the tailored information better than general information. It may be that having provided general information before exposure to the tailored intervention (e.g., by means of a video with group discussion), the tailored intervention is more effective because awareness and general interest have already been established. This needs to be tested in a further experiment.

A limitation of the present study is that the focus was on behavioural intention instead of actual behaviour. Information on actual behaviour cannot be made available due to privacy protection legislation. Future research should address the need for actual registration behaviour by including a longer follow-up.

Presently, both the video with group discussion and the computertailored programme are integrated in a school-based education programme consisting of two lessons. Although the computer-tailored component did not have a significant effect, it was included because it was found to be much more attractive to the students, is more flexible in its applications and is less costly to apply. 



\section{Chapter 4}

\section{THE EFFECTS OF PRACTICING REGISTRATION OF ORGAN DONATION PREFERENCE ON SELF-EFFICACY AND REGISTRATION INTENTION: AN ENACTIVE MASTERY EXPERIENCE.}

\section{Abstract}

To evaluate an intervention to increase self-efficacy intentions to register organ donation preference, a Randomised Controlled Trial was conducted among 242 Dutch high-school students aged 15 to 18 years. On the basis of Social Cognitive Theory, practicing with a standard registration form (according to the Dutch system) was expected to increase the intention to register an organ donation preference through increasing self-efficacy. The participants in the experimental group practiced how to complete a registration form while the control group did not receive an intervention. Students in both groups completed a self-administered questionnaire before and after the intervention took place. The results showed that selfefficacy and intentions to register organ donation preferences at post-test were significantly higher in the intervention group.

Published as: Reubsaet, A., Brug, J., De Vet, E. \& Van den Borne, H.W. (2003). The effects of practicing registration or organ donation preference on self-efficacy and registration intention: an enactive mastery experience. Psychology and Health, 18(5), 585-594. 


\section{I ntroduction}

Transplantation medicine has improved worldwide, because of better technology, better medication to fight physical rejection of donor organs or tissues and more experience with treatments. This means that more patients with organ deficiencies or in need of body tissues are now eligible for transplantation and consequently the demand of donor organs and tissues has increased substantially (Kranenburg et al., 1998; Seldenrijk, 1993).

To increase the supply of organs and tissues, the Dutch government introduced new legislation related to organ donation in 1998. This new legislation is based on a 'decision system' (opting-in system), which means that each citizen decides by virtue of his/her own free will whether to be registered as a posthumous organ and tissue donor or not (Cleiren \& Van Zoelen, 1998; Roels et al., 1995). Registration is not compulsory. After a nation-wide, one-off distribution of registration forms among all inhabitants of 18 years and older in 1998, all inhabitants who turn 18 are now invited to register their organ donation preference by returning a specific registration form. On this form, Dutch adults can choose one of four registration alternatives: (1) registration as a posthumous organ donor (with the possibility to exclude specific organs or tissues from donation), (2) registration as a non-donor, (3) to leave the decision to the next of kin, or (4) to a specific (other) person.

Completed forms are returned to the Donor Register, a governmental organisation that centrally registers all preferences. Of the 12.5 million people who have been approached by the Dutch Government since 1998, only 4.6 million people ( $37 \%$ ) returned the registration form, which means that the majority of the Dutch population is not registered with respect to organ donation preference (Donorregister, 2001b). The law states that for non-registered people, the next of kin will need to be asked for permission for organ and tissue donation. In such cases, health care providers will need to ask a difficult question on a very emotional moment. Past experience has showed that in such situations many potential donors are missed because of emotional and logistic barriers (Cleiren \& Van Zoelen, 1998; Kranenburg et al., 1998). Therefore, in order to increase the number of potential posthumous organ donors and to make the new legislation 
work effectively, it is important that more people register their will with respect to organ donation. Annually, approximately 200,000 Dutch adolescents reach the age of 18 years and all receive a registration form (Donorregister, 2000). However, recently conducted research among Dutch adolescents (Brug, van Vugt et al., 2000; Reubsaet, Brug et al., 2001; Reubsaet, Van den Borne et al., 2001) has showed that many of these adolescents do not return their registration form because of psychosocial barriers. In these studies, as well as in studies conducted in other countries (Birkimer et al., 1994; Radecki \& J accard, 1997), it was found that early experiences with organ donation and self-efficacy related to organ donation registration were important predictors of the willingness to complete and return a registration form. The results from these studies suggest that, in order to increase registration of organ donation preference by adolescents, education programmes should be developed which address these particular determinants. In order to encourage 18-year-old adolescents to complete their registration forms and to help them to make a well-considered decision about donor registration, these education programmes should be offered to them well before they turn 18. In this chapter a self-efficacy enhancement intervention is evaluated, which will be part of a two-lesson school-based organ donation programme. The present chapter deals with the following research questions:

1. Is the intervention effective in increasing the intention to register an organ donation preference?

2. Are the effects of the intervention on registration intention mediated by the impact of the intervention on self-efficacy?

3. Is the effect of the intervention dependent on prior experiences with organ donation forms?

4. Does the intervention have an impact on willingness to register as organ donor?

5. How do the participants evaluate the intervention? 
Theoretical framework

According to Social Cognitive Theory (SCT), behaviour is influenced by anticipated effects related to this behaviour. These anticipations, referred to as self-efficacy expectations and outcome expectations, are regarded as the main determinants of (intention to participate in) a particular behaviour (Bandura, 1986).

Self-efficacy is the judgement a person makes about his or her ability to successfully accomplish a particular behaviour. A person, who has positive self-efficacy expectations with regard to a particular behaviour, is more likely to be motivated and to successfully perform that behaviour (Bandura, 1986).

According to Bandura, self-efficacy expectations are influenced most by prior experiences, or enactive mastery experiences. On the basis of such experiences, an individual learns to make a judgement about the abilities needed to succeed in a particular behaviour and likewise to succeed in a new, but similar behaviour. An increase in self-efficacy beliefs through enactive mastery experiences creates cognitive and self-regulatory tools for successfully performing a particular behaviour (Bandura, 1997). Thus, inducing an enactive mastery experience may be an effective strategy to increase self-efficacy.

The present study examined the impact of an enactive mastery experience intervention on self-efficacy and motivation to register organ and tissue donation preferences. On the basis of Social Cognitive Theory, self-efficacy with respect to registration was expected to increase if adolescents had an enactive mastery experience, that is to say if they could practice with filling in the registration form. Because of the expected increase in self-efficacy, intention to complete and intention to return the registration form was also expected to increase, where self-efficacy was expected to mediate the effects of the intervention on registration intention. 


\section{Methods}

The effects of the intervention were tested in a pretest-post-test control group design. Each individual student was randomly assigned to the experimental or control condition and data were collected by means of selfadministered questionnaires.

\section{Participants and procedure}

Groups of fourth- and fifth-grade students $(\mathrm{N}=242)$, aged 15 to 18 years (Mean=15.4), at three levels (medium level, high level and university preparation level) of seven high schools in the south of the Netherlands participated in the study. Of these 242 adolescents, 125 participants were assigned to the experimental group and 117 participants to the control group. Of all participants, 51\% was female, $67 \%$ was Roman Catholic, $22 \%$ reported to be non-religious and the remaining $11 \%$ reported to have other religions like Dutch reformed church, Islam, et cetera.

Before the study started, all students received written information about the study and two informed consent forms, one for the students and one for the parents. In the Netherlands, for people between 12 and 18 years old, agreement of both participants and parents is required. After informed consent of both students and parents was documented, the experiment was conducted during school hours.

In all participating classes, the teacher read a standardised introduction to explain the procedures of the study, without reading the objectives of the study, to the students. Subsequently all students completed a baseline questionnaire. After completing the questionnaire, students were randomly assigned to the control group or to the experimental group. Students in the experimental group received an official donor registration form and they were invited to practice filling in the registration form. They were told explicitly that completing the registration form was an exercise and that their organ donation preference would not be officially registered in the Donor Register. Participants in the control group did not receive an intervention and did regular classroom activities. One week after the intervention, all students completed a second questionnaire. 


\section{Measures}

Baseline and post-test data were collected by means of written selfadministered questionnaires. Completion of each questionnaire took about 15 minutes. In the baseline measurement, data were collected on the students' sex, age, religion, level of education and whether they carried an organ donation registration card. Four questions were included to measure prior experiences with the donor registration form (e.g., "Have you ever seen a donor registration form?") since it is possible that the effects of the intervention on intention and self-efficacy are less among those participants who had prior experiences with the donor registration form. Baseline and post-test data were collected on self-efficacy with respect to organ donation registration and registration intention. Self-efficacy was measured with eight questions (e.g., "How difficult or easy do you think it is to complete a donor registration form?"). The questions could be answered on seven-point Likert scales, ranging from very difficult/fully disagree (1) to very easy/fully agree (7). After a Principal Component Factor Analysis was conducted to test for one-dimensionality, the sum of all item-scores was divided by the number of items in order to get an overall self-efficacy score (ranging from -3 to +3 ). Registration intention was measured with one question: "Do you intend to complete and return the registration form when you reach the age of 18 years?" This question could also be answered on a seven-point scale (fully disagree-fully agree). Finally, one question was included to describe the participants' registration preference. Participants were asked to indicate the registration that they would choose if they were to receive a registration form at that time. As on the actual registration form, there were four registration possibilities: (1) registration as a posthumous organ donor (with the possibility to exclude specific organs or tissues from donation), (2) registration as a non-donor, (3) to leave the decision to the next of kin, or (4) to a specific (other) person.

The post-test questionnaire was similar to the baseline questionnaire but for the experimental group seven additional evaluation questions were included (e.g., "How much did you learn from practicing with completing a donor registration form?"; "Did you like practicing with completing a donor registration form?"). These questions were included to assess how the participants in the experimental group appreciated the intervention. 


\section{Self-efficacy scale}

A Principal Component Factor analysis was conducted on the self-efficacy items in order to test for one-dimensionality of the self-efficacy scale. All self-efficacy items loaded on a single factor and this factor accounted for $45 \%$ of the total variance with an eigenvalue of 3.59. A total self-efficacy score (Chronbach's alpha $=0.82$ ) was computed, varying from -3 to +3 (the sum of all item-scores divided by the number of items).

\section{Results}

\section{Predictors of Self-efficacy and Intention}

A Logistic Regression analysis, using forced entry, was performed to check for baseline differences and showed that there were no significant differences at baseline between the experimental group and the control group in sex, level of education, age, religion, carrying a donor card, selfefficacy and intention.

Table 4.1 presents the mean self-efficacy and intention scores at baseline and post-test for the experimental group and control group. The mean scores and standard deviations for the participants' reactions to practicing with completing a donor registration form are also presented in this table. On average, participants reported that they found it rather easy to complete the intervention activities and that they enjoyed practicing with the form. On a scale of 1 to 10 , respondents scored the intervention with a mean grade of 6.58. Further, before participants had practiced with completing a donor registration form $41 \%$ of them thought that it was difficult to complete a registration form. After the registration training session only $12 \%$ of the participants thought that completion was difficult.

Table 4.2 shows the bivariate correlations between key variables. As may be expected, the intention to register at baseline was highly correlated with the intention to register at post-test and self-efficacy at baseline was highly correlated with self-efficacy at post-test. 
Table 4.1 Mean scores (SD) for self-efficacy and intention at baseline (T1) and post-test (T2) and participants' opinions about the intervention

\begin{tabular}{lcc}
\hline Scale/Item (possible range) & Experimental group & Control group \\
\hline Self-efficacy $(-3 /+3)$ & & \\
$\quad$ T1 & $0.92(1.03)$ & $0.94(0.97)$ \\
T2 & $1.25(1.04)$ & $1.10(1.05)$ \\
Intention to register $(-3 /+3)$ & & \\
T1 & $0.90(1.82)$ & $1.00(1.77)$ \\
T2 & $1.40(1.59)$ & $1.10(1.67)$ \\
Important $(-3 /+3)$ & $0.33(1.69)$ & $\mathrm{NA}^{1}$ \\
Useful $(-3 /+3)$ & $0.81(1.80)$ & $\mathrm{NA}^{1}$ \\
Nice $(-3 /+3)$ & $1.44(2.06)$ & $\mathrm{NA}^{1}$ \\
Relevant $(-3 /+3)$ & $0.51(1.48)$ & $\mathrm{NA}^{1}$ \\
Learned $(-3 /+3)$ & $0.00(1.62)$ & $\mathrm{NA}^{1}$ \\
Difficult $(-3 /+3)$ & $1.95(1.27)$ & $\mathrm{NA}^{1}$ \\
Grade $(1-10)$ & $6.58(1.70)$ & $\mathrm{NA}^{1}$ \\
\hline
\end{tabular}

${ }^{1} \mathrm{NA}=$ Not applicable

Table 4.2 Pearson correlation matrix

\begin{tabular}{cllll}
\hline & 1 & 2 & 3 & 4 \\
\hline 1 & 1.00 & & & \\
2 & $0.62^{* *}$ & 1.00 & & \\
3 & $0.25^{* *}$ & $0.14^{*}$ & 1.00 & \\
4 & $0.22^{* *}$ & $0.18^{* *}$ & $0.72 * *$ & 1.00 \\
\hline
\end{tabular}

$* p<.05$ (2-tailed); ** $p<.01$ (2-tailed); Note: 1) Intention to register at baseline; 2) Intention to register at post-test; 3) Self-efficacy at baseline; 4) Self-efficacy at post-test.

Further significant correlations were found between intention to register at baseline and self-efficacy at baseline and self-efficacy at post-test. Intention to register at post-test was significantly correlated with selfefficacy at baseline as well as with self-efficacy at post-test.

In line with recommendations given by Judd \& Kenny (1981) as well as Baron \& Kenny (1986) and MacKinnon (1994) three interrelated multiple regression analyses were carried out. Firstly, the potential mediating factor was disregarded, and therefore the impact of study group on registration intention was assessed, controlling for baseline intentions. The results 
showed that experimental versus control group condition $(\beta=0.13 ; p<0.01)$ and 'intention at baseline' $(\beta=0.70 ; p<0.001)$ were both significant predictors, explaining $50 \%$ of the total variance. Secondly, the effect of the intervention on the potential mediator was assessed, and therefore posttest self-efficacy was regressed on study group and baseline self-efficacy. Both self-efficacy at baseline $(\beta=0.73 ; p<0.001)$ and experimental versus control group condition $(\beta=0.12 ; p<0.01)$ were significant predictors of self-efficacy at the post-test, explaining $54 \%$ of the total variance. After the intervention, participants in the experimental group had significantly higher self-efficacy beliefs with regard to completing and returning a donor registration form, than participants in the control group. Finally, both the mediating variable and the independent variable were included in the regression equation as possible predictors of the effectiveness of the intervention. Therefore, a third Multiple Linear Regression was used to examine self-efficacy beliefs as a mediator of the effect of the intervention on the intention to register organ donation preferences. The set of independent variables explained $58 \%$ of the variance in intention. Intention to register at the post-test was significantly predicted by self-efficacy at the post-test $(\beta=0.40 ; p<0.001)$, intention at baseline $(\beta=0.58 ; p<0.001)$ and self-efficacy at baseline $(\beta=$

$-0.15 ; p<0.05)$. Furthermore, the analyses showed that study group was borderline significant $(\beta=0.09 ; p=0.05)$. To test whether this indicated that the effect of the intervention on registration intention was achieved through the mediating role of self-efficacy beliefs, a significance test (the Baron and Kenny modification of the Sobel test) was performed. This test showed no significant mediation effect $(p=0.14>\alpha)$. The path diagram in Figure 4.1 integrates the results of the regressions. 


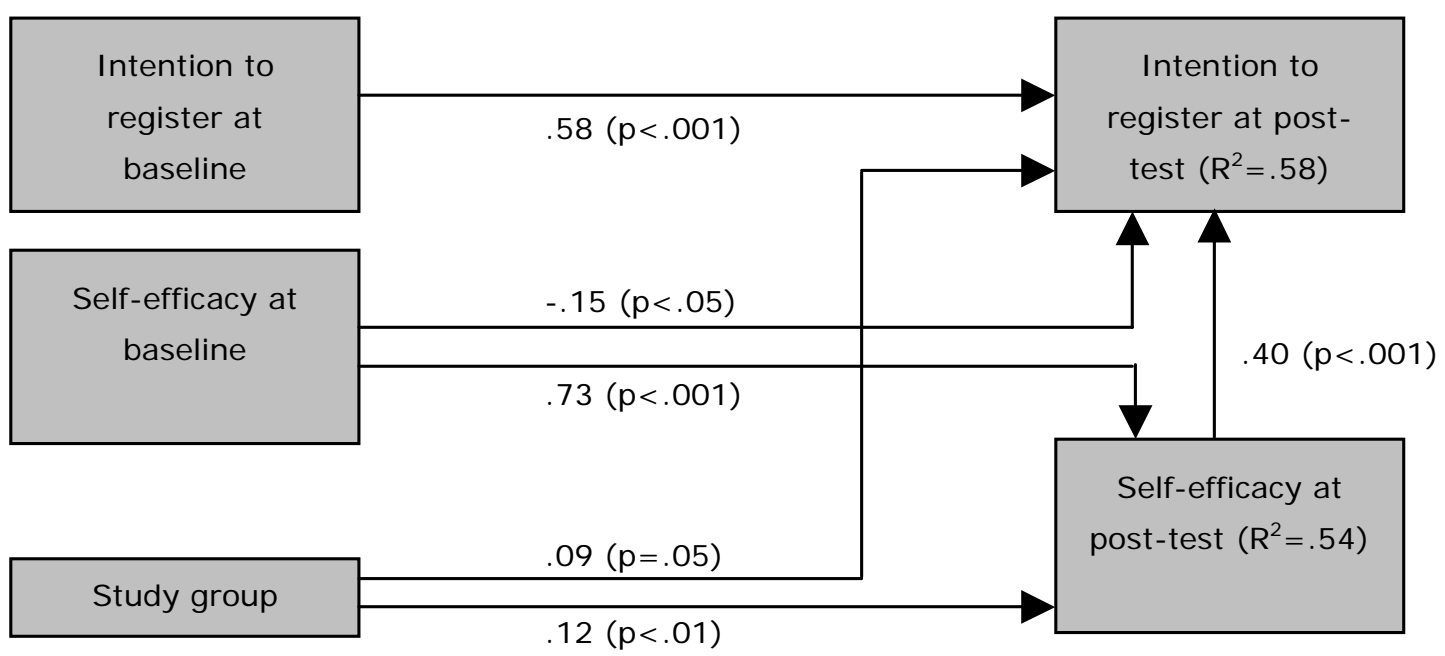

Figure 4.1 Path diagram based on the Linear Regression Analyses with self-efficacy at post-test and intention to register at post-test as dependent variables.

In order to test for a possible interaction between study group and prior experiences, we performed two Linear Regression analyses in which intention at post-test and self-efficacy at post-test were used as dependent variables. These additional analyses showed that prior experiences with the donor registration did not significantly influence the effects of the intervention on registration intention and self-efficacy at post-test. Furthermore, although the present study, in line with the aim of the intervention, focused primarily on the intention to register an organ donation preference, regardless of what that preference would be, we also tested, by means of a Logistic Regression analysis, for effect of the intervention on willingness to register as an organ donor. The independent variables study group and intention to register as organ donor at baseline were entered into the regression equation at once and intention to register as organ donor at post-test was used as dependent variable. The analysis showed that intention to register as organ donor at baseline ( $O R=47.95$; $\mathrm{Cl}=21.75-105.71$ ) was significantly associated with willingness to become a potential posthumous organ and tissue donor and that study group $(\mathrm{OR}=1.47 ; \mathrm{Cl}=.67-3.25)$ was not a significant predictor. 


\section{Discussion}

The present study deals with organ donation decision-making and specifically the effectiveness of an enactive mastery experience intervention in order to increase self-efficacy and the intention to complete and return the organ donation registration form at the age of 18 years. It is the first study in which the intervention is not directed at persuading people to posthumously donate their organs and tissues, but rather it is directed at empowering people to comply with the Dutch system of donation registration. The results show that practicing the completion of a registration form may result in an increase in registration intention, but not in higher willingness to register as a potential posthumous organ donor. Furthermore, self-efficacy with regard to completing and returning a donor registration form increased significantly because of the intervention.

The new legislation that was implemented in the Netherlands in 1998 resembles an opting-in system. The system is unique in the sense that the organ donation choice is centrally registered in the so-called Donor Register, which is organised by the Dutch government. The new system will only work effectively if most Dutch inhabitants register their organ donation preference. An increase in the number of registrants leads to more clarity for caregivers and next of kin and because of this quicker organ donation procedures, less emotional burden, et cetera. In the present study, therefore, the intention to register organ donation preferences (either willing or not willing to donate) was the main outcome variable instead of a positive intention to become a posthumous organ donor. To date, most organ donation studies examined the influence of interventions on (motivation for) positive registration (i.e., registration as an organ donor). Hence, the present results cannot easily be translated and compared to other studies on this topic or to organ donation studies conducted in other countries. Nevertheless, some comparisons may be warranted.

The results of the present study support the positive association of earlier experiences in relation to organ donation with actual registration or registration intention that was found in previous studies (Birkimer et al., 1994; Brug, van Vugt et al., 2000; Carducci et al., 1989; Nolan \& McGarth, 1990; Reubsaet, Brug et al., 2001; Reubsaet, Van den Borne et al., 2001; Smith et al., 1994). In those studies, adolescents who had ever thought 
about organ donation, who had discussed this topic with others, who knew someone else who died and donated organs, or who ever completed a registration card before, were more likely to register as a posthumous organ donor. In the present study, we tried to give our participants some experience with organ donation registration procedures and practices, by giving them a chance to become familiar with the registration forms. According to Bandura (Bandura, 1997), this prior experience or enactive mastery experience should increase self-efficacy with regard to complete and return a donor registration form.

A technique, which rather resembles the present intervention, is the so-called 'Foot-in-the-door'-technique (Carducci \& Deuser, 1984; Carducci et al., 1989; Freedman \& Fraser, 1966). With this technique, a small initial request is made and compliance with this request leads to the rewarding perception of being helpful. Once individuals have agreed to this first request, they may be more willing to agree with a second larger request. The underlying theoretical framework that has been suggested in order to explain this phenomenon is Bem's Self-perception Theory (Bem, 1972), which postulates that attitudes are inferred by the (direct or indirect) experience with behaviour. People who agree to a first request will see themselves as being helpful (rewarding perception) and receptive to requests and this will lead to their agreeing to the second larger request. This line of thought is indeed very similar to Bandura's Social Cognitive Theory in which also interrelations between experience and outcome expectances are predicted. However, Bandura also proposes that selfefficacy is an important mediating variable between experience and motivation to act in a certain way. Carducci and Deuser (1984) assessed the effectiveness of a 'Foot-in-the-door'-technique applied to organ donation ('Foot-in-the-Donor'-technique). Their initial request involved asking respondents to complete a questionnaire consisting of 20 organ donation related measures. After two weeks, the respondents were asked to indicate their willingness to become an organ donor on a scale from 0 (not at all willing) to 100 (extremely willing). The respondents in the control group were not asked to complete the 20-item questionnaire, but they were simply asked to indicate their willingness to become an organ donor. As Carducci and Deuser predicted, the results showed that respondents in the initial request group were more willing to become organ 
donors than respondents in the control group. The 'Foot-in-the-door'technique is a way to encourage thought and experience with organ donation issues. However, the present intervention was designed to increase thought and experience as well as self-efficacy with regard to organ donation registration.

As mentioned before, an increase in the number of people who register their organ donation preference may be successful because of more clarity. Furthermore, the Dutch government follows a policy, which encourages people to register their preference through neutral education. The present study shows that the intervention has an effect on the intention to register an organ donation preference, but did not result in a higher willingness to register as a posthumous organ and tissue donor. In order to increase the number of potential posthumous organ donors, a broader approach than the registration training session may be required. Moreover, an intervention should be aimed at influencing other potential determinants.

A limitation of the study is that we measured self-reported intention instead of actual behaviour. Information on actual registration behaviour cannot be made available due to privacy protection legislation. Furthermore, including registration behaviour in our study would have implied a long follow-up period.

It can be concluded that practicing with an organ donation registration form, as used in our intervention led to a higher level of selfefficacy and higher intentions related to organ donation registration. The present intervention will be integrated in a school-based organ donation curriculum, which will be tested in a larger field experiment in the Netherlands. 



\section{Part 3}

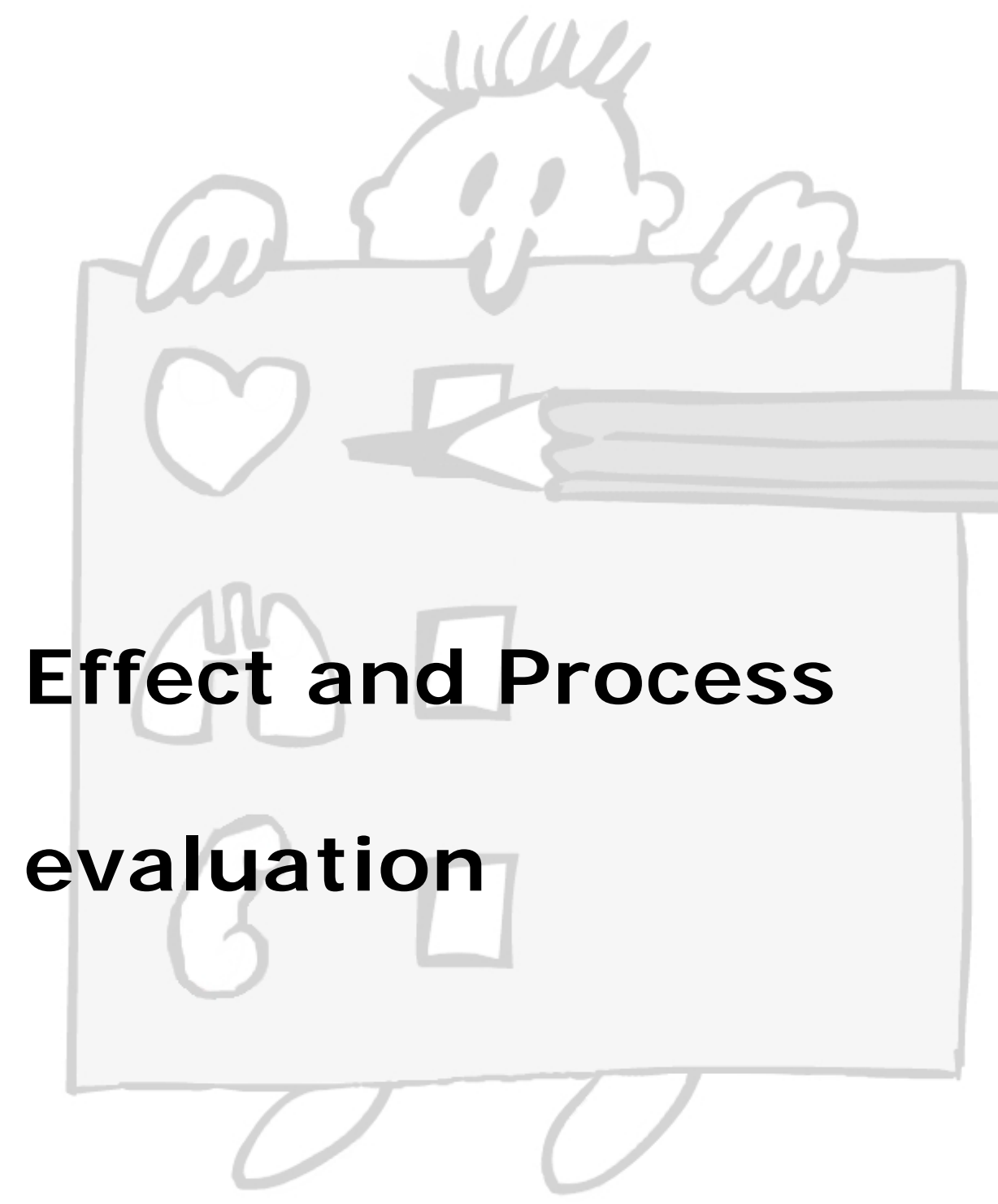





\section{Chapter 5}

\section{THE IMPACT OF AN ORGAN DONATION REGISTRATION INFORMATION PROGRAMME FOR HIGH SCHOOL STUDENTS IN THE NETHERLANDS.}

\section{Abstract}

In 1998, a new organ donor registration system was implemented in the Netherlands to increase the number of potential donors. A high school education programme was developed to prepare adolescents to make an informed decision about organ donation.

A post-test only randomised controlled trial was conducted in 39 high schools including 2868 students. Students within schools were randomly allocated to either attend the organ donation education programme or not. The impact of the programme on students' intention to register their organ donation preference (and determinants thereof) were analysed using multivariate multileveling modeling (MlwiN).

The results show that students who were exposed to the education programme had more favourable registration intentions $(B=.40)$, were more often willing to be donors $(O R=1.45)$, and had greater knowledge about $(B=3.84)$ and more positive social outcome expectations $(B=.09)$ and self-efficacy regarding organ donation registration $(B=.22)$. Lastly, they experienced significantly less negative outcome expectations related to organ donation registration ( $B=-.15)$. Students' evaluation of the schoolbased education programme was favourable.

The present organ donation registration programme proved to be effective in changing determinants of organ donation registration, and its large-scale implementation in the Dutch high school curriculum is planned.

Accepted for publication as: Reubsaet, A., Brug, J., Nijkamp, M.D., Candel, M.J.J.M., Van Hooff, J.P. \& Van den Borne, H.W. (2004). The impact of an organ donation registration information programme for high school students in the Netherlands. Social Science \& Medicine. 


\section{Introduction}

Organ transplantation can improve the quality of life of many patients on waiting lists, and each posthumous donor can save an average of eight lives (Eurotransplant, 2003). However, in many countries, including the Netherlands, the demand for donor organs exceeds their supply (Eurotransplant, 2002). In order to increase the number of posthumous organ and tissue donors, the Dutch government introduced a new registration system for organ donation preferences in 1998. In this new system all Dutch citizens who reach the age of 18 years receive an organ donation registration form at their home address. The registration form offers five registration alternatives: (1) registration as a posthumous organ and tissue donor; (2) registration as a posthumous donor for specific organs and tissues; (3) registration as a non-donor; (4) registration to leave the decision to the next of kin and (5) registration to leave the decision to a specific person. All organ donation preferences are registered in a central Donor Register.

So far registration rates have been low. Of the adolescents born in 1982, 1983 and $1984,34 \%, 36 \%$ and 33\% respectively responded to the invitation of the Dutch government to register their organ donation preference, and approximately half of these adolescents registered their willingness to donate organs and tissues posthumously (Donorregister, 2001a, 2002a, 2003a). Earlier studies have shown that many adolescents lack the necessary knowledge and entertain misconceptions about certain organ donation and registration issues (Brug, van Vugt et al., 2000; Reubsaet, Brug et al., 2001; Reubsaet, Van den Borne et al., 2001). The fact that low registration rates among Dutch adolescents exist demonstrates the need for an effective education programme. Therefore, in order to prepare Dutch adolescents to make a well-considered organ donation decision and to increase registration rates, a school-based education programme was developed and tested.

Educational programmes should be theory-driven and based on empirical evidence on possible determinants of the targeted behaviour to increase the likelihood of an effective intervention (Bartholomew et al., 2001). The present school-based education programme is based on three studies that explored significant socio-demographic and psychosocial 
correlates of organ donation registration preferences (Brug, van Vugt et al., 2000; Reubsaet, Brug et al., 2001; Reubsaet, Van den Borne et al., 2001). These studies were informed by Bandura's Social Cognitive Theory (1986) and were extended with factors that were identified as potential determinants in earlier studies (knowledge about organ donation and registration and past experience) (Horton \& Horton, 1990, 1991). These studies showed that the most important correlates of organ donation registration intention were; negative outcome expectations (e.g., "by registration as an organ donor, my death may be established too soon"), positive outcome expectations (e.g., "by completing and returning the registration form, I can decide what happens with my organs and tissues after my death") and social outcome expectations (e.g., "I think that my parents would want me to register as an organ donor"), anxiety related to organ donation registration (e.g., "it scares me to think about registration as an organ donor), involvement with organ donation issues (e.g., "the deficiency of organ donors is an important problem"), past behaviour and experience (e.g., "have you ever thought about organ donation?") and knowledge about organ donation and registration. Further, self-efficacy related to registration (i.e., confidence about being able to complete the registration procedure) was identified as an indirect predictor.

In accordance with general recommendations for the development of complex interventions (Campbell et al., 2000; Windsor, Baranowski, Clark $\&$ Cutter, 1994), three draft intervention components for school-based organ donation education were first developed and tested in controlled studies (Reubsaet, Brug, De Vet \& Van den Borne, 2003; Reubsaet, Brug, Kitslaar, Van Hooff \& Van den Borne, 2004). After the pilot testing, the three promising intervention components were integrated in a comprehensive two-lesson organ donation programme. The present chapter describes and discusses the short-term impact of this programme among Dutch high school students aged 15 to 18 years. 


\section{Methods}

\section{Design and procedure}

The education programme was tested in a 'Post-test-Only' design with randomisation at the student level (i.e., random numbers). The design is a true experimental design and because it involves randomisation and comparison groups, its internal validity is strong, even without a pretest (Gross Portney \& Watkins, 2000). A total of 2868 students within schools and classes were randomly assigned to the experimental group $(\mathrm{N}=1287)$ or to a control group $(\mathrm{N}=1581$ ) (see Figure 5.1). Students in the experimental group attended two 50-minute lessons on organ donation registration. During the first lesson, students in the control group were brought to another room to complete the evaluation questionnaire. A member of the research team assisted the students in the control group. Approximately one week later, all students (i.e., experimental and control group) received the second lesson. One week after the second lesson, the students in the experimental group completed the evaluation questionnaire with some additional questions on how they experienced and evaluated the programme. Students in the control group completed a questionnaire on a subject that was not related to organ donation and registration (physical activity).

\section{Participants}

A total of 2868 students, aged 15 to 18 years ( $M e a n=16.5 ; S D=0.67$ ), from 39 high schools in the Netherlands participated in the present study. Since the ethical approval for the study did not allow a pre-intervention measure, nor the provision of information from the schools on non-responders (due to privacy reasons), we have no information about the non-responders other than that the reason for non-response was absence during at least one of the two lessons or absence at the post-test. Cases of non-response always resulted from student illness, bad weather, or class cutting for unknown reasons. We found no cases where students refused to participate in the intervention or were not willing to fill-out the post-test. Because the experiment was conducted during school hours students were obliged to attend the lessons on organ donation registration. In the Netherlands, three different high school graduation levels are distinguished: preparatory 
secondary vocational education $(\mathrm{N}=308)$, senior general secondary education $(\mathrm{N}=1379)$ and university preparation education $(\mathrm{N}=1180)$. Of all students, $55 \%$ was female, 53\% reported that they lived in a village or smaller town, $42 \%$ in a larger city and only $5 \%$ reported living in the country. Most students were non-religious (43\%), 23\% were members of the Protestant Church, 22\% were Roman Catholics and 12\% reported that they adhered to other religions like Islam or Jewish. In the present study, female students were slightly overrepresented and preparatory secondary vocational education was underrepresented compared to national statistics on high school students (CBS, 2002).

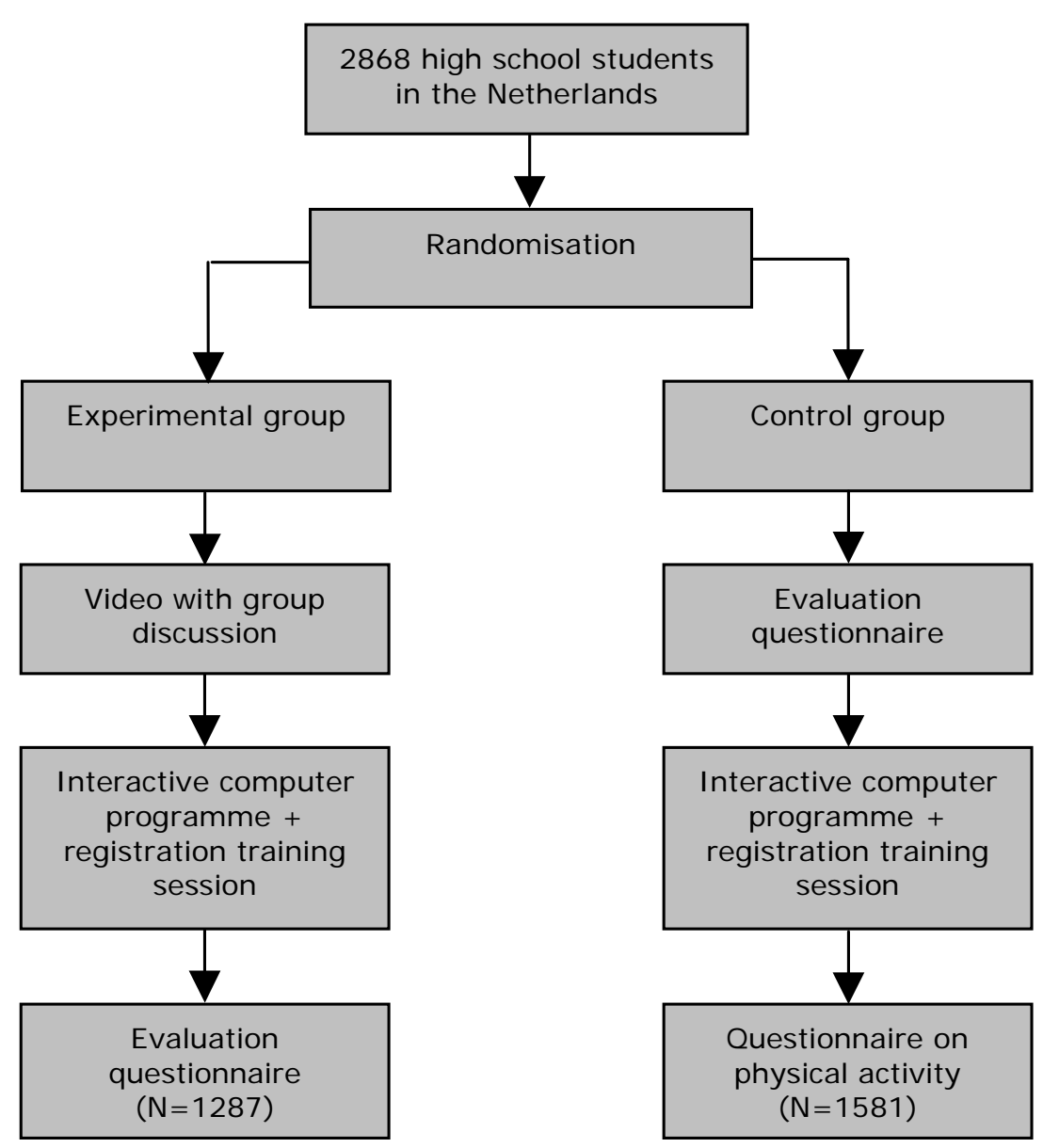

Figure 5.1 Study procedure and design 


\section{The intervention}

During the first lesson, students watched a video consisting of four fiveminute episodes that introduced various possible outcome expectations and misconceptions concerning organ donation and registration and the importance of discussing organ donation registration preferences with family members. These outcome expectations were identified as prevalent in this age group based on prior studies (Brug, van Vugt et al., 2000; Reubsaet, Brug et al., 2001; Reubsaet, Van den Borne et al., 2001). The video aimed to elicit a discussion about the importance of organ donation registration and the various misconceptions, and the teacher encouraged the students to discuss their opinions and beliefs after each episode. The video and group discussions took about 50 minutes. The first video episode dealt with the concept of "brain death". Students were encouraged to think about and discuss what brain death means and who decides when a person is diagnosed as brain death. The second episode encouraged students to discuss their opinions about the belief that by registering as a posthumous organ donor, one may be able to help a person who is in need of a donor organ. The third episode dealt with discussing organ donation and registration issues with parents and other family members. In the last episode, the importance of registering an organ donation preference, independent of whether one wants to be a donor, is illustrated (Reubsaet et al., 2004).

In the first part of the second lesson, students worked with an interactive computer programme that provided individually tailored information about organ donation and registration (Reubsaet et al., 2004). By tailoring the information about organ donation and registration to the characteristics, needs and beliefs of the students, it was possible to provide information that was personally relevant and therefore more specific and less redundant. Five topics related to organ donation and registration were presented, and students could choose with which topic they wanted to start: (1) what do you think about organ donation and registration?; (2) what do other people think about organ donation and registration?; (3) is organ donation scary?; (4) the organ donation knowledge test; (5) do you want to receive more information about organ donation and registration? By clicking on a topic, questions related to that particular topic appeared on 
the screen, and the tailored information (based on the given answers) was provided immediately after all questions on a topic were completed. It was further possible to print the tailored information. After reading and/or printing the information on a topic, students could continue with one of the other topics.

In the second part of lesson 2, students received a realistic but invalid copy of a donor registration form, and they were invited to practice completing the registration form, in order to increase registration selfefficacy (Reubsaet et al., 2003). They were told explicitly that completion of the registration form was an exercise and that their organ donation preference would not be officially registered in the Donor Register.

\section{Questionnaire}

Data were collected using self-administered written questionnaires for which good psychometric qualities has been established in earlier studies (Brug, van Vugt et al., 2000; Reubsaet et al., 2003; Reubsaet, Brug et al., 2001; Reubsaet, Van den Borne et al., 2001). The questionnaire included measures for:

Registration intentions: One item was included to measure the intention to register an organ donation preference on a five-point scale ("I am willing to register my organ donation preference"; fully disagree $=1$ / fully agree $=5$ ). A second item was included to measure willingness to register as a posthumous organ donor. Students were asked to indicate the registration they would choose if they were to receive a registration form at that time. In parallel with the actual registration procedure, there were five possibilities: (1) registration as a posthumous organ and tissue donor; (2) registration as a posthumous donor for specific organs and tissues; (3) registration as a non-donor; (4) registration to leave the decision to the next of kin and (5) registration to leave the decision to a specific person. Students could also indicate that they would not return the registration form. For the multilevel analyses a dichotomous variable was computed to compare students who indicated that they would register as potential donors (registration choice $=1$ or 2 ) to other students (registration choice = 3-5).

Knowledge: Students were asked whether 26 statements related to organ donation and registration were true, false, or that they did not know. 
Examples of statements were "Nearly all western religions are in favour of organ donation' or 'Older people are not suitable for organ donation' (see also Reubsaet, Brug et al., 2001; Reubsaet, Van den Borne et al., 2001). Correct answers were coded " 1 ", and incorrect answers and questions answered with "don't know" were coded " 0 ". The item scores were added up in order to compute a total knowledge score (range 0-26).

For self-efficacy, negative outcome expectations and social outcome expectations mean scores were obtained by summation of item scores divided by the number of items, after the internal consistency was established.

Self-efficacy: Self-efficacy related to organ donation registration was measured by means of 11 questions (e.g., "How easy or difficult do you think it is to complete a donor registration form?"). Questions could be answered on 5-point Likert scales, ranging from very difficult/fully disagree (1) to very easy/fully agree (5). An overall self-efficacy score was calculated by adding up all item scores divided by the number of completed items, ranging from -2 tot +2 (Cronbach's $\alpha=0.83$ ).

Negative outcome expectations: Eight statements were included to measure negative outcome expectation with respect to organ donation and registration (e.g., "By registration as an organ donor, I run the risk that my organs may be traded after my death."). Students were asked to indicate on 5 -point scales, ranging from fully disagree $(-2)$ to fully agree $(+2)$, their agreement with the statements (Cronbach's $\alpha=0.74$ ). Because the education programme was mainly focused on counter arguing negative outcome expectations (misconceptions) instead of increasing positive outcome expectations, we did not include items regarding positive outcome expectations.

Social outcome expectations: Social outcome expectations concerning organ donation and registration were assessed by means of agreement with four statements (e.g., "My friends find it important that I register my organ donation preference."). Students could indicate their agreement with the statements on 5 -point scales ranging from fully disagree (-2) to fully agree (+2) (Cronbach's $\alpha=0.81$ ).

Sociodemographic variables: Students were asked about their sex, nationality, level of education, name of their school, class number, whether they lived in a city, village or in the country and their religion. 
Evaluation of the 'Organ donation and Registration' Programme: In order to assess how students in the experimental group appreciated the 'Organ donation and Registration' Programme, five additional evaluation questions were included. Questions assessed how many students read or saw the information, and rated the information on for example interestingness, comprehensibility and credibility. Questions could be answered on five-point scales, varying from "not at all" (1) to "very much" (5).

\section{Statistical analyses}

Since we had a nested sampling procedure (students within classes within schools) with a high probability of interdependence of observations, multilevel analyses (MlwiN 1.10.0007) (Rasbash et al., 1999) were used to analyse the relationship between the education programme and determinants of organ donation registration (Goldstein, 1995; Snijders \& Bosker, 2003). Six sets of hierarchical prediction models were analysed in order to test the influence of the education programme on:

1. Intention to register an organ donation preference.

2. Intention to register as a potential posthumous organ and tissue donor.

3. Knowledge about organ donation registration issues.

4. Self-efficacy with respect to organ donation registration.

5. Negative outcome expectations concerning organ donation and registration.

6. Social outcome expectations regarding organ donation and registration.

In all six analyses, the main independent variable was group (experimental group versus control group), controlling for gender, level of education, religion and degree of urbanisation. The variables religion and degree of urbanisation were transformed into three and two dichotomies, respectively, by dummy coding. 'No religion' was the reference group and was compared to 'Roman Catholic', 'Protestant' and 'other religion'. For urbanisation, 'living in a city' was the reference group, which was compared to 'smaller city or town' and 'rural area'. All analyses were done in a socalled "top-down" procedure (i.e., starting with the most comprehensive model and leaving out the least significant and non-significant effects). 


\section{Results}

Chi-square analyses and t-tests showed that there were no significant differences between the experimental and control condition in demographic variables, with the exception of level of education (experimental condition vs. control condition: $10 \%$ vs. $11 \%$ preparatory secondary vocational education, $51 \%$ vs. $46 \%$ senior general secondary education, and $39 \%$ vs. $43 \%$ university preparation education). Significant differences $(p<.05)$ on school and class level justified the use of multilevel analysis. Table 5.1 shows the mean scores and standard deviations for intention to register (as posthumous organ donor) and for its determinants in both study groups after the experimental group was exposed to the programme, while Table 5.2 shows the significant parameter estimates for all outcome measures.

\section{Table 5.1 Intentions and determinants of intention to register as posthumous donor among students in the experimental and the control groups}

\begin{tabular}{|c|c|c|c|}
\hline \multicolumn{2}{|l|}{ Scale/Item } & Experimental group & Control group \\
\hline \multicolumn{2}{|c|}{ Mean (SD) intention to register } & $0.90(1.03)$ & $0.52(1.09) *$ \\
\hline \multirow[t]{6}{*}{ Number (\%): } & with positive registration intention & $870(68)$ & $795(51) *$ \\
\hline & registration as donor & $355(28)$ & $357(23)^{*}$ \\
\hline & registration as restricted donor & $320(26)$ & $366(24) *$ \\
\hline & registration as non-donor & $305(24)$ & $327(21)^{*}$ \\
\hline & $\begin{array}{l}\text { leave the decision to next of kin or to } \\
\text { specific person }\end{array}$ & $151(12)$ & $246(16)^{*}$ \\
\hline & $\begin{array}{l}\text { not willing to return the registration } \\
\text { form }\end{array}$ & $124(10)$ & $250(16)^{*}$ \\
\hline \multirow[t]{4}{*}{ Mean (SD): } & self-efficacy $(-2 /+2)$ & $0.58(0.52)$ & $0.36(0.51)^{*}$ \\
\hline & $\begin{array}{l}\text { negative outcome expectations } \\
(-2 /+2)\end{array}$ & $-0.86(0.70)$ & $-0.72(0.61)^{*}$ \\
\hline & $\begin{array}{l}\text { social outcome expectations } \\
(-2 /+2)\end{array}$ & $-0.21(0.69)$ & $-0.32(0.66)^{*}$ \\
\hline & knowledge $(0-26)$ & $18.78(4.13)$ & $15.12(3.24)^{*}$ \\
\hline
\end{tabular}

* $p<.001$ 

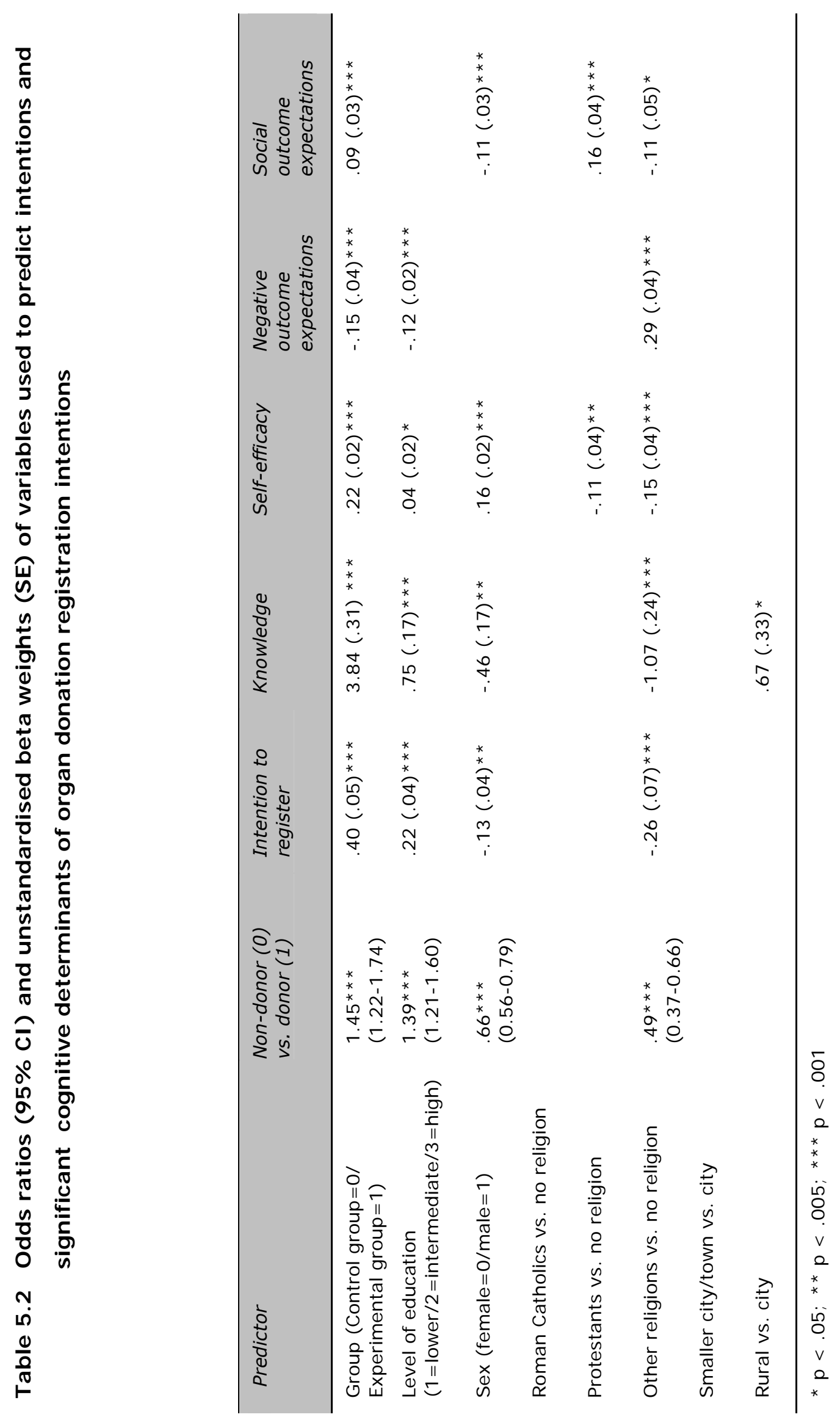
There were effects of group on all outcome measures. Students in the experimental group had significantly higher measures of intention to register their organ donation preference (effect size/ES $=0.035$ ) and were more often intended to register as a posthumous organ donor ( $E S=0.007$ ). Further, students were exposed to the lessons on average answered four more knowledge items correctly (item range: 0 -26) compared to students who were not exposed to the lessons $(B=3.85 ; E S=0.23)$. Students in the experimental group experienced greater registration self-efficacy $(B=.22$; $E S=0.04)$ and fewer negative outcome expectations ( $B=-.15 ; E S=0.02)$ and more positive social outcome expectations regarding organ donation registration ( $B=.09 ; E S=0.004)$ than students in the control group.

Female students had significantly higher measures of intention to register $(B=-.13 ; p<.005)$, were more willing to register as organ donor $(O R=0.66 ; p<.001)$, had greater knowledge $(B=-.46 ; p<.005)$ but less selfefficacy $(B=.17 ; p<.001)$, and experienced more positive social outcome expectations $(B=-.11 ; p<.001)$ than male students. Measures of intention to register were significantly higher among students attending university preparatory education $(B=.22 ; p<.001)$ (as organ donors; $O R=1.39$; $p<.001)$, greater knowledge $(B=.75 ; p<.001)$ and greater self-efficacy beliefs ( $B=.04 ; p<.05)$, and expected fewer negative outcome expectations $(B=-.12 ; \quad p<.001)$ than students attending preparatory secondary vocational education and senior general secondary education. Students reporting other religions than Roman Catholic or Protestant had significantly smaller registration intention measures $(B=-.26 ; p<.001)$, were less inclined to register as organ donors $(O R=.49 ; p<.001)$, had less knowledge $(B=-1.07 ; p<.001)$ and less self-efficacy $(B=-.15 ; p<.001)$ and experienced more negative outcome expectations $(B=.29 ; p<.001)$ and fewer positive social outcome expectations $(B=-.11 ; p<.05)$ than students with no religion. Protestant students had less self-efficacy $(B=-.11$; $p<.005)$ and experienced more positive social outcome expectations of registration $(B=.16 ; p<.001)$ than students with no religion. Finally, students living in rural areas had greater knowledge about organ donation registration issues $(B=.67 ; p<.05)$ than those living in towns or cities.

Of the students exposed to the programme, $88 \%$ felt that the information they had received was easy or very easy to understand, while $27 \%$ indicated that they had received little new information on organ 
donation registration. Forty percent indicated that they had learned much or very much, and almost $70 \%$ felt that it was useful or very useful to receive organ donation registration education. The education programme was scored with a mean appreciation rating of $6.7(\mathrm{SD}=1.30)$ on a scale 1 (very poor) to 10 (very good).

\section{Discussion}

The present study evaluated an integrative, planned national Dutch schoolbased education programme primarily aiming to prepare high school students for a well-considered decision about organ donation, and to encourage them to centrally register their organ donation preferences. The results show that the intention to register an organ donation preference had increased significantly after exposure to the programme. In addition, students exposed to the programme were more inclined to register as a posthumous organ and tissue donor, had greater knowledge about and more positive social outcome expectations and self-efficacy regarding organ donation registration and lastly, they experienced less negative outcome expectations related to organ donation registration.

Most effect studies on organ donation education examined the influence of interventions on knowledge about organ donation and on willingness to donate organs and tissues posthumously. Because of the unique system of organ donation registration in the Netherlands, one of the main outcome variables of the present study was willingness to register independent of the organ donation preference. Therefore, the present results can only partly be compared to other effect studies on organ donation in other countries. The significant increase in adolescents' knowledge found in the present study is in line with the findings of previous studies on the effectiveness of organ donation interventions (Anantachoti et al., 2001; Meier et al., 1999; Merion et al., 2003; Weaver et al., 1999). However, Morgan and colleagues (2002) did not find a significant increase in knowledge resulting from a worksite organ donation project. In most previous studies, willingness to posthumously donate organs and tissues increased significantly as a result of organ donation interventions (Meier et al., 1999; Merion et al., 2003; Morgan et al., 2002). Students reporting 
other religions than Roman Catholic or Protestant appear to be less likely to return a registration form and were less inclined to register as organ donors. One explanation might be that in these other religions stronger conflicting values occur, such as the duty of charity (i.e., saving the lives of other people) and the preservation of the integrity of life (Sanders, 2003). Another explanation might be that people with these other religions mainly belong to groups (immigrants or refugees) from another culture in which decisions about issues like organ donation are more likely made in the context of the person's family and less likely on the basis of an individual decision.

A limitation of the present study is that self-reported behavioural intention was measured instead of actual registration behaviour. Information on actual registration behaviour among adolescents is not available since the data from the Dutch registry are protected by privacy legislation. However, it is well established that behavioural (registration) intentions are a strong and consistent determinant of actual (registration) behaviour (Ajzen, 1991; Horton \& Horton, 1990, 1991).

Students who were randomly assigned to receive the education programme but who were absent during one or both lessons did not complete the post-intervention questionnaire (lesson 3 ) and thus dropped out of the research. This resulted in a lower response rate in the experimental group resulting from "loss-to-follow-up". The students in the control condition completed the evaluation questionnaire during the first lesson. Consequently, in spite of the randomisation the comparison groups differed in the number of participants. This may cause serious problems because the sample size was reduced and secondly, the differences in outcome measures we found between the experimental and control condition might have been due to factors other than the education programme. To deal with our problem of dropout, we have performed secondary analysis, which more or less resembles the "intention-to-treat" principal (Gross Portney \& Watkins, 2000). In order to equalise the sample sizes in both groups, we computed the mean scores on the effect variables in the control condition for the respondents that were lost to follow-up in the experimental group. Obviously, significant differences will then be harder to find. The results of the secondary analysis confirmed our hypothesis: the effect sizes were smaller but still statistically significant. 
Since the ethical approval for the study did not allow a pre-intervention measure, nor the provision of information from the schools on nonresponders, we have no information about the non-responders other than that the reason for non-response was absence during at least one of the lessons.

The new organ donation legislation in the Netherlands states that if a person has failed to register their organ donation preference, the next of kin will need to be asked for permission for donation, when appropriate. In order to create clarity and to prevent family members from having to make a difficult decision at a very emotional moment, it is important that people not only register their organ donation preference but also inform family members about their decision or organ donation preference. Furthermore, if the next of kin are aware of the wishes of the deceased, the registered organ donation preference is almost always followed, compared to a $20 \%$ consent rate where wishes are not known (NIGZ-Donorvoorlichting, 2003). The present education aimed to make such social influences more explicit and our results show that the programme resulted in more positive perceived social outcome expectations. Future research may attempt to measure more directly the influence of donor education on social interaction about this topic within families.

So far, most organ donation interventions have failed to use social science theories. The present programme is based on a thorough understanding of the correlates of organ donation registration, primarily founded on Social Cognitive Theory (Bandura, 1986), and on a stepwise series intervention development studies in line with the evaluation theory proposed by Campbell and colleagues (2000). The use of theories is crucial in the development and evaluation of educational interventions (Glanz et al., 1997). Theory provides insight into the causal pathways from intervention activities via intermediate outcomes such as knowledge, expected outcomes, self-efficacy and intentions in order to target behaviour, i.e., registering an organ donation preference (Glanz et al., 1997; Morgan et al., 2002). 
Because of the positive findings presented in this chapter, the education programme is ready for dissemination and the Dutch Foundation of Donor Education has now implemented the programme on a larger scale in high schools in the Netherlands. To date, 408 out of 735 Dutch high schools are working with the programme. Moreover, efforts are being made to include the programme as a regular nationwide topic within the school curriculum. The research team is consulting with several (governmental) agencies about structural adoption of the education programme in the educational curriculum. Based on the present study, the large-scale implementation of the programme is expected to lead to a larger proportion of registrations, and eventually to more potential posthumous organ and tissue donors. 


\section{Chapter 6}

\section{PROCESS EVALUATION OF A SCHOOL-BASED EDUCATION PROGRAMME ABOUT ORGAN DONATION AND REGISTRATION AND THE INTENTION FOR CONTINUANCE.}

\section{Abstract}

This chapter describes the implementation, evaluation and intention for continuance of a school-based education programme on organ donation and registration of which the effectiveness was established. A cross-sectional survey was conducted among fifty high school teachers who had recently worked with the programme.

The results show that all teachers reported to have implemented at least two of the three intervention components, while a majority of teachers reported to have implemented all components. Teachers' attitudes toward the programme were generally positive. They reported that the opinions of students and colleagues in their own department were most influential in their decision to provide the organ donation registration education programme. Furthermore, teachers were very confident about their ability to apply the different parts of the education programme. The educational quality of the programme was evaluated as moderately positive and almost all teachers had the intention to use the programme again in the future. Because of the positive evaluations and intentions for future implementation by teachers, and justified by its previously established effectiveness, the education programme should be considered for largescale dissemination among high schools in the Netherlands.

Accepted for publication as: Reubsaet, A., Reinaerts, E.B.M., Brug, J., Van Hooff, J.P. \& Van den Borne, H.W. Process evaluation of a school-based education programme about organ donation and registration and the intention for continuance. Health Education Research. 


\section{Introduction}

The shortage of organ and tissue donors remains an important problem in the Netherlands as well as in other countries. In 2001, only 552 people in the Netherlands received a donor organ (cadaveric donations only), whereas 1458 people were waiting for a transplantation (Eurotransplant, 2001). Organ donation and transplantation is partly dependent on the legislation concerning organ donation and attitudes of people (Akgün, Tokalak \& Erdal, 2002).

In order to increase the number of potential organ and tissue donors, the Dutch government introduced a new organ donation registration scheme in 1998. This new law is based on a 'decision system', which means that each citizen decides by virtue of his/her own will and integrity of the body whether he or she wants to be registered as a potential organ and tissue donor. From 1998 on, every Dutch person who reaches the age of 18 years receives a registration form with four registration options: (1) registration as a posthumous organ and tissue donor; (2) registration as a donor but only for some specific organs and tissues; (3) registration as a non-donor; (4) registration to leave the decision to the next of kin or a specific person. In order to create clarity for all those involved in a possible transplantation, the decision is centrally registered in a Donor register.

However, to date the majority of the Dutch population (63\%) (Donorregister, 2002b) did not react on the invitation of the Dutch government to register their organ donation preference. Furthermore, only one third of the adolescents completed and returned a donor registration form (Donorregister, 2003a). Three Social Cognitive Theory (SCT) (Bandura, 1986) based studies (Brug, van Vugt et al., 2000; Reubsaet, Brug et al., 2001; Reubsaet, Van den Borne et al., 2001) were conducted among Dutch adolescents to identify important predictors of organ donation registration. Based on the predictors of willingness to register an organ donation preference, a school-based education programme about organ donation and registration was systematically developed to enable adolescents to make a well-considered decision about organ donation and to encourage them to centrally register their decisions with respect to organ donation. 
The 'Organ Donation and Registration' programme consisted of three intervention components, which were used in two lessons. In the first lesson, students watched a video in which positive and negative outcome expectations concerning organ donation and registration were discussed. The different outcome expectations in the video were aimed at eliciting a class discussion among adolescents. The second lesson consisted of working with an interactive computer programme that provided tailored information about organ donation and registration. Lastly, students were invited to practice the completion of a donor registration form (registration training session). In an earlier study, the efficacy of this school-based organ donation programme was established (Reubsaet et al., accepted for publication). Students who were exposed to the programme were more likely to register their organ donation preference at the age of 18 years, were more willing to become an organ donor posthumously, experienced fewer negative outcome expectations concerning organ donation registration, were more aware of social outcome expectations, reported more knowledge about organ donation registration issues and experienced more self-efficacy beliefs with respect to organ donation registration.

Evaluation research most often focuses on the effects of an intervention, frequently without paying much attention to how the effects were achieved (Israel et al., 1995). Effectiveness alone is not enough to disseminate an education programme. In the Netherlands, schools can choose their teaching materials without interference of the Dutch government (Eurydice, 2001). The intermediaries - the people who need to use and implement the programme - should be convinced about the usefulness and applicability of the programme. Therefore, in addition to effect studies, it is important to systematically analyse the process of intervention implementation. The main purpose of such a process evaluation would be to determine the extent, accuracy and quality of the implementation of a specific intervention (Israel et al., 1995; Windsor et al., 1994). 
The present chapter examines these issues among the most important intermediaries for the present programme: teachers. The framework of the education programme was guided by Bandura's Social Cognitive Theory (1986) and prior research on the intention to register organ donation preferences among adolescents. The present chapter deals with the following research questions:

1. To what extent did the teachers implement the 'Organ Donation and Registration' programme?

2. How did the teachers evaluate the 'Organ Donation and Registration' programme (attitudinal, subjective and control beliefs; educational quality; and characteristics of innovations)?

3. How many teachers intend to use the 'Organ Donation and Registration' programme in the future?

\section{Theoretical framework}

Roger's Diffusion of Innovations Theory (Rogers, 1995) was used as the framework for the present study. Rogers defines an innovation as "an idea, practice or object that is perceived as new by an individual or other unit of adoption". Rogers (1995) and Zaltman \& Duncan (Zaltman \& Duncan, 1977) identified characteristics that can expedite a possible adoption or continuation of an innovation. For the present study, the concepts relative advantage (observed or actual advantages of the innovation compared with the current situation), complexity (the degree to which the innovation is perceived as easy to understand and use), trialability (the extent to which the innovation can be tested), observability (visibility of the results of the innovation for others), compatibility (the extent to which the innovation fits with the target group), reversibility (the extent to which an innovation can be reversed or discontinued), risk (the degree of uncertainty caused by the introduction of the innovation) and modifiability (the extent to which the innovation can be updated or modified) of the programme were studied.

In addition, meta-analyses of health promotion interventions have identified that specific principles derived from learning theories were generally found to be predictive for programme effectiveness (Mullen, Green \& Persinger, 1985; Mullen, Mains \& Velez, 1992). In the present study, five of these 'learning principles' were used to assess the perceived educational quality of the 'Organ Donation and Registration' programme: 
(1) Relevance (the degree to which the content of the education programme is perceived to be tailored to the level of knowledge and beliefs of students); (2) Individualisation (the perceived degree to which students can individually attend the education programme); (3) Feedback (the degree to which students receive information about the extent of progress achievement); (4) Reinforcement (the teachers' perception of the degree to which students receive rewarding information about the desired behaviour); and (5) Combination (the perceived degree to which the programme provides multiple or alternative learning principles).

Lastly, the Theory of Planned Behaviour (TPB) (Ajzen, 1991) was applied to structure the social and psychological dispositions towards providing organ donation education. Although this model has not often been applied within the context of curriculum innovation, there is good reason for its application because teaching may be regarded as an intentional act that is guided by teachers' beliefs (Paulussen, 1994). According to the TPB, the intention to perform a certain action is the main determinant of actual behaviour (providing organ donation education) and is best predicted by attitudes, subjective norms and perceived behavioural control. Attitude refers to the perceived consequences of providing organ donation education and is determined by the evaluation of the consequences of that behavior. Subjective norms are conceptualised as the weighted result of perceived opinions of important others about providing organ donation education and the motivation to comply with these expectations. Perceived behavioural control refers to the perceived degree of difficulty to provide organ donation education. A person who has a positive attitude, who experiences a positive subjective norm and has high perceived behavioural control with respect to providing organ donation education, will be more likely to use the organ donation education programme in the future. 


\section{Methods}

\section{Respondents and Procedure}

All teachers $(\mathrm{N}=77)$ who had worked with the 'Organ Donation and Registration' programme for the first time were invited to complete a questionnaire measuring their opinions about the programme. A total of fifty teachers $(65 \%)$ responded. Because of anonymity, the reasons for non-response could not be studied. Respondents were teachers at three different high school graduation levels: preparatory secondary vocational education ( $4 \%$ ), senior general secondary education (26\%) and university preparatory education (32\%). A total of 19 teachers taught in both senior general secondary education and university preparation level and 32\% were female. On average, teachers had been in teaching for 18.5 years and $56 \%$ had no experience with organ donation registration education.

\section{Design and Measurements}

The design of the study was cross-sectional and the self-administered questionnaire was based on earlier evaluation studies of school-based education programmes, adjusted for the specific topic of the present programme. The questionnaire consisted of the following parts:

Sociodemographic variables: Respondents were asked for their sex, level of graduation education they taught at, years of experience as a teacher, experience with organ donation education and their religion.

Implementation of the 'Organ Donation and Registration' programme: Six items were included to measure which parts of the education programme actually were used during the lessons. In addition, respondents were asked how serious students had worked with the different components of the 'Organ Donation and Registration' programme.

Evaluation of the 'Organ Donation and Registration' programme: Respondents were able to evaluate the components of the education programme with a grade ranging from 1 (very bad) to 10 (excellent).

Attitudes toward the 'Organ Donation and Registration' programme: Attitudes toward the programme were measured as a weighted result of feasibility (F) and the subjective importance (I) of the learning outcomes proposed by the programme $\left(\sum F_{i} l_{i}\right)$ (Ajzen, 1991). Seven propositions were included to measure the feasibility of learning outcomes ("Do you 
expect that by providing the 'Organ Donation and Registration' programme, students will be better prepared to make a well-considered decision about organ donation?") (Cronbach's $\alpha=0.84$ ) and seven propositions assessed the subjective importance of these beliefs $(\alpha=0.88)$. Respondents could indicate on four-point and five-point scales their agreement with these propositions.

Subjective norm: A total of five items was included to measure the normative beliefs with respect to the use of the 'Organ Donation and Registration' programme $(\alpha=0.80)$, and respondents could answer the questions on 5-point scales (e.g., "How will the students react when you use the 'Organ Donation and Registration' programme in the future?"). Five items measured the normative beliefs with respect to general education about organ donation and registration $(\alpha=0.63)$, and respondents could indicate on 4-point scales their agreement with the propositions. A sample item was: "Do you think that the school board finds it important to educate about organ donation and registration?". Respondents' motivations to comply with the different referents (students, school board, colleagues in other departments and parents) were measured by five items $(\alpha=0.67)$, and agreement could be indicated on 4-point scales (e.g., "How much do you comply with the opinions of colleagues in other departments with respect to organ donation and registration education?"). Two subjective norm scores (one with respect to the education programme and one with respect to education about organ donation and registration in general) were calculated by multiplying each normative belief ( $\mathrm{nb}$ ) by the respondents' corresponding motivation to comply $(\mathrm{mc})$ and adding these different scores into a new subjective norm variable $\left(\sum \mathrm{nb}_{\mathrm{i}} \mathrm{mc}_{\mathrm{i}}\right.$ ) (Ajzen, 1991).

Perceived behavioral control: Seven propositions reflected perceived behavioral control beliefs with respect to different aspects of the education programme $(\alpha=0.81)$ and respondents could indicate their agreement on 4point Likert scales (e.g., "Do you think you are capable of having students discuss the pros and cons of organ donation and registration in small groups?"). 
Educational quality: Seven items reflecting the so-called learning principles 'relevance', 'individualisation', 'feedback and reinforcement' and 'combination' were included to measure the perceived educational quality of the 'Organ Donation and Registration' programme $(\alpha=0.69)$.

Characteristics of innovation: Eight propositions were included to measure the concepts of innovation 'relative advantage', 'complexity', 'trialability', 'observability', 'reversibility', 'risk', 'modifiability' and 'compatibility'. All propositions could be answered on 4-point scales.

Intention to use the 'Organ Donation and Registration' programme in the future: Three propositions measured the intention to use the programme in the future and respondents were asked to indicate their agreement with these propositions $(\alpha=0.89)$.

Table 6.1 presents the means and standard deviations of the abovementioned scales.

Table 6.1 Mean scores (SD) and number of items of the scales and items used

\begin{tabular}{lcc}
\hline Scale/Item (range) & $\begin{array}{c}\text { Number of } \\
\text { items }\end{array}$ & Mean (SD) \\
\hline Attitude $(-10 /+10)$ & 14 & $4.63(2.25)$ \\
Programme-related subjective norm (-8/+8) & 10 & $0.23(2.03)$ \\
Donation education-related subjective norm $(-10 /+10)$ & 10 & $0.24(2.55)$ \\
Perceived behavioural control $(-2 /+2)$ & 6 & $1.12(0.44)$ \\
Educational quality $(-2 /+2)$ & 7 & $0.54(0.55)$ \\
Compatibility $(-2 /+2)$ & 1 & $0.82(0.81)$ \\
Complexity $(-2 /+2)$ & 1 & $1.20(0.54)$ \\
Observability $(-2 /+2)$ & 1 & $-0.49(1.16)$ \\
Reversibility $(-2 /+2)$ & 1 & $1.24(0.66)$ \\
Risk $(-2 /+2)$ & 1 & $0.76(0.96)$ \\
Relative advantage $(-2 /+2)$ & 1 & $0.89(0.64)$ \\
Trialability $(-2 /+2)$ & 1 & $1.14(0.35)$ \\
Modifiability $(-2 /+2)$ & 1 & $1.00(0.51)$ \\
Intention to use the programme $(-2 /+2)$ & 3 & $1.00(0.77)$ \\
\hline
\end{tabular}




\section{Results}

Implementation of the 'Organ Donation and Registration' programme

In the first lesson, all teachers showed the video and used the different episodes (in which positive and negative outcome expectations were discussed) to elicit a discussion among the students in the class. Then, all teachers had their students in the class discuss their opinions and beliefs about the subject addressed in each episode. With respect to the first part of the second lesson, all classes were made to work with the interactive computer programme and $83 \%$ of the teachers indicated that students had worked seriously with the computer-tailored programme. Lastly, almost one third of the teachers did not implement the registration training session in the second lesson due to lack of time.

\section{Evaluation of the 'Organ Donation and Registration' programme}

Teachers evaluated the video and subsequent group discussion with a mean grade of 7.1 ( $S D=.77$; range $1=$ very bad to $10=$ excellent), the interactive computer programme was graded with a $6.7(\mathrm{SD}=1.23)$ and the registration training session was evaluated with a mean grade of 6.2 $(S D=1.74)$. Overall, the 'Organ Donation and Registration' programme was evaluated with a mean grade of $6.9(\mathrm{SD}=1.03)$.

Attitude. Teachers' attitudes toward the learning objectives for the 'Organ Donation and Registration' programme were generally positive (Table 6.2). They were most positive about 'gaining insight into problems concerning organ donation and registration', 'taking a motivated opinion about organ donation and registration' and 'being prepared for making a decision about organ donation and registration'. Teachers were least positive about the activity of completing a donor registration form. 
Table 6.2 Mean scores (SD) of attitudes toward the 'Organ Donation and Registration' programme

\begin{tabular}{lccc}
\hline Learning objective & $\begin{array}{c}\text { Feasibility } \\
(-2 /+2)\end{array}$ & $\begin{array}{c}\text { Importance } \\
(+1 /+5)\end{array}$ & $\begin{array}{c}\text { Attitude }(F * I) \\
(-10 /+10)\end{array}$ \\
\hline $\begin{array}{l}\text { Will discuss organ donation registration } \\
\text { with others }\end{array}$ & $1.14(0.71)$ & $3.73(0.73)$ & $4.45(2.94)$ \\
$\begin{array}{l}\text { Will discuss organ donation registration } \\
\text { with parents }\end{array}$ & $1.02(0.72)$ & $3.78(0.85)$ & $4.12(2.80)$ \\
$\begin{array}{l}\text { Will gain insight into the problems } \\
\text { concerning organ donation registration }\end{array}$ & $1.43(0.50)$ & $3.94(0.70)$ & $5.71(2.48)$ \\
$\begin{array}{l}\text { Will gain a motivated opinion about } \\
\text { organ donation registration }\end{array}$ & $1.29(0.58)$ & $4.04(0.71)$ & $5.45(2.81)$ \\
$\begin{array}{l}\text { Will be prepared to make a decision } \\
\text { about organ donation registration }\end{array}$ & $1.25(0.43)$ & $3.98(0.69)$ & $5.04(2.25)$ \\
$\begin{array}{l}\text { Will start thinking about organ donation } \\
\text { registration }\end{array}$ & $1.12(0.70)$ & $4.00(0.65)$ & $4.69(2.94)$ \\
$\begin{array}{l}\text { Will complete the registration form at } \\
\text { the age of } 18 \text { years }\end{array}$ & $0.63(1.04)$ & $3.51(1.04)$ & $2.83(3.54)$ \\
\begin{tabular}{l} 
Total \\
\hline
\end{tabular} & $1.12(0.49)$ & $3.85(0.59)$ & $4.63(2.25)$ \\
\hline
\end{tabular}

Subjective norms. Teachers perceived moderate social pressure from colleagues, students and students' parents with respect to implementing the 'Organ Donation and Registration' programme and with respect to education about organ donation and registration in general (Table 6.3). Colleagues from other departments were perceived as less influential on the decision to provide organ donation registration education in general as well as on the decision to provide the education programme. Students and colleagues from their own department were regarded as most influential on both decisions. 
Table 6.3 Mean scores (SD) of normative beliefs toward the 'Organ Donation and Registration' programme (NB $)$ and toward general organ donation education $\left(\mathrm{NB}_{2}\right)$, the motivation to comply (MC) and the subjective norms $\left(\mathrm{SN}_{1}+\mathbf{S N}_{2}\right)$

\begin{tabular}{lccccc}
\hline Social referents & $\begin{array}{c}N B_{1} \\
(+1 /+4)\end{array}$ & $\begin{array}{c}N B_{2} \\
(+1 /+5)\end{array}$ & $\begin{array}{c}M C \\
(-2 /+2)\end{array}$ & $\begin{array}{c}S N_{1} \\
(-8 /+8)\end{array}$ & $\begin{array}{c}S N_{2} \\
(-10 /+10)\end{array}$ \\
\hline Students & $2.96(0.64)$ & $3.72(0.61)$ & $0.81(0.96)$ & $2.40(3.13)$ & $2.96(3.71)$ \\
School board & $3.06(0.59)$ & $3.98(0.59)$ & $-0.42(1.11)$ & $-1.17(3.53)$ & $-1.52(4.51)$ \\
$\begin{array}{l}\text { Colleagues in own } \\
\text { department }\end{array}$ & $3.16(0.55)$ & $4.02(0.51)$ & $0.85(0.77)$ & $2.79(2.46)$ & $3.52(3.06)$ \\
$\begin{array}{l}\text { Colleagues in other } \\
\text { departments }\end{array}$ & $2.67(0.47)$ & $3.49(0.51)$ & $-0.85(1.05)$ & $-2.13(2.92)$ & $-2.77(3.81)$ \\
$\begin{array}{l}\text { Parents } \\
\text { Total }\end{array}$ & $2.86(0.40)$ & $3.66(0.48)$ & $-0.27(1.18)$ & $-0.83(3.45)$ & $-0.98(4.37)$ \\
\hline
\end{tabular}

Perceived behavioural control. Teachers were very positive about their ability to apply the different parts of the education programme (Table 6.4). Teachers were most confident about their ability to control disruptive behaviour during class discussion and to create an open atmosphere for discussing organ donation registration in class. However, they felt more insecure about their ability to apply small group discussions about the pros and cons of organ donation registration and to cope with students with personal questions or problems related to organ donation issues. 
Table 6.4 Mean scores (SD) of perceived behavioural control beliefs

\begin{tabular}{lc}
\hline Perceived behavioural control regarding: $(-2 /+2)$ & Mean (SD) \\
\hline $\begin{array}{l}\text { Coping with students who express personal questions or problems related to organ } \\
\text { donation issues }\end{array}$ & $1.02(0.62)$ \\
$\begin{array}{l}\text { Creating open and safe classroom atmosphere for students to talk about organ } \\
\text { donation issues }\end{array}$ & $1.18(0.53)$ \\
$\begin{array}{l}\text { Controlling disruptive behaviour during discussions on organ donation registration } \\
\text { Guaranteeing that students listen respectfully to others' opinions related to organ }\end{array}$ & $1.20(0.53)$ \\
$\begin{array}{l}\text { donation issues } \\
\text { Facilitating a class discussion about students' own questions regarding organ }\end{array}$ & $1.10(0.59)$ \\
$\begin{array}{l}\text { donation registration } \\
\text { Facilitating a class discussion not prescribed by the teacher's own opinions on organ }\end{array}$ & $1.12(0.59)$ \\
$\begin{array}{l}\text { donation registration } \\
\text { Facilitating small group discussions on the pros and cons of organ donation }\end{array}$ & $1.02(0.80)$ \\
registration & $1.12(0.44)$ \\
\hline \begin{tabular}{l} 
Total \\
\hline
\end{tabular}
\end{tabular}

Educational quality. Teachers evaluated the educational quality of the 'Organ Donation and Registration' programme moderately positive (Table 6.5). According to the teachers, the video and group discussion appealed to most students. Further, they perceived the programme to be well tailored to the level of knowledge of students. Teachers were less positive about the extent to which students received information about their achievement in learning about organ donation and registration and the practicability of the registration training session.

Innovation characteristics of the programme. Table 6.1 shows the teachers' evaluations of the innovation characteristics of the programme. The extent to which the programme could be discontinued (reversibility) if needed was evaluated as the most important characteristic, followed by the degree to which they perceived the programme as easy to use (complexity). Furthermore, they thought that the programme could easily be tested in other schools. Teachers were least positive about the degree of observability of the programme by others (e.g., parents, other schools). 
Table 6.5 Mean scores (SD) of the principle of educational quality

\begin{tabular}{lll}
\hline Concept & Item (Range $=-2 /+2)$ & Mean (SD) \\
\hline Relevance & The programme is tailored to the students' level of knowledge & $0.92(0.64)$ \\
& The programme is tailored to the students' developmental & $0.80(0.78)$ \\
& stage & \\
Individualisation & The video appeals to students and is helpful in clarifying their & $0.94(0.75)$ \\
& experiences, questions and beliefs. & \\
& $\begin{array}{l}\text { The CD-ROM appeals to students and is helpful in clarifying } \\
\text { their experiences, questions and beliefs. }\end{array}$ & $0.33(1.16)$ \\
& $\begin{array}{l}\text { The registration training session appeals to students and is } \\
\text { helpful in clarifying their experiences, questions and beliefs. }\end{array}$ & $0.02(1.16)$ \\
Feedback & $\begin{array}{l}\text { The programme provides sufficient feedback about the extent } \\
\text { of progress achievement. }\end{array}$ & $0.22(1.05)$ \\
The programme provides sufficient alternative learning & $0.52(0.93)$ \\
Total & principles. & $0.54(0.55)$ \\
\hline
\end{tabular}

Intention to use the 'Organ Donation and Registration' programme in the future

A mean intention score of $1.00(S D=.77$; range $-2 /+2)$ was found, with only $16 \%$ of the respondents reporting a negative intention for future use. Of all respondents, $94 \%$ had the intention to plan classroom education about organ donation and registration next school year, 96\% thought that it was important to provide education about organ donation and registration in the future and $80 \%$ intended to adopt the 'Organ Donation and Registration' programme in the curriculum. 


\section{Discussion}

The present study was conducted to assess whether an effective 'Organ Donation and Registration' programme was implemented as originally planned by the most important intermediaries for the programme (i.e., teachers), how they evaluated the programme and to assess their willingness to use the programme in the future.

The present study showed that all teachers implemented at least two of the three components of the education programme, while two thirds implemented all three components. Lack of time seemed to be the most important reason for not using the registration training session. Consequently, the training session was evaluated least positively in comparison with the other components. Since the registration training session was found to be very efficacious in an earlier study (Reubsaet et al., 2003), teachers should be convinced of the usefulness and importance of the training. Moreover, students reported that they enjoyed practicing with the registration form (Reubsaet et al., 2003). In total, the 'Organ Donation and Registration' programme was evaluated with 6.9 (on a scale from $1=$ very bad to $10=$ excellent).

Teachers' attitudes toward the learning objectives for the programme were positive. They were most favourable toward the objective of gaining insight in the subject of the programme, taking a motivated opinion and making an informed decision about organ donation. Teachers were least positive about the expected effects of the programme on completing a donor registration form at the age of 18 years. Teachers' reservation toward this learning outcome was mainly due to their low perceived feasibility expectations. This perceived feasibility might be a consequence of the fact that completing a donor registration form concerns behaviour that should occur after several years (long-term effects).

The Dutch education policy is based on the idea of educational freedom, which means that schools can choose their teaching materials without interference of the Dutch government. In general, teachers make the decisions (Eurydice, 2001). In the present study, opinions of colleagues in their own department and of students were found to have the most influence on teachers' decisions to provide organ donation and registration education in general, as well as on providing the present 'Organ Donation 
and Registration' programme. In their decision to adopt the programme, teachers were influenced by their colleagues' approval and by their expectations of the programme. In a study on possible correlates of adoption of classroom-based AIDS education in the Netherlands (Paulussen, Kok \& Schaalma, 1994), it also was found that colleagues within the same department and students were perceived as important in the decision to adopt specific classroom-based education.

Half of the teachers who participated, never provided education on organ donation and registration before. However, teachers were very confident in applying the different components of the programme. In contrast to Paulussen et al. (1994), the present study found that teachers were most positive about their management skills to control disruptive behaviour during organ donation classroom activities. It appeared that teachers were more insecure about situations in which they had to cope with students expressing personal problems with respect to organ donation (Paulussen et al., 1994) and in which they had to organise small group discussions on the pros and cons of organ donation and registration. The inexperience with the topic of organ donation registration among half of the teachers may account for this uncertainty. In the future, more specific instructions and manuals for organising small group discussions and more specific information on the pros and cons of organ donation registration may be included in the programme.

Teachers' evaluation of the educational quality of the 'Organ Donation and Registration' programme was moderately positive. They were least positive about the registration training component and the extent to which this training exercise was helpful in clarifying students' personal experiences, questions and beliefs about organ donation and registration. In addition to lack of time, this may explain the fact that one third of the teachers did not apply the registration training session. As for content and layout, teachers believed that the programme matched the students' level of knowledge and developmental stage well. Therefore, it seems reasonable to conclude that the programme can be applied at all three different high school graduation levels (i.e., at the medium, higher and university preparation levels). 
With respect to characteristics of an innovation that are expected to regulate adoption (Rogers, 1995), teachers regarded the degree of reversibility of the programme and its low level of complexity as very important. Teachers were less positive about the visibility of the organ donation education activities for others. Organ donation seems to be considered as a socially relevant issue and teachers may find it important that parents or colleagues, for example, can see that they teach students about organ donation and registration. Publicity of the 'Organ Donation and Registration' programme in media, such as school papers or local journals, may therefore be an effective strategy.

Almost all respondents indicated that they intend to use the programme in the future and the majority was willing to adopt the 'Organ Donation and Registration' programme in the curriculum. However, this positive adoption intention of teachers is no guarantee for actual adoption or continuation (Levenson Gingiss, Gottlieb \& Brink, 1994; Rohrbach, Graham \& Hansen, 1993). Further research should be directed at the relation between the intention to adopt the programme and its actual adoption later.

Because of the positive evaluation and intentions among high school teachers and the established effectiveness (Reubsaet et al., accepted for publication), the school-based education programme seems ready for largescale dissemination. The Dutch Foundation of Donor Education is now implementing the education programme at 408 (out of 735) high schools in the Netherlands and efforts are taken to include the programme as a regular topic within the school curriculum. 


\section{Chapter 7}

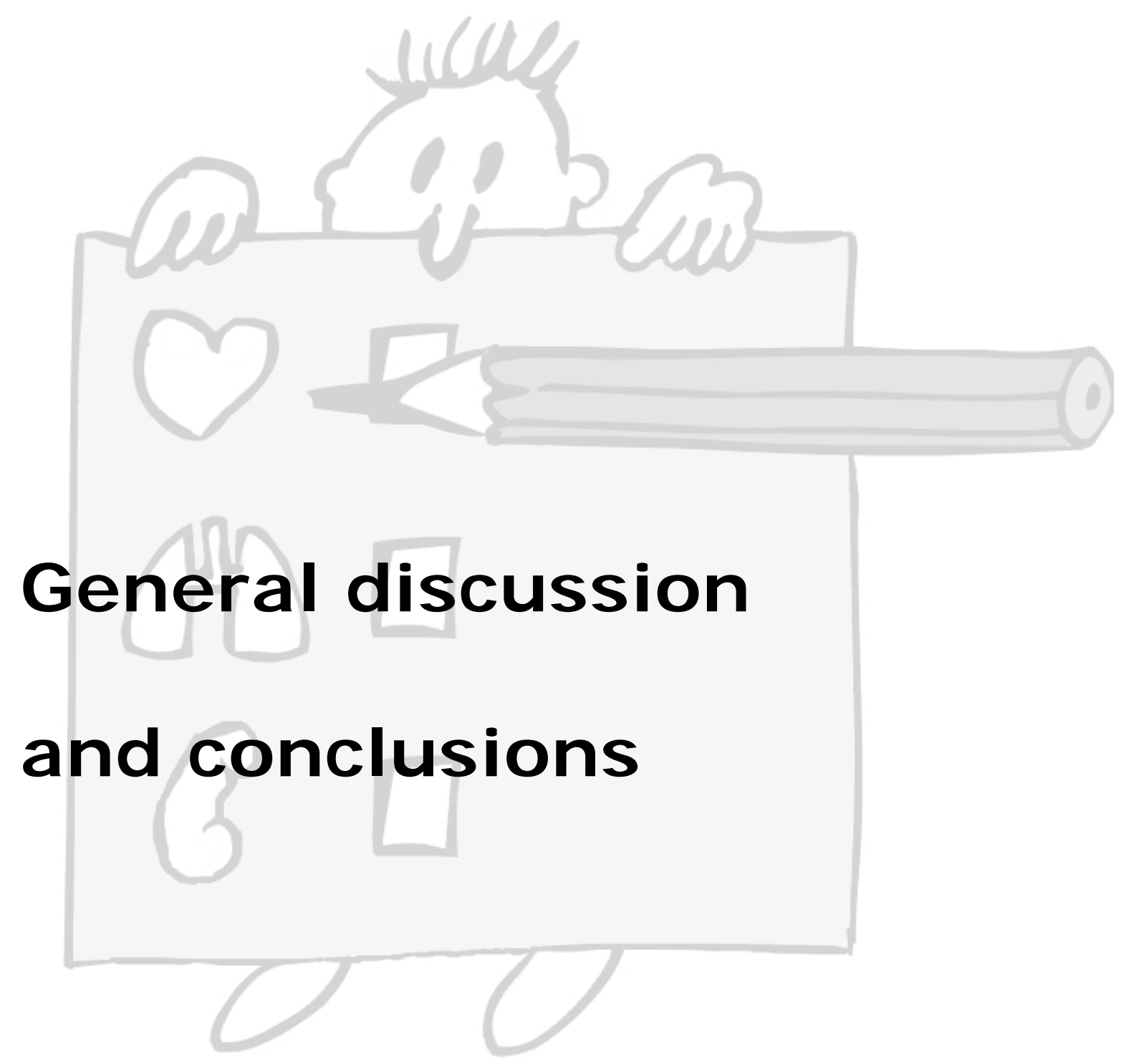




\section{Introduction}

The present thesis deals with the development and evaluation of schoolbased organ donation education for adolescents aged 15 to 18 years. The project included several studies, mainly using Bandura's Social Cognitive Theory (SCT) (1986) as the theoretical framework. To begin, a large-scale cross-sectional study was conducted to examine possible correlates of organ donation registration among Dutch adolescents. Subsequently, the intervention was developed, and the effectiveness of the three main intervention components was explored in three separate pilot studies. Based on the experiences gained with these pilot studies, the final version of the intervention was composed. Finally, two studies were conducted to evaluate the school-based organ donation programme among Dutch high school students and teachers. The purpose of this final chapter is to summarise and discuss the results of the studies presented in this thesis, and to discuss theoretical and practical implications, methodological issues and suggestions for future research. The main results are described and discussed separately for the three parts of the thesis.

\section{Part 1: Determinants of organ donation registration}

The first part of the thesis describes the results of a cross-sectional study conducted among Dutch adolescents in order to identify relevant predictors of organ donation registration. Chapter 1 describes predictors of the intention to register as organ donor among adolescents who had not yet been approached for registration (aged 16 to 18 years) and Chapter 2 describes the predictors of actual registration of their organ donation preference and the choice they have made among adolescents aged 18 and 19 who had already received an organ donation registration form. Of the participants who had received a registration form, $57 \%$ indicated that they were willing to donate their organs or tissues posthumously, which is comparable with the national figures for 2003 (53\%) (Donorregister, 2003a). Almost one fifth of these adolescents failed to return the registration form to the central Donor Registry, whereas the national figures for 2003 show a considerably higher percentage of non-registration among 18-year-olds (65\%) (Donorregister, 2003a). Of the respondents in the 16 -18-age category, $67 \%$ indicated that they were willing to become 
posthumous donors and only $3 \%$ thought that they would not return the registration form when they receive it at the age of 18 years. This indicates that adolescents not willing to register their organ donation preferences were over-represented among the non-responders in our study or that participants gave answers that they considered socially desirable.

Organ donation registration was most strongly associated with negative outcome expectations. Adolescents, who held beliefs such as that being registered as a posthumous organ donor might cause their death to be declared too soon or who did not want to put their family through the ordeal of them being an organ donor, were less willing to register their organ donation preferences. This finding is consistent with those of previous studies, which showed that the absence of negative outcome expectations was a stronger predictor of organ donation than the presence of positive outcome expectations (Brug, van Vugt et al., 2000; Cacioppo \& Gardner, 1993; Horton \& Horton, 1990; Parisi \& Katz, 1986; Skowronski, 1997). Refuting negative outcome expectations should therefore be given priority in attempts to increase willingness to register organ donation preferences. However, to further facilitate the decision process concerning organ donation registration, education should also focus on confirming and enhancing positive outcome expectations.

In addition to positive and negative outcome expectations, organ donation registration was found to be significantly associated with social outcome expectations. In particular, adolescents who thought that their parents or friends would like them to register their organ donation preference were more willing to register. The finding that registration is influenced by the (perceived) social environment is also in line with previous studies (Brug, van Vugt et al., 2000; Morgan \& Miller, 2002; Morgan et al., 2002; Radecki \& Jaccard, 1997).

Correct knowledge about organ donation and registration procedures appeared to be a significant, albeit weak predictor of the intention to register as a posthumous donor. This is again consistent with earlier findings (Horton \& Horton, 1991; Kopfman \& Smith, 1996; McNamara et al., 1999; Miller \& Hagihara, 1997; Morgan \& Miller, 2002; Schulz et al., 2000; Yuen et al., 1998). Although several studies have reported that correct knowledge was significantly associated with registration as an organ donor (Horton \& Horton, 1991; Kopfman \& Smith, 1996; Morgan \& Miller, 
2002; Morgan et al., 2002), our findings did not support this. In spite of the fact that correct knowledge was not a significant predictor of selfreported registration as an organ donor, various misconceptions about organ donation registration appeared to exist among adolescents.

In line with earlier findings, we found that adolescents who had past experiences with organ donation registration issues were more likely to register as organ donors (Birkimer et al., 1994; Brug, van Vugt et al., 2000; Carducci et al., 1989; Nolan \& McGarth, 1990; Smith et al., 1994). Based on the first part of the present thesis, it can be concluded that a school-based education programme aimed at enabling adolescents to make a considered decision about organ donation and encouraging them to register this decision should focus on: (1) countering negative outcome beliefs as well as providing information to confirm positive outcome beliefs; (2) encouraging adolescents to discuss their beliefs and thoughts regarding organ donation registration by involving parents and other family members in the programme; (3) enhancing knowledge about organ donation registration by providing factual information about the most prominent misconceptions existing among adolescents; and (4) improving experience and self-efficacy with respect to completing a donor registration form.

\section{Part 2: Pilot studies}

The results of the studies reported in Chapters 1 and 2 were used to develop a school-based education programme on organ donation and registration, encouraging adolescents to register their organ donation preferences. Based on the psychosocial correlates of organ donation registration preferences, we developed three intervention components, which were tested in controlled studies (Campbell et al., 2000; Windsor et al., 1994). The results of these studies are described in Chapters 3 and 4. Chapter 3 outlines the short-term impact of two intervention components: a video presentation with a group discussion (Study 1 ) and an interactive computer-tailored programme (Study 2 ). In study 1 , we concluded that the video-based intervention followed by a discussion among classmates increased the willingness to register organ donation preferences as well as the willingness to register as a potential posthumous organ donor. The positive effects of the video-based intervention followed by the group discussion are consistent with studies using a similar intervention approach 
addressing other behaviours (Ferland et al., 2002; O'Donnell et al., 1995; Torabi et al., 2000). Although the interactive computer-tailored intervention in Study 2 was better appreciated than general information on organ donation and registration (i.e., a brochure), it did not have a significantly greater impact on either the intention to register preferences or the intention to register as an organ donor. In contrast to the results of our study, studies on dietary change (Brug et al., 1999) and smoking behaviour (Dijkstra et al., 1998; Strecher, 1999) have reported positive effects of computer-tailored interventions. Perhaps receiving and reading fairly specific information on organ donation registration in a brochure is as well-fitting and influential as the computer-tailored information (MW Kreuter et al., 2000). Students in our control group were made to read the entire information brochure in the same period during which the intervention group was working with the interactive computer-tailored intervention (about 50 minutes).

The study reported in Chapter 4 assessed the effects of an enactive mastery experience on self-efficacy and intentions to register an organ donation preference. We tried to provide adolescents with some experience of organ donation registration procedures by giving them the opportunity to practice completing an organ donation registration form. In line with predictions from Social Cognitive Theory (Bandura, 1997), the registration training session led to increased self-efficacy expectations about completing a registration form and increased intention to register organ donation preferences. The positive relation between prior experience and registration intention is consistent with previous studies (Birkimer et al., 1994; Brug, van Vugt et al., 2000; Carducci et al., 1989; Nolan \& McGarth, 1990; Smith et al., 1994) and with the results presented in Chapter 1 of this thesis.

Based on the pilot studies, the intervention components were integrated in a two-lesson organ donation programme. Although the computer-tailored component was not more effective than reading a comprehensive brochure offering similar information, it was included in the programme because adolescents appreciated it more than the written information, and because it is more flexible and less costly to apply. 


\section{Part 3: Effect and process evaluation}

Chapters 5 and 6 report on the results of the effect and process evaluations of the organ donation registration programme. We assessed the impact of the education programme on (1) intention to register preferences; (2) intention to register as an organ donor; (3) knowledge about organ donation; (4) self-efficacy expectations; (5) negative outcome expectations; and (6) social outcome expectations. After exposure to the programme, adolescents appeared to be more willing to register organ donation preferences, were more willing to become posthumous donors and showed more positive changes in determinants of organ donation registration. The programme was most effective in increasing knowledge about organ donation registration issues. Although Morgan and colleagues (2002) did not find a positive effect on knowledge, our findings are in line with other studies on the impact of organ donation interventions (Anantachoti et al., 2001; Meier et al., 1999; Merion et al., 2003; Morgan et al., 2002; Weaver et al., 1999). The fact that the intervention most strongly impacted knowledge, a rather weak correlate of willingness to register, can be seen as a strong as well as a weak result of our intervention. Strong, since it shows that our education programme thus enables adolescents to make a better-informed decision, and weak since this will not have a strong impact on their decision. Since most studies on the effectiveness of organ donation interventions explored the influence on knowledge about organ donation and on willingness to become a posthumous organ and tissue donor, our results can be only partly compared with those of other studies. Furthermore, our intervention is the first to use an education programme not aimed at persuading people to posthumously donate organs and tissues, but rather at encouraging people to register their organ donation preferences and hence comply with the Dutch system of organ donation registration.

The process evaluation was conducted to assess how teachers evaluated the education programme and whether they intended to use it in the future. It can be concluded that teachers were generally positive about the programme and confident about their ability to apply the various components, which resulted in a large number of teachers intending to use the programme in the coming years. 


\section{School-based education programmes and their effectiveness}

Since an average of 190,000 adolescents at the age of 18 years are approached each year by the Dutch government to register their organ donation preferences, this group is considered to be the most important target group for encouraging organ donation registration. To allow adolescents to make a well-considered decision about organ donation at the age of 18 , it is important to prepare and inform them about organ donation and registration procedures in the years before they turn 18. Moreover, in late adolescence (16 years and older) children increasingly achieve independence by developing their own identity, and acquire more sophisticated problem-solving capabilities, which are essential in deciding about organ donation (Weintraub Austin, 1995). Schools are appropriate settings for offering interventions to adolescents, since these children spend most of their time in school and the school is an important social environment (Parcel, Kelder \& Basen-Engquist, 2000). We, therefore, decided to develop a school-based organ donation education programme for adolescents aged 16 to 18 years. Successful school-based education interventions appear to involve similar elements (Contento et al., 1995; Flay, 1985; Hoelscher, Evans, Parcel \& Kelder, 2002; Parcel et al., 2000). First, educational interventions are more likely to be effective in changing behaviour when they are behaviourally focused (i.e., focused on specific behaviours and determinants and behavioural skills) instead of knowledgebased (i.e., enhancing knowledge, skills and attitudes). Accordingly, our school-based organ donation programme focused on registration of organ donation preferences and registration as an organ donor specifically, as well as on the corresponding determinants and behavioural skills (e.g., by including a registration training session). However, due to privacy legislation we were not able to assess the actual registration behaviour in our sample. Including measurement of registration behaviour as an outcome in the present studies would also have implied a longer follow-up, which time restrictions did not allow. However, previous studies show that behavioural (registration) intentions are a strong and consistent, but certainly not perfect, predictor of actual (registration) behaviour (Ajzen, 1991; Horton \& Horton, 1990, 1991; Kopfman, 1994). 
The second aspect characteristic of effective interventions concerns the application of a suitable theoretical framework. Bandura's SCT is the most frequently used theory in the development of interventions for adolescents, since it addresses individual behaviours as well as the environmental factors influencing behaviour. As in our studies, SCT is often supplemented with other social psychological theories (Contento et al., 1995).

Third, including an environmental component (e.g., family involvement) increases the effectiveness of school-based interventions. Parents are important role models for their children, and family involvement appears to be particularly useful in educational interventions for younger children (Parcel et al., 2000). However, there is little evidence supporting the inclusion of a parent component in interventions for high school students (Contento et al., 1995). The present organ donation education intervention was not supplemented with an intervention that focused on the parents. Since family members are important in the decision-making process on organ donation, however, future research might include such active family involvement.

It may be asked whether more lessons on organ donation would have resulted in more change. In general, research on health education interventions shows that interventions with longer durations (i.e., more contact hours) are more effective in achieving behaviour change than shorter ones. Although one study on nutrition education reported that at least 50 hours were necessary to produce behavioural changes (Connel \& Turner, 1985), the present intervention components were integrated in two 50-minute lessons due to the limited amount of time available in the school curriculum. Moreover, changing nutrition behaviour involves more complex actions (changes in lifestyle) than organ donation registration (e.g., in that registering an organ donation preference is a once-only action). In order to use the two available lessons as efficiently as possible, the programme focused on clear and specific learning outcomes (Contento et al., 1995), which were derived from a report by the Dutch Institute for Curriculum Development (Van Graft \& Lensink, 2000). 


\section{Theoretical reflection}

This section discusses several theoretical issues related to this study and the findings presented in this thesis. The section briefly explains the rationale behind using Bandura's Social Cognitive Theory as a theoretical starting point, after which some shortcomings of this framework are discussed: the discrepancy between positive attitudes and subsequent behaviour and that between positive intentions and subsequent behaviour. The section ends with implications for the future use of theories or constructs in explaining willingness to register as an organ donor.

\section{Social Cognitive Theory and its limitations}

Bandura's Social Cognitive Theory (1986) was mainly used to examine possible determinants of organ donation registration intentions. As mentioned above, this theoretical framework is frequently used in research on adolescents (Contento et al., 1995; Hoelscher et al., 2002; Parcel et al., 2000) and was for several reasons relevant to our studies. First, SCT integrates cognitive, emotional and behaviouristic understandings of behaviour change, which may be very helpful in explaining complex behaviours such as organ donation registration. Second, it addresses both the psychosocial correlates associated with organ donation registration and methods to promote registration of organ donation preferences. Lastly, SCT allows aspects of other disciplines to be incorporated, hence benefiting from those insights and ideas (Baranowski et al., 1990; Parcel et al., 2000).

A key concept in SCT is that of reciprocal determinism, which means that dynamic relationships exist between the behaviour of a person, characteristics of that person and aspects of the environment within the behaviour is performed. Therefore, health promotion intervention should not only focus on influencing people's beliefs and perceptions but also on reducing actual barriers (Bandura, 1986). Within the framework of organ donation this means that environmental interventions on increasing the number of potential organ donors or the number of registrants might focus on making registration as easy as possible. To facilitate the registration procedure, Dutch inhabitants nowadays can register or change their organ donation preference online. Another more complex environmental change 
might be the introduction of presumed consent legislation. In this way, barriers such as losing the registration form or misunderstanding the registration form might be reduced.

Two issues are specifically important with respect to SCT and understanding organ donation registration: the attitude-behaviour discrepancy and the intention-behaviour discrepancy.

\section{Attitude-behaviour discrepancy}

Understanding the consistency (or lack of it) between attitude and behaviour is clearly relevant to the issue of organ donation. Nationwide opinion polls in the Netherlands as well as in the USA suggest that people hold very favourable attitudes toward the concept of organ donation, but only about $20 \%$ of the population have registered as posthumous organ and tissue donors (Cossé \& Weisenberger, 2000; Den Hartogh, 2003; Gallup Organisation, 1993). One explanation for this large discrepancy between attitude and behaviour is that in many studies, attitude and behaviour measurements do not correspond in terms of specificity (Ajzen \& Fishbein, 1977; Bohner \& Schwarz, 2001; Sabini, 1995). In order to obtain a strong and significant relation between attitude and behaviour, both measures should have the same degree of specificity, that is, general attitudes will predict aggregated behaviour, while specific attitudes can accurately predict specific behaviour. Most studies on organ donation predict a specific behaviour (e.g., signing an organ donor card) from a general attitude measure about organ donation (e.g., "I am in favour of organ donation"), which may result in low attitude-behaviour correlations. Increasing the specificity of the attitude measure reduces the attitudebehaviour discrepancy. In the studies presented in this thesis, we included specific attitude measures of organ donation registration (e.g., "By registering my organ donation preference I can decide what happens to my organs after my death") instead of a general attitude measure.

Secondly, past behavioural experience with the attitude object may affect the attitude-behaviour consistency (Bohner \& Schwarz, 2001; Eagly \& Chaiken, 1993; Sabini, 1995). Attitudes based on direct experience predict relevant behaviours better than attitudes that reflect indirect experience, because they are clearer, are held with more conviction and are more resistant. Furthermore, attitudes based on behavioural experience 
are more easily retrieved (i.e., activated more quickly) from memory and research shows that greater attitude accessibility might be an important mediator of attitude-behaviour consistency (Fazio \& Zanna, 1981). Most adolescents have not yet been confronted with organ donation or with registration procedures for organ donation, and the lessons on organ donation and registration were usually their first confrontation with the topic. The registration training session in the school-based education programme presented in this thesis was designed to increase their experience with completing an organ donation registration form and hence may have brought about greater attitude-behaviour consistency.

\section{Intention-behaviour discrepancy}

In SCT and other cognition-behaviour models, intention is presumed to be the most immediate and important predictor of behaviour (e.g., (Ajzen, 1991; Bandura, 1986). Meta-analytic reviews show that measures of intention are indeed satisfactory predictors of behaviour, accounting for 20$30 \%$ of the variance in behaviour (Ajzen, 1991; Godin \& Kok, 1996; Sheeran, 2002; Sheeran \& Orbell, 1998). However, these findings also imply that behavioural intention does not always result in performance of the intended behaviour. This gap between intention and actual behaviour may also be apparent in organ donation registration. Actual registration rates among 18-year olds are considerably lower than the intention rates reported in Chapter 1 (35\% vs. 97\%). Since registration of organ donation preferences is a once-only action and most adolescents lack experience with organ donation registration, Gollwitzer's concept of implementation intentions (Gollwitzer, 1993; Gollwitzer \& Brandstätter, 1997) may affect the intention-behaviour inconsistency. Implementation intentions are plans that commit a person to a time and place to perform the intended behaviour. Studies on several behaviours have provide evidence to suggest that people who possess goal intentions (e.g., "I will register my organ donation preference") supplemented by an implementation intention (e.g., "I will register my organ donation preference when I receive the registration form at my home address at the age of 18") are more likely to successfully perform the intended behaviour (e.g., actual registration of organ donation preferences) than those without implementation intentions (Gollwitzer \& Brandstätter, 1997; Sheeran \& Orbell, 1999, 2000; Sheeran \& 
Silverman, 2003). Implementation intentions appear to be effective because they create strong memory traces, which may influence attentional and memorial processes relevant to a successfully enactment of one's intentions (Gollwitzer, 1993). In sum, evidence suggests that the gap between the intention to register organ donation preferences and actual organ donation registration may be reduced by the formation of an implementation intention specifying where and when to complete and return the registration form.

Theoretical models and their implications for organ donation registration

Other theories or constructs from social psychology may be applied in explaining organ donation registration among adolescents. First, the organ donation decision-making process may be significantly influenced by values (Gijsbers, 2000; Horton \& Horton, 1991; Mahoney \& Pechura, 1980) and personality traits (K. Campbell \& de Man, 2000; Cleveland \& Johnson, 1970; Hessing \& Elffers, 1985, 1986). A useful theory to explain relations between value priorities and various attitudes and behaviour with respect to organ donation registration may be Schwartz' value theory (Sagiv \& Schwartz, 1995; Schwartz, 1992). Schwartz distinguished four categories, containing ten different value types which appeared to exist in approximately 60 countries: (1) openness to change (self-direction and stimulation), (2) conservation (conformity, tradition and security), (3) selftranscendence (universalism and benevolence) and (4) self-enhancement (achievement and power). Hedonism is related to openness to change as well as to self-enhancement. These values can be defined as criteria people use to select and justify behaviour and to evaluate people and events (Schwartz, 1992). A study conducted by Ryckman and colleagues (2002) showed that several value types were related to organ donation registration among American university students. As predicted by Schwartz' theory (1992), registration as a posthumous organ and tissue donor was significantly related with greater importance to benevolence, universalism and achievement goals. In contrast to what was expected from the value theory, participants who scored higher on stimulation were more likely to be registered to donate their organs posthumously (Ryckman et al., 2002). Another factor that could be used to analyse the willingness to donate 
organs and tissues posthumously is religion. Literature reviews on religious beliefs, as well as our determinant studies (Chapters 1 and 2), are inconsistent in their findings regarding the influence of religion on acts of charity, such as organ donation (Batson, Schoenrade \& Ventis, 1993; Fisher, Derison, Polley, Cadman \& Johnston, 1994). One explanation for this inconsistency is that belonging to a particular religion may be a poor measure of religious beliefs. Therefore, research to measure religion should focus more on individual differences between people, like intrinsic and extrinsic orientations to religion (Allport, 1966; Allport \& Ross, 1967). Intrinsically oriented people live in accordance with their religious beliefs and the concept of caring for others and hence are considered to be more likely to posthumously donate their organs. Extrinsic religiosity comprises two subgroups, namely, individuals who are religious mainly because it offers support in times of personal crisis (i.e., personally oriented) and individuals who hold religious beliefs because they may be helpful in social relationships (i.e., socially oriented) (Kirkpatrick, 1989). Socially oriented extrinsically religious people are expected to be more willing to become organ donors, whereas personally orientated extrinsic religiosity is not expected to correlate with willingness to donate. These hypotheses were indeed confirmed by a study on religious beliefs and willingness to register as organ donor (Ryckman, Van den Borne, Thornton \& Gold, 2004). However, contrary to Allport's arguments, this study did not find a significant relation between intrinsic orientations and willingness to donate. 


\section{Methodological issues}

This section addresses several methodological issues of the studies presented in the three parts of this thesis. These issues are potential threats to the internal validity (i.e., the question whether the results obtained can indeed be attributed to the intervention) or the external validity (i.e., the question whether the results obtained can be generalised to other populations and settings) (Green \& Lewis, 1986).

\section{Part 1: Determinants of organ donation registration}

Three methodological issues should be considered in interpreting the findings presented in Part 1 of this thesis. The first issue concerns the design selected to identify important correlates of organ donation registration, that of cross-sectional surveys. Non-experimental research only reveals (partial) correlations between the outcome measures (i.e., organ donation registration) and potential predictors (e.g., negative outcome expectations). Consequently, we can state with some degree of confidence that the potential correlates are related to organ donation registration, but we cannot imply causality or prediction (Bouter \& van Dongen, 1991; Tabachnick \& Fidell, 1996).

Secondly, we did not identify significant correlates of the intention to register organ donation preferences among adolescents aged 16 to 18 years. Chapter 1 describes factors that are significantly associated with the willingness to register as an organ donor, while Chapter 2 describes significant predictors of the behaviour regarding organ donation registration among adolescents who had already received a donor registration form from the Dutch government. We did not study potential predictors of the willingness to register organ donation preferences, because only three percent of the sample indicated that they would not return the registration form when they would receive it at their home address at the age of 18 .

Third, research in the field of organ donation beliefs may be affected by social desirability, which refers to the inclination of participants to comply with behaviour that is socially desirable or preferred (Green \& Lewis, 1986). This tendency particularly occurs in research on socially important issues whose the prevailing standards are well known 
(Swanborn, 1994). Public opinion polls and scientific research in the Netherlands on attitudes toward organ donation show that although most people are in favour of organ donation, only $20 \%$ of the adult population have actually been registered as posthumous organ and tissue donors (Den Hartogh, 2003). The present study showed that the majority of the adolescents also reported to be willing to register as organ donors (see Chapters 1 and 2). Respondents may have given answers that they believe are socially preferred. Others may have been convinced they would register as organ donors but in fact would not when confronted with a donor registration form (Spital, 2001). Moreover, questionnaires were completed during class hours in the presence of teachers, and students may have wanted to please them by giving socially desirable answers. However, we tried to minimise social desirability by (1) stressing the anonymity of the respondents; (2) stressing that there were no right or wrong answers, but that their responses should reflect their true opinions; and (3) using fivepoint scales instead of dichotomous scales, so that respondents would be more inclined to give answers that are suitable for their situation.

\section{Part 2: Pilot studies}

Our school-based organ donation education programme, like many health education interventions nowadays, includes multiple components instead of a single intervention. The evaluation of such complex interventions often raises problems because researchers have not fully developed and tested the individual components. In such situations, it remains unclear which components are effective and hence essential for inclusion in the integrated education programme. As recommended, we regarded the process of development and evaluation of the present education programme as consisting of several phases, in which draft intervention components were first developed and tested in controlled studies (Campbell et al., 2000; Windsor et al., 1994). After pilot testing, the individual intervention components were integrated in a comprehensive two-lesson organ donation programme. A limitation of testing the individual components is that we could not account for possible interactions between the components. 
A second issue that needs to be considered in interpreting the results presented in the studies in Part 2 is selection bias. Selection bias can be a threat to both the internal and the external validity of studies. If an experimental group differs from the control group before the intervention, the internal validity may be threatened, whereas the external validity may threatened if the selection of the sample is biased (Green \& Lewis, 1986). Random assignment of participants is the best way to avoid differences between the comparison groups. Therefore, the risk of selection bias will have been minimal in our study on the effectiveness of the registration training session (Chapter 4 ), since each individual student was randomly assigned to the experimental or control condition. In the studies presented in Chapter 3, selection bias may have occurred because classes instead of individuals were randomly assigned to the experimental or control group. The use of pretest data in the study on the effectiveness of the video presentation and group discussion allowed us to partially account for a potential selection bias. One indication that selection bias may have occurred is the overrepresentation of female participants in the group who watched the video (i.e., the experimental group). Unfortunately, the study on the effectiveness of the tailored intervention did not involve random assignment of students or the use of a pretest measure, which means that we could not control for selection bias.

A third issue concerns the possible influence of repeated measurements among the same participants. A pretest questionnaire assessing peoples' opinion about organ donation registration may encourage them to think about organ donation registration and make them more sensitive to the intervention, resulting in increases in registration intentions and beliefs at post-test. Another possibility is that completion of a questionnaire can be regarded as an intervention in itself. Indeed, this intervention technique ('Foot-in-the-door'-technique) has been used in promoting organ donation (Carducci \& Deuser, 1984; Carducci et al., 1989; Freedman \& Fraser, 1966). If people are asked to complete a questionnaire on organ donation and they comply with this small request, they will see themselves as being helpful and become more receptive to further requests. This rewarding perception may induce them to agree with a second, larger request, such as registering as an organ donor. We examined a possible pretesting effect in the study described in Chapter 3 , 
where a Solomon four-group design was applied. Two post-test only groups were added to the basic pretest-post-test design. The results of this study showed that there was no impact of the pretest questionnaires on either the intention to register organ donation preferences at post-test or the intention to become an organ donor.

\section{Part 3: Effect and process evaluation}

Several methodological issues should be considered in the interpretation of the findings presented in Part 3 (Chapters 5 and 6). First, there are several limitations and strengths of the results presented in Chapter 5.

The most important issue in the effect study (randomised post-test only control group design) on the integrated education programme concerns the differences in the numbers of participants between the experimental group and the control group, resulting from "loss-to-followup". Students in the experimental group who were absent at one or both lessons did not complete the evaluation questionnaire in the third lesson and thus dropped out of the study. The students in the control condition, by contrast, completed the evaluation questionnaire while students in the experimental condition had their first lesson. Consequently, in spite of the randomisation the comparison groups differed in the number of participants. This might have caused serious problems because it reduced the sample size and might meant that the differences in outcome measures we found between the experimental and control conditions were due to factors other than the education programme. To deal with this dropout problem, we conducted a secondary analysis, which more or less resembled the "intention-to-treat" principle (Gross Portney \& Watkins, 2000). In order to equalise the sample sizes in the two groups, we supplemented the data for the experimental group with the mean scores of the data from the control condition. Obviously, this procedure makes significant differences harder to find. The results of the secondary analysis confirmed our hypothesis that adding fictitious respondents to the sample made the effects of the organ donation education programme slightly smaller, though it remained statistically significant. 
The second issue that needs to be addressed is the rationale for using a post-test only design in the effect study. In the Netherlands, as in most other countries, the law demands that people give informed consent before participating in scientific research (Ministerie van VWS, 2001). For adolescents aged between 12 and 18 years, agreement is required from the participants as well as from one of the parents. Before our pilot studies started in which we tested individual intervention components, participants received written information about the study concerned and two informed consent forms. After agreement from both students and parents had been obtained, participants were entitled to participate in the studies. However, due to logistical problems (students forgot to take home or bring back the consent forms) quite a number of students were not allowed to participate in these pilot studies, even though neither the students nor their parents had actually refused for fundamental reasons. In order to prevent this kind of dropout due to these logistical problems, the medical ethics committee therefore gave us permission not to apply the informed consent procedure to the effect study. Therefore, a 'Post-test-Only' design was applied which did not require written approval from parents and adolescents.

Third, since the students in the effect study were randomly assigned to the experimental group or the control group, we may assume that selection bias did not occur. However, we had a nested sampling procedure (students within classes within schools) with a high probability of interdependence among individuals. To account for possible class or school influences, multilevel regression analyses, using the MIwiN (Rasbash et al., 1999) statistical package, were performed to study differences in organ donation registration intentions and their psychosocial determinants (Goldstein, 1995; Snijders \& Bosker, 2003). In terms of generalisability of the results to a larger population (i.e., external validity), we may assume that the selection of the schools for the studies was not biased. The recruitment of schools proceeded according to a protocol, by one member of the research team. In addition, only three of the schools that were approached refused to participate in the effect study due to lack of time. This low refusal rate may be due to the fact that the education programme met the criteria for optimal integration within the curriculum (Van Graft \& Lensink, 2000). Finally, schools were offered the organ donation education programme without cost, which may have induced them to participate. 
The fourth issue concerns the effect of evaluating a newly developed education programme (novelty effect). Many innovations, especially with educational technologies, are evaluated more favourably than they would be under normal conditions (Green \& Lewis, 1986). The present education programme used some educational technologies (e.g., a video presentation and an interactive computer-tailored programme), which may have captured students' attention and interest more than normal lessons would have done. However, as students nowadays are confronted with educational video materials and computerised education materials on a regular basis, this effect may have been marginal.

Finally, the effectiveness of school-based education programmes may be particularly prone to the time-dependent problem of the 'sleeper effect'. The sleeper effect refers to a possible delay of the impact of a programme and is found in situations in which time is required to convert existing beliefs or knowledge into intentions or behaviour (Green \& Lewis, 1986). The results presented in Chapter 5 show that after exposure to the schoolbased organ donation programme, students had significantly more favourable beliefs regarding organ donation registration and greater knowledge about organ donation and registration and were more inclined to register their (positive) organ donation preferences. Post-test measurements were conducted one week after the lessons on organ donation registration. Although the effects of the programme were all significant, the effect sizes were moderate. Improvement in the students' post-test level of knowledge was most significant and fairly high (effect size $=0.23$ ). Since organ donation is a relatively new topic for adolescents and since for many students it was the first time they had ever thought about this topic, development of beliefs and intentions on this topic may require more time than one week. The effects of the education programme on intentions and beliefs may be slower in developing and consequently might be larger after, for instance, one year. Several follow-up assessments of the effects of the education programme might give indications about possible increasing effects of the programme on beliefs and registration intentions, and 'booster' interventions might be applied to maintain or increase the effectiveness of the intervention. 
The findings presented in Chapter 6 must be interpreted in light of the methodology used. Whereas process evaluation usually employs qualitative analysis, we performed a quantitative analysis of the results from a sample size of 50 teachers (response rate $=65 \%$ ), without support from qualitative research results. Face-to-face interviews or telephone interviews would have been good methods to support the quantitative results. Lack of time and funding, however, prevented us from conducting personal interviews with the teachers.

\section{I mplications}

The results of the studies presented in this thesis have several implications for future research and organ donation education. The recommendations for future research relate mainly to issues that remained unclear after the present study and the investigation of possible improvements to the education programme. Recommendations for practice relate to the application of the present school-based intervention in the context of different legislation systems for organ donation.

\section{Implications for future research}

An important issue in the studies presented in this thesis is the lack of information on the effects of the education programme on behavioural outcomes, that is, registering organ donation preferences and registering as posthumous organ and tissue donors at the age of 18 years. Due to time restrictions and privacy legislation, we were not able to assess registration behaviour in the present studies. We therefore recommend studying the long-term effects of the programme in terms of the number of registered adolescents and actual changes in the organ donation rates over the coming years because of the programme. Since the Dutch government annually approaches all 18-year-old adolescents, the inclusion of an additional item in the donor registration form on whether they have received the lessons on organ donation and registration may help to assess long-term effects. Another option to conduct a longer follow-up study among the recipients of the programme by measuring their organ donation beliefs and behaviours at the age of 18 years (i.e., when they receive the 
donor registration form at their home address).

The results reported in Chapter 3 show that the interactive computertailored intervention was not more effective than reading an extensive brochure with similar information, in terms of increasing either willingness to register organ donation preferences or willingness to register as an organ donor. In spite of this disappointing result, the computer-tailored component was integrated in the present education programme because of its attractiveness, flexibility and less costly application. Since hardly anything is yet known about the impact of tailored web-based and multimedia information (Campbell, Honess-Morreale, Farrell, Carbone \& Brasure, 1999; Oenema \& Brug, 2003; Oenema, Brug \& Lechner, 2001), we recommend examining why the present interactive computer-tailored intervention was not more effective than reading the brochure, at least not in the short-term.

The effectiveness of school-based education programmes appears to increase when parents and other family members are involved in the intervention (Contento et al., 1995; Hoelscher et al., 2002). Results of the studies presented in Chapters 1 and 2, as well as those of other studies (Birkimer et al., 1994), show that adolescents are inclined to discuss organ donation registration issues with their parents. Involving families and extending the education programme to parents and other family members may affect their beliefs regarding organ donation registration and may even increase the likelihood of organ donation preferences being registered by family members as well as the adolescents themselves. Moreover, by discussing organ donation registration issues within the family, the individual registration preferences may become clear, which may prevent the next of kin from having to take a difficult decision when a loved one has died. Future studies should examine whether a parental intervention component can be effective in increasing the willingness to register organ donation preferences among adolescents as well as their family members.

Since schools indicated that teachers could devote only limited time to organ donation education within the school curriculum, we implemented the education programme in two 50-minute lessons. We recommend further exploration of the number of contact hours and the intensity needed for the organ donation and registration lessons to be most effective in improving beliefs and intentions on this topic. 
As mentioned in the above discussion of methodological issues, our results may have been affected by students' inclination to give socially desirable answers, and future studies might assess the tendency to respond in a socially desirable manner. The Marlowe-Crowne scale is a reliable and validated questionnaire containing 13 true-false items, with higher scores reflecting a greater need for social approval (Crowne \& Marlowe, 1964; Reynolds, 1982).

Further, the effects of the school-based organ donation intervention described in Chapter 5 may be prone to a delay in the impact of the intervention (i.e., a "sleeper effect"). Future research should therefore include several follow-up assessments to determine whether the results are affected by a possible sleeper effect. Moreover, the effects of booster interventions may be tested for their effectiveness in maintaining or increasing school programme effects.

In accordance with the results presented in Chapters 5 and 6, it can be concluded that the school-based education intervention proved to be effective in changing determinants of organ donation registration, and was evaluated positively by both students and teachers. Consequently, the programme is now being implemented in 408 of the 735 Dutch high schools. However, structural implementation in the educational curriculum and adoption of the school-based education programme will be essential if we wish to increase the number of adolescents who register their will with respect to organ donation in the long term, and hence increase the number of potential organ and tissue donors. We therefore recommend gaining insight into the supporting and impeding factors affecting the adoption and maintenance of the present education programme. Studies should be conducted among students, teachers, school boards and relevant policy organisations (e.g., government departments).

\section{Implications for practice}

How can the school-based education programme presented in this thesis be linked to the current organ donation legislation in the Netherlands? The present school-based organ donation intervention was primarily aimed at raising awareness about a socially important issue and encouraging adolescents to think about and discuss this problem. It is the first education programme in the Netherlands or abroad whose primary 
intention is not to persuade people to posthumously donate organs and tissues, but rather to empower adolescents to make a well-informed decision about organ donation and to comply with the Dutch system of organ donation (i.e., registration of organ donation preferences). These considerations fit in well with the context of the Dutch decisional organ donation system, since decisions to become posthumous organ and tissue donors in this country are based on the concept of voluntarism and autonomy. The introduction of the new organ donation legislation in 1998 was based on the idea that it was possible to enhance the right to selfdetermination as well as increase the number of potential donor organs (Den Hartogh, 2003). As was stated earlier in this thesis, the response to the registration forms, and thus the number of registered organ donors, has remained far below expectations. It remains unclear whether this lack of response is the result of autonomous and well-informed decisions not to register, or of emotional barriers toward registration or, of other, more down-to-earth factors such as laxity.

Presumed consent legislation is often presented as the solution that could take laxity into account and increase the number of organ donors. Table 7.1 shows the total number of donors and the number of donors per million inhabitants for some West-European countries. The figures in this table imply that the countries in which presumed consent legislation is operational have the largest numbers of donors per million inhabitants, with the exception of Sweden. Although a pure opting-out legislation is applied in Sweden, it has the smallest number of donors per million inhabitants. Apparently, the type of organ donation legislation operative in a country is not the only factor that determines the number of posthumous donor organs. The most important factor is the decrease in the number of brain-dead individuals caused by improved treatments of CVA-patients and more effective measures to increase traffic safety (e.g., safety belts or maximum speed). Furthermore, the number of potential organs may also be determined by differences in the donation process (i.e., the process between the time of death and successful transplantation). Coppen and colleagues (2003) concluded that the small number of organ donors in the Netherlands compared to other West-European countries is mainly caused by the fact that the Netherlands is a relatively safe country in terms of the number of (traffic) accidents. 
I rrespective of the organ donation legislation that is operative in countries, education about organ donation issues is required to allow people to come to a well-considered decision about organ donation. The present schoolbased education programme is effective in the present Dutch decision system, but can easily be adjusted to presumed consent legislation.

\section{Table 7.1 Number of donors in West-European countries in 2001}

(Coppen et al., 2003)

\begin{tabular}{lll}
\hline Country & Number of donor p.m.i. & Total number of donors \\
\hline Spain $^{1}$ & 29.1 & 1200 \\
Austria $^{2}$ & 24.8 & 204 \\
Belgium $^{1}$ & 23.8 & 245 \\
France $^{1}$ & 17.8 & 1066 \\
Italy $^{1}$ & 15.8 & 913 \\
Germany $^{3}$ & 13.3 & 1094 \\
United Kingdom $^{3}$ & 13.1 & 777 \\
Switzerland $^{4}$ & 13.0 & 95 \\
The Netherlands $^{3}$ & 13.0 & 208 \\
Sweden $^{2}$ & 12.1 & 108 \\
\hline
\end{tabular}

Legend: 1 = opting-out legislation; 2 = pure opting-out legislation; 3 = decision system; $4=$ different in each canton; $p . m . i=$ per million inhabitants 


\section{General conclusion}

In spite of the implementation of new organ donation legislation, registration rates in the Netherlands remain below expectations. A schoolbased organ donation education programme was developed to prepare adolescents for a well-informed decision about organ donation and to encourage them to register their organ donation preferences centrally. The programme consisted of three components: a video presentation with group discussion, an interactive computer-tailored programme and a registration training session. It can be concluded that the two 50-minute lessons on organ donation and registration are effective in increasing organ donation registration intentions and in changing the psychosocial determinants associated with organ donation registration. Moreover, teachers who had worked with the organ donation education programme were positive about it and expressed their intention to use the programme in the future. The Dutch Foundation of Donor Education is now implementing the education programme at more than 408 (out of a total of 735) high schools in the Netherlands. 

References

References

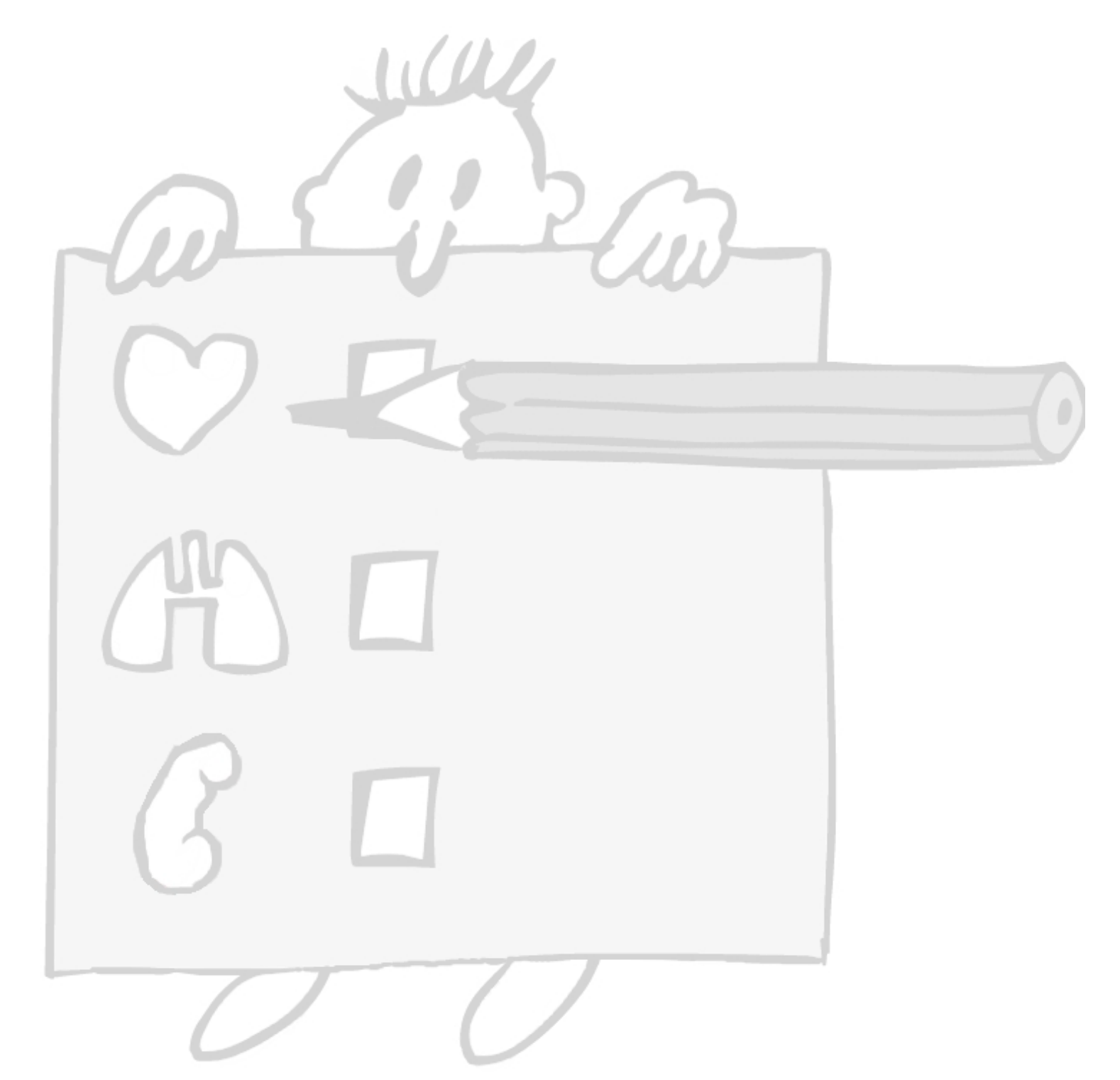


Ahern, T., Peck, K., \& Laycock, M. (1992). The effects of teacher discourse in computer-mediated discussion. Journal of educational computing research, 8, 291-309.

Ajzen, I. (1991). The theory of planned behavior. Organizational Behavior and Human Decision Processes, 50, 179-211.

Ajzen, I., \& Fishbein, M. (1977). Attitude-behavior relations: A theoretical analysis and review of empirical research. Psychological Bulletin, 84, 888-918.

Akgün, S., Tokalak, I., \& Erdal, R. (2002). Attitudes and behavior related to organ donation and transplantation: a survey of university students. Transplantation Proceedings, 34, 2009-2011.

Alden, D., \& Cheung, A. (2000). Organ donation and culture: A comparison of Asian American and European American beliefs, attitudes, and behaviors. Journal of Applied Social Psychology, 30, 293-314.

Allport, G. (1966). Religious context of prejudice. Journal for the Scientific Study of Religion, 5, 447-457.

Allport, G., \& Ross, J . (1967). Personal religious orientation and prejudice. Journal of Personality and Social Psychology, 5, 423-443.

Anantachoti, P., Gross, C., \& Gunderson, S. (2001). Promoting organ donation among high school students: an educational intervention. Progress in Transplantation, 11(3), 201-207.

Baluch, B., Randhawa, G., Holmes, S., \& Duffy, L. (2001). Signing the organ donor card: The relationship between expressed attitude, the actual behavior, and personality traits. The Journal of Social Psychology, 14(1), 124-126.

Bandura, A. (1986). Social foundations of thought \& action: A social cognitive theory. Englewood Cliffs, NJ: Prentice Hall.

Bandura, A. (1997). Self-efficacy: The exercise of control. New York: W.H. Freeman and Company.

Baranowski, T., Perry, C., \& Parcel, G. (1990). How individuals, environments, and health behavior interact. In K. Glanz \& F. Lewis $\&$ B. Rimer (Eds.), Health behavior and health education: Theory, research, and practice. (pp. 153-178). San Francisco, CA: JosseyBass Inc, Publishers. 
Baron, R., \& Kenny, D. (1986). The moderator-mediator variable distinction in social psychological research: conceptual, strategic, and statistical considerations. Journal of Personality and Social Psychology, 51(6), 1173-1182.

Bartholomew, L., Parcel, G., Kok, G., \& Gottlieb, N. (2001). Intervention mapping: designing theory-and evidence-based health promotion programs. California: Mayfield Publishing Company.

Batson, C., Schoenrade, P., \& Ventis, W. (1993). Religion and the individual. New York, NY: Oxford University Press.

Beckman, R. (1952). How to train supervisors: Manual and Outlines for Determinate Discussion. Oxford: Harper.

Bem, D. (1972). Self-perception theory. In L. Berkowitz (Ed.), Advances in Experimental Social Psychology. (Vol. 6, pp. 1-62). New York: Academic Press.

Birkimer, J., Barbee, A., Francis, M., \& Berry, M. (1994). Effects of refutational messages, thought provocation, and decision deadlines on signing to donate organs. Journal of Applied Social Psychology, 24, 1735-1761.

Bohner, G., \& Schwarz, N. (2001). Attitudes, persuasion, and behavior. In A. Tesser \& N. Schwarz (Eds.), Blackwell Handbook of Social Psychology. Malden (MA): Blackwell Publishers Inc.

Bouter, L., \& van Dongen, M. (1991). Epidemiologisch onderzoek: opzet en interpretatie. Houten/Zaventem: Bohn Stafleu van Loghum.

Brug, J. (1999). Dutch research into the development and impact of computer-tailored nutrition education. European Journal of Clinical Nutrition, 53, S78-S82.

Brug, J., Campbell, M., \& Van Assema, P. (1999). The application and impact of computer-generated personalized nutrition education: A review of the literature. Patient Education and Counseling, 36, 145156.

Brug, J., Glanz, K., Van Assema, P., Kok, G., \& Van Breukelen, G. (1998). The impact of Computer-Tailored Feedback and Iterative Feedback on Fat, Fruit, and Vegetable Intake. Health Education \& Behavior, $25,517-531$. 
Brug, J., Schaalma, H., Kok, G., Meertens, R., \& Van der Molen, H. (Eds.). (2000). Gezondheidsvoorlichting en gedragsverandering: Een planmatige aanpak. Assen: Van Gorcum \& Comp. B.V.

Brug, J., Steenhuis, I., Van Assema, P., \& De Vries, H. (1996). The Impact of a Computer-Tailored Nutrition Intervention. Preventive Medicine, 25, 236-242.

Brug, J., van Vugt, M., Van den Borne, B., Brouwers, A., \& Van Hooff, H. (2000). Predictors of willingness to register as an organ donor among Dutch adolescents. Psychology and Health, 15, 357-368.

Cacioppo, J., \& Gardner, W. (1993). What underlies medical donor attitudes and behavior. Health Psychology, 12, 269-271.

Campbell, K., \& de Man, A. (2000). Threat perception and reluctance to donate organs. North American Journal of Psychology, 2(1), 21-26.

Campbell, M., Fitzpatrick, R., Haines, A., Kinmonth, A., Sandercock, P., Spiegelhalter, D., \& Tyrer, P. (2000). Framework for design and evaluation of complex interventions to improve health. British Medical Journal, 321, 694-696.

Campbell, M., Honess-Morreale, L., Farrell, D., Carbone, E., \& Brasure, M. (1999). A tailored multimedia nutrition education pilot program for low-income women receiving food assistence. Health Education Research, 14, 257-267.

Carducci, B., \& Deuser, P. (1984). The Foot-in-the Donor Technique: initial request and organ donation. Basic and Applied Social Psychology, 5 (1), 75-81.

Carducci, B., Deuser, P., Bauer, A., Large, M., \& Ramaekers, M. (1989). An application of the foot in the door technique to organ donation. Journal of Business and Psychology, 4, 245-249.

CBS. (2002). Demographics of high school students in 2001-2002. Retrieved April 6, 2004, from the World Wide Web: http://staline.cbs.nl

Cleiren, M., \& Van Zoelen, A. (1998). Orgaandonatie \& nabestaanden: winst \& verlies. [Organ donation \& next of kin: profit \& loss.]. Leiden: DSWO Press.

Cleiren, M., \& Van Zoelen, A. (1999). Altruism or protecting your bereaved: motivations to register as an organ donor. Gedrag \& Gezondheid, 27, 91-95. 
Cleveland, S., \& Johnson, D. (1970). Motivation and readiness of potential human tissue donors and nondonors. Psychosomatic medicine, 32, 225-231.

Cohen, B. (2001). Balancing supply and demand in organ transplantation. Unpublished Thesis, Universiteit Maastricht, Maastricht.

Connel, D., \& Turner, R. (1985). Summary findings of the School Health Education Evaluation: health promotion effectiveness, implementation, and costs. Journal of School Health, 55, 316-321.

Contento, I., Balch, G., Bronner, Y., Lytle, L., Maloney, S., White, S., Olson, C., \& Swadener, S. (1995). The effectiveness of nutrition education and implications for nutrition education policy, programs, and research: a review of research. Journal of Nutrition Education, 27(6), 298-311.

Coppen, R., Marquet, R., \& Friele, R. (2003). Het Donorpotentieel: Een vergelijking van het donorpotentieel in Nederland en 9 andere West Europese landen. Utrecht: Nivel.

Cossé, T., \& Weisenberger, T. (2000). Words versus actions about organ donation: a four-year tracking study of attitudes and self-reported behavior. Journal of Business Research, 50, 297-303.

Crowne, D., \& Marlowe, D. (1964). The approval motive. New York: John Wiley \& Sons.

De Bourdeauduij, I., \& Brug, J. (2000). Tailoring dietary feedback to reduce fat intake: An intervention at the family level. Health Education Research, 15, 449-462.

De Vries, H., \& Brug, J . (1999). Computer-tailored interventions motivating people to adopt health promoting behaviors: Introduction to a new approach. Patient Education and Counseling, 36, 99-105.

Den Hartogh, G. (2003). Gift of bijdrage? Over morele aspecten van orgaandonatie. Den Haag: Rathenau Instituut.

Dijker, A., Koomen, W., \& Kok, G. (1997). Interpersonal determinants of fear of people with AIDS: The moderating role of predictable behavior. Basic and Applied Social Psychology, 19 (1), 61-79.

Dijkstra, A., \& De Vries, H. (1999). The development of computergenerated tailored interventions. Patient Education and Counseling, $36,193-203$. 
Dijkstra, A., De Vries, H., \& Rooijakkers, J. (1998). Long-term effectiveness of computer-generated tailored feedback in smoking cessation. Health Education Research, 13, 207-214.

Donorregister. (2000). Press report. Kerkrade.

Donorregister. (2001a). Number of registered adolescents (year of birth:1982) in 2001. Retrieved June, 2003, from the World Wide Web: http://www.donorregister.nl

Donorregister. (2001b). Number of registered people in the Netherlands. Kerkrade.

Donorregister. (2002a). Number of registered adolescents (year of birth: 1983) in 2002. Retrieved June, 2003, from the World Wide Web: http://www.donorregister.nl

Donorregister. (2002b). Total number of registered people in the Netherlands in September 2001. Retrieved March 17, 2003, from the World Wide Web: http://www.donorregister.nl/

Donorregister. (2003a). Number of registered adolescents (year of birth: 1984) in 2003. Retrieved J anuary, 2004, from the World Wide Web: http://www.donorregister.nl

Donorregister. (2003b). Total number of registered people in the Netherlands in November 2003. Retrieved November 26, 2003, from the World Wide Web: http://www.donorregister.nl

Eagly, A., \& Chaiken, S. (1993). The psychology of attitudes. Orlando: Harcourt Brace Jovanovich College Publishers.

Eurotransplant. (1998). Annual report 1998. Leiden, The Netherlands.

Eurotransplant. (2001). The Netherlands: transplant statistics for 2001.

Retrieved March 17, 2003, from the World Wide Web: http://www.transplant.org/Statistics/2001/netherlands01.ht,

Eurotransplant. (2002). The Netherlands: transplant statistics for 2002.

Retrieved June 11, 2003, from the World Wide Web:

http://www.transplant.org/statistics/netherlands02.html

Eurotransplant. (2003). Which organs can be transplanted? Retrieved J une 11, 2003, from the World Wide Web:

http://www.eurotransplant. nl/index.php?id=organs 
Eurydice. (2001). Informatiedossier over het Nederlandse onderwijssysteem. [Information file on the Dutch education system.]. Retrieved November 4, 2003, from the World Wide Web: http://www.minocw.nl/onderwijs/download/onderwijssys_nl2001. pdf

Evers, S., Farewell, V., \& Halloran, P. (1988). Public awareness of organ donation. Canadian Medical Association Journal, 138(1), 237-239.

Fazio, R., \& Zanna, M. (1981). Direct experience and attitude-behavior consistency. Advances in Experimental Social Psychology, 14, 161202.

Ferland, F., Ladouceur, R., \& Vitaro, F. (2002). Prevention of problem gambling: modifying misconceptions and increasing knowledge. Journal of Gambling Studies, 18(1), 19-29.

Fisher, R., Derison, D., Polley, C., Cadman, J., \& Johnston, D. (1994). Religiousness, religious orientation, and attitudes toward gays and lesbians. Journal of Applied Social Psychology, 24(24), 614-630.

Flay, B. (1985). Psychosocial approaches to smoking prevention: A review of the findings. Health Psychology, 4, 449-488.

Freedman, J., \& Fraser, S. (1966). Compliance without pressure: the footin-the-door technique. Journal of Personality and Social Psychology, 4, 195-202.

Gallup Organisation. (1993). The U.S. public's attitudes toward organ transplants/donation. New Jersey: Princeton.

Gijsbers, S. (2000). Determinanten van orgaan- en weefseldonatie: de rol van waarden en emotionele disposities. (Scriptie). Maastricht: Universiteit Maastricht.

Girandola, F. (2002). Sequential requests and organ donation. The Journal of Social Psychology, 142(2), 171-178.

Glanz, K., Lewis, F., \& Rimer, B. (1997). Health Behavior and Health Education: Theory, Research, and Practice. San Francisco: J osseyBass.

Gnant, M., Wamser, P., Goetzinger, P., Sautner, T., Steininger, R., \& Muehlbacher, F. (1991). The Impact of the Presumed Consent Law and a Decentralized Organ Procurement System on Organ Donation: Quadruplication in the Number of Organ Donors. Transplantation Proceedings, 23, 2685-2686. 
Godin, G., \& Kok, G. (1996). The theory of planned behavior: A review of its application to health-related behaviors. American Journal of Health Promotion, 11, 87-97.

Goldstein, H. (1995). Kendall's Library of Statistics 3: Multilevel Statistical Models (2nd ed. Vol. 3). Londen: Arnold.

Gollwitzer, P. (1993). Goal achievement: The role of intentions. In W. Stroebe \& M. Hewstone (Eds.), European Review of Social Psychology (Vol. 4, pp. 141-185). Chichester, England: Wiley.

Gollwitzer, P., \& Brandstätter, V. (1997). Implementation intentions and effective goal pursuit. Journal of Personality and Social Psychology, 73(1), 186-199.

Goodmonson, C., \& Glaudin, V. (1971). The relationship of commitmentfree behavior and commitment behavior: a study of attitude toward organ transplantation. Journal of Social Issues, 27, 171-183.

Green, L., \& Kreuter, M. (1991). Health Promotion Planning: An educational and environmental approach. Mountain View, CA: Mayfield.

Green, L., \& Lewis, F. (1986). Measurement and evaluation in health education and health promotion. Palo Alto, California: Mayfield Publishing Company.

Gross Portney, L., \& Watkins, M. (2000). Foundations of clinical research: applications to practice. New Jersey: Prentice Hall Health.

Gross, T., Martinoli, S., Spagnoli, G., Badia, F., \& Malacrida, R. (2001). Attitudes and behavior of young european adults towards the donation of organs - a call for better information. American Journal of Transplantation, 1, 74-81.

Hessing, D., \& Elffers, H. (1985). General and physical self-esteem and altruistic behavior. Psychological reports, 56, 930.

Hessing, D., \& Elffers, H. (1986). Attitude toward death, fear of being declared dead too soon, and donation of organs after death. OMEGA, 17, 115-126.

Hoelscher, D., Evans, A., Parcel, G., \& Kelder, S. (2002). Designing effective nutrition interventions for adolescents. Journal of the American Dietetic Association, 102(3), S52-S63.

Horton, R., \& Horton, P. (1990). Knowledge regarding organ donation: identifying and overcoming barriers to organ donation. Social Science and Medicine, 31, 791-800. 
Horton, R., \& Horton, P. (1991). A model of willingness to become a potential organ donor. Social Science and Medicine, 33, 1037-1051.

Ipso Facto. (2000). Evaluatie WOD - Communicatie en voorlichting. Houten.

Israel, B., Cummings, K., Dignan, M., Heany, C., Perales, D., SimonsMorton, B., \& Zimmerman, M. (1995). Evaluation of health education programs: current assessment and future directions. Health Education Quarterly, 22(3), 364-389.

Judd, C., \& Kenny, D. (1981). Estimating the effects of social interventions. Cambridge: Cambridge University Press.

Kirkpatrick, L. (1989). A psychometric analysis of the Allport-Ross and Feagin measures of intrinsic-extrinsic religious orientation. In M. Lynn \& D. Moberg (Eds.), Research in the social scientific study of religion. Greenwich (CT): J Al Press.

Kodde, J., \& Kerkhoff, A. (1992). Schatting van het potentiële aantal donororganen in 1988 en 1989 in 13 ziekenhuizen met een hoofdfunctie neurochirurgie. [Estimation of the potential number of donor organs in 1988 and 1989 in 13 hospitals with a major neurosurgical department.]. Nederlands Tijdschrift voor Geneeskunde, 136, 839-844.

Kok, G., Schaalma, H., De Vries, H., Parcel, G., \& Paulussen, T. (1996). Social Psychology and Health Education. In W. Stroebe \& $M$. Hewstone (Eds.), European Review of Social Psychology (Vol. 7, pp. 241-282).

Kok, G., Van den Borne, B., \& Mullen, P. (1997). Effectiveness of health education and health promotion: meta-analyses of effect-studies and determinants of effectiveness. Patient Education and Counseling, 30, 19-27.

Kokkedee, W. (1998). De Wet op de orgaandonatie aangenomen. Tijdschrift voor Gezondheidsrecht, 4, 202-212.

Kopfman, J. (1994). Understanding the willingness to become a potential organ donor: Testing a theoretical explanation. Paper presented at the annual meeting of the Speech Communication Association, New Orleans, LA. 
Kopfman, J., \& Smith, S. (1996). Understanding the audiences of a health communication campaign: a discriminant analysis of potential organ donors based on intent to donate. Journal of Applied Communication Research, 24, 33-49.

Kranenburg, J., Willems, L., Sieber-Rasch, M., Geertsma, A., \& Ploeg, R. (1998). Het Don Quichot onderzoek: donortekort of donatietekort? [The Don Quichot research: Shortage of donors or shortage of donations?]. Groningen: Academisch Ziekenhuis Groningen.

Kreuter, M., Farell, D., Olevitch, L., \& Brennan, L. (2000). Tailoring health messages: Customizing communication with computer technology. New Jersey: Lawrence Erlbaum Assicoiates, Inc.

Kreuter, M., Oswald, D., Bull, F., \& Clark, E. (2000). Are tailored health education materials always more effective than non-tailored materials? Health Education Research, 15(3), 305-315.

Kunst, M., \& Witlox, N. (1999). Doelgroepenonderzoek donorregistratie jongeren en ouderen. [Target group reseach donor registration adolescents and parents.]. Amsterdam: CO-efficiënt.

Levenson Gingiss, C., Gottlieb, N., \& Brink, S. (1994). Increasing teacher receptivity toward use of tobacco prevention education programs. Journal of Drug Education, 24(2), 163-176.

Lieberman, D. (1997). Interactive video games for health promotion: effects on knowledge, self-efficacy, social support, and health. In R. Street \& W. Gold \& T. Manning (Eds.), Health Promotion and interactive technology: theoretical applications and future directions. (pp. 103-120). Mahwah, New Jersey: Lawrence Erlbaum Associates, Publishers.

MacKinnon, D. (1994). Analysis of mediating variables in prevention and intervention research. NIDA Research Monograph Series, 139, 127153.

Mahoney, J., \& Pechura, C. (1980). Values and volunteers: axiology of altruism in a crisis center. Psychological Reports, 47, 1007-1012.

McNamara, P., Guadagnoli, E., Evanisko, M., Santiago-Delpin, E., Callendar, C., \& Christiansen, E. (1999). Correlates of support for organ donation among three ethnic groups. Clinical Transplantation, 13, 45-50. 
Meier, D., Schultz, K., Kuhlencordt, R., Clausen, C., \& Rogiers, X. (1999). Effects of an educational segment concerning organ donation and transplantation. Transplantation Proceedings, 32, 62-63.

Merion, R., Vinokur, A., Couper, M., Jones, E., Dong, Y., Wimsatt, M., Warren, J., Katz, S., Leichtman, A., \& Beyersdorf, T. (2003). Internet-based intervention to promote organ donor registry participation and family notification. Transplantation, 75(8), 11751179.

Miller, A., \& Hagihara, A. (1997). Organ transplanting in Japan: the debate begins. Public Health, 111, 367-372.

Ministerie van VWS. (2001). WMO. De wet medisch-wetenschappelijk Onderzoek met mensen. Retrieved January, 2004, from the World Wide Web: http://www.ccmo.nl/download/WMO_BRO.pdf

Morgan, S., \& Miller, J. (2002). Communicating about gifts of life: The effect of knowledge, attitudes, and altruism on behavior and behavioral intentions regarding organ donation. Journal of Applied Communication Research, 30(2), 163-178.

Morgan, S., Miller, J., \& Arasaratnam, L. (2002). Signing cards, saving lives: an evaluation of the Worksite Organ Donation Promotion Project. Communication Monographs, 69(3), 253-273.

Mullen, P., Green, L., \& Persinger, G. (1985). Clinical trials of patient education for chronic conditions: a comparative meta-analysis of intervention types. Preventive Medicine, 14, 753-781.

Mullen, P., Mains, D., \& Velez, R. (1992). A meta-analysis of controlled trials of cardiac patient education. Patient Education and Counseling, 19, 143-162.

NIGZ-Donorvoorlichting. (2003). Nieuwsbrief voor docenten: orgaan- en weefseldonatie. [newsletter for teachers: organ and tissue donation.]. Unpublished manuscript, Woerden.

Nolan, B., \& McGarth, P. (1990). Social-cognitive influences on the willingness to donate organs. In J. Shanteau \& R. Jackson Harris (Eds.), Organ donation and transplantation: psychological and behavioral factors (pp. 25-36). Washington, DC: American Psychological Association. 
Nolan, B., \& Spanos, N. (1989). Psychosocial variables associated with willingness to donate organs. Canadian Medical Association Journal, $141,27-32$.

O'Donnell, L., Doval, A., Duran, R., \& O'Donnell, C. (1995). Video-based sexually transmitted disease patient education: its impact on condom acquisition. American Journal of Public Health, 85(6), 817822.

Oenema, A., \& Brug, J. (2003). Feedback strategies to raise awareness of personal dietary intake: results of a randomized controlled trial. Preventive Medicine, 36, 429-439.

Oenema, A., Brug, J., \& Lechner, L. (2001). Web-based tailored nutrition education: results of a randomized controlled trial. Health Education Research, 16(6), 647-660.

Parcel, G., Kelder, S., \& Basen-Engquist, K. (2000). The school as setting for Health Promotion. In B. Poland \& L. Green \& I. Rooman (Eds.), Settings for Health Promotion. (pp. 86-137). Thousand Oaks: Sage Publications.

Parisi, N., \& Katz, I. (1986). Attitudes toward posthumous organ donation and commitment to donate. Health Psychology, 5 (6), 565-580.

Paulussen, T. (1994). Adoption and implementation of AIDS education in Dutch secondary schools. Unpublished Thesis, Maastricht University, Maastricht.

Paulussen, T., Kok, G., \& Schaalma, H. (1994). Antecedents to adoption of classroom-based AIDS education in secondary school. Health Education Research, 9(4), 485-496.

Pranger, D. (1998). Kerken en orgaandonatie. [Churches and organ donation.]. Hilversum: Nierstichting.

Prochaska, J., \& Velicer, W. (1997). The transtheoretical MODEL of health behavior. American Journal of Health Promotion, 12, 38.

Radecki, C., \& Jaccard, J . (1997). Psychological aspects of organ donation: a critical review and synthesis of individual and next-of-kin donation decisions. Health Psychology, 16 (2), 183-195.

Radecki, C., \& Jaccard, J. (1999). Signing an Organ Donation Letter: The Prediction of Behavior From Behavioral Intentions. Journal of Applied Social Psychology, 29, 1833-1853. 
Rasbash, J., Browne, W., Goldstein, H., Yang, M., Plewis, I., Draper, D., Healy, M., \& Woodhouse, G. (1999). A User's Guide to MIwiN. London: Institute of Education.

Reubsaet, A., Brug, J., De Vet, E., \& Van den Borne, B. (2003). The effects of practicing registration of organ donation preference on selfefficacy and registration intention: an enactive mastery experience. Psychology and Health, 18(5), 585-594.

Reubsaet, A., Brug, J., Kitslaar, J ., Van Hooff, J.P., \& Van den Borne, H.W. (2004). The impact and evaluation of two school-based interventions on intention to register an organ donation preference. Health Education Research, 19(4), 447-456.

Reubsaet, A., Brug, J., Nijkamp, M.D., Candel, M.J.J.M., Van Hooff, J.P., \& Van den Borne, H.W. (accepted for publication). The impact of an organ donation registration information curriculum for high school students in the Netherlands.

Reubsaet, A., Brug, J., Van den Borne, B., \& Van Hooff, J. (2001). Predictors of organ donation registration among Dutch adolescents. Transplantation, 72(1), 51-56.

Reubsaet, A., Van den Borne, B., Brug, J., Pruyn, J., \& Van Hooff, H. (2001). Determinants of the intention of Dutch adolescents to register as organ donors. Social Science and Medicine, 53, 383-392.

Reynolds, W. (1982). Development of a reliable and valid short form of the Marlowe-Crowne Social Desirability Scale. Journal of Clinical Psychology, 38, 119-125.

Rijksvoorlichtingsdienst/DTC. (1999). Analyse databestand Donorregister 18-jarigen: voorlopige bevindingen. Leiden: Research voor Beleid bv.

Robbins, R. (1990). Signing an organ donor card: psychological factors. Death Studies, 14, 219-229.

Roels, L., Coosemans, W., Christiaens, M., Waer, M., \& Vanrenterghem, Y. (1995). The Relative Impact of Legislatives on Multi-Organ Donation Rates in Europe. Transplantation Proceedings, 27, 795-796.

Rogers, E. (1995). Diffusion of innovations. New York: Free Press.

Rohrbach, L., Graham, J., \& Hansen, W. (1993). Diffusion of a schoolbased substance abuse prevention program: predictors of program implementation. Preventive Medicine, 22, 237-260. 
Ryckman, R., Van den Borne, B., Thornton, B., \& Gold, J. (2002). Value priorities and organ donation in young adults. Unpublished manuscript, Orono.

Ryckman, R., Van den Borne, B., Thornton, B., \& Gold, J. (2004). Intrinsicextrinsic religiosity and university students' willingness to donate organs posthumously. Journal of Applied Social Psychology, 34(1), 196-205.

Sabini, J. (1995). Social psychology. New York: W.W. Norton \& Company.

Sagiv, L., \& Schwartz, S. (1995). Value priorities and readiness for outgroup social contact. Journal of Personality and Social Psychology, 69(3), 437-448.

Sanders, J. (2003). Leven door geven: Religieuze en levensbeschouwelijke standpunten over orgaan- en weefseldonatie. [Living by giving: Religious perspectives on organ and tissue donation.]. Zoetermeer: Uitgeverij Meinema.

Sanner, M. (2002). A Swedish survey of young people's views of organ donation and transplantation. Transplantation International, 15, 641-648.

Sanner, M., Hedman, H., \& Tufveson, G. (1995). Evaluation of an organdonor-card campaign in Sweden. Clinical Transplantation, 9, 326333.

Schulz, K., Meier, D., Clausen, C., Kuhlencordt, R., \& Rogiers, X. (2000). Predictors of the intention to donate organs: an empirical model. Transplantation Proceedings, 32, 64-65.

Schwartz, S. (1992). Universals in the content and structure of values: Theoretical advances and empirical tests in 20 countries. Advances in Experimental Social Psychology, 25, 1-65.

Seldenrijk, R. (1993). Organen en weefsels: Een medisch-ethische afweging van de transplantatiegeneeskunde. Leiden: Uitgeverij J.J Groen en Zoon.

Sheeran, P. (2002). Intention-behavior relations: A conceptual and empirical review. In W. Stroebe \& M. Hewstone (Eds.), European Review of Social Psychology (Vol. 12, pp. 1-36). Chichester, England: Wiley. 
Sheeran, P., \& Orbell, S. (1998). Do intentions predict condom use? Metaanalysis and examination of six moderator variables. British Journal of Social Psychology, 37, 231-250.

Sheeran, P., \& Orbell, S. (1999). Implementation intentions and repeated behaviour: argumenting the predictive validity of the theory of planned behaviour. European Journal of Social Psychology, 29, 349369.

Sheeran, P., \& Orbell, S. (2000). Using implementation intentions to increase attendance for cervical cancer screening. Health Psychology, 19(3), 283-289.

Sheeran, P., \& Silverman, M. (2003). Evaluation of three interventions to promote workplace health and safety: evidence for the utility of implementation intentions. Social Science and Medicine, 56, 21532163.

Sherman, N., Sherman, M., Smith, R., \& Rickert-Wilbur, P. (2001). Disgust sensitivity and attitudes toward organ donation among AfricanAmerican college students. Psychological Reports, 89, 11-23.

Skowronski, J. (1997). On the psychology of organ donation: attitudinal and situational factors related to the willingness to be an organ donor. Basic and Applied Social Psychology, 19 (4), 427-456.

Skumanich, S., \& Kintsfather, D. (1996). Promoting the organ donor card: A causal model of persuasion effects. Social Science and Medicine, 43(3), 401-408.

Slavin, L. (1993). Transplant and organ donation education in schools: does it work? Renal Education, 13(4), 57-60.

Smith, S., Morrison, K., Kopfman, J., \& Ford, L. (1994). The influence of prior thought and intent on the memorability and persuasiveness of organ donation message strategies. Health Communication, 6 (1), 1-20.

Snijders, T., \& Bosker, R.J. (2003). Multilevel analysis: an introduction to basic and advanced multilevel modeling. Londen: SAGE Publications.

Spital, A. (2001). Public attitudes toward kidney donation by friends and altruistic strangers in the United Sates. Transplantation, 71(8), 1061-1064. 
Strecher, V. (1999). Computer-tailored smoking cessation materials: A review and discussion. Patient Education and Counseling, 36, 107117.

Swanborn, P. (1994). Methoden van sociaal-wetenschappelijk onderzoek. Meppel: Boom.

Tabachnick, B., \& Fidell, L. (1996). Using multivariate statistics. New York: HarperCollins Publishers Inc.

Torabi, M., Crowe, J., Rhine, S., Daniels, D., \& Jeng, I. (2000). Evaluation of HIV/AIDS education in Russia using a video approach. Journal of School Health, 70(6), 229-233.

Van den Ban, A., \& Hawkins, H. (1996). Agricultural extensions. Oxford: Blackwell Science Ltd.

Van den Driessche, A., Van Zoelen, A., Cleiren, M., \& Van Hoorn, W. (1996). Orgaandonatie en culturele verschillen: workshop. [Organ donation and cultural differences: workshop.]. Leiden: Rijksuniversiteit Leiden.

Van Graft, M., \& Lensink, H. (2000). Orgaandonatie en registratie: analyse van examenprogramma's ten behoeve van mogelijkheden voor een educatief programma. [Organ donation and registration: analysis of the school curriculum on the possibilities for an education program.]. Enschede: Stichting Leerplan Ontwikkeling.

Van 't Hoog, A. (Ed.). (2001). Zo goed als nieuw! De toekomst van orgaanvervanging. [As good as new! The future of organ replacement.]. Amsterdam: Boom/Rathenau Instituut.

Weaver, M., Spigner, C., Pineda, M., Rabun, K., French, L., Taylor, L., \& Allen, M. (1999). Impact of School-Based Teaching on Students' Opinions of Organ Donation and Transplantation. Transplantation Proceedings, 31, 1086-1087.

Weintraub Austin, E. (1995). Reaching young audiences: developmental considerations in designing health messages. In E. Maibach \& R. Parrot (Eds.), Designing health messages: approaches from communication theory and public health practice. (pp. 114-144). Thousand Oaks: Sage Publications.

Wetzel, C., Radtke, P., \& Stern, H. (1994). Instructional effectiveness of video media. Hillsdale, New Jersey: Lawrence Erlbaum Associates, Publishers. 
Windsor, R., Baranowski, T., Clark, N., \& Cutter, G. (1994). Evaluation of health promotion, health education, and disease prevention programs. Mountain View, CA: Mayfield.

Yeung, I., Kong, S., \& Lee, J. (2000). Atitudes towards organ donation in Hong Kong. Social Science \& Medicine, 50, 1643-1654.

Yuen, C., Burton, W., Chiraseveenuprapund, P., Elmore, E., Wong, S., Ozuah, P., \& Mulvihill, M. (1998). Attitudes and beliefs about organ donation among different racial groups. Journal of the National Medical Association, 90 (1), 13-18.

Zaltman, G., \& Duncan, R. (1977). Strategies for planned change. New York: Wiley.

ZonMW. (2001). Evaluatie Wet op de Orgaandonatie. Den Haag. 



\section{Summary \\ $\&$ \\ Samenvatting}

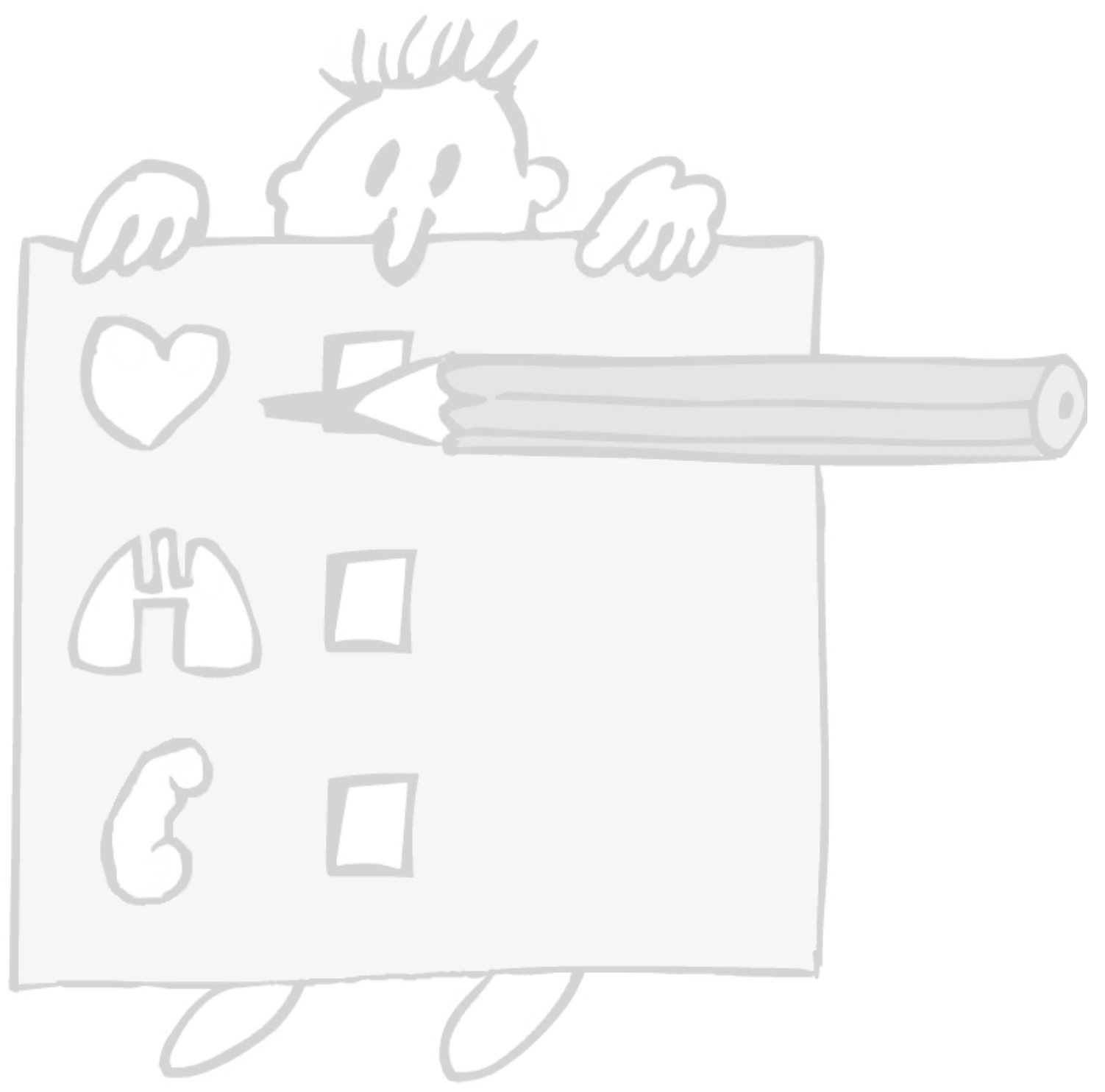




\section{Summary}

In the Netherlands, as in most countries, a vast disparity exists between the demand for donor organs and tissues and their available supply. In spite of the new organ donation legislation that was implemented in 1998, low registration rates in the Netherlands continue to exist. It is recommended that educational organ donation interventions should focus on groups with low registration rates. The present thesis describes the development and evaluation of a school-based organ donation registration intervention aimed at enabling adolescents to make a well-informed decision about organ donation and to encourage them to register their organ donation preferences.

The first part of the thesis (Chapters 1 and 2) presents the results of a large-scale study conducted among Dutch adolescents to identify psychosocial determinants associated with organ donation registration. Based on the results of part 1, the second part (Chapters 3 and 4) describes the development and evaluation of the three separate components for an educational intervention. Part 3 (Chapters 5 and 6) describes the process and effect evaluation of an integrated school-based education programme among students and teachers. The thesis ends with a general discussion and implications for future research.

In developing a school-based organ donation intervention, it is important to know why many adolescents fail to register their organ donation preferences. Chapter 1 describes possible determinants of the intention to register as organ and tissue donors among Dutch adolescents who had not yet been approached to register an organ donation preference (i.e., aged 16 to 18 years), while Chapter 2 describes the determinants among adolescents in the age of 18 and 19 years who already received an organ donation registration form. More negative outcome beliefs, fewer positive outcome beliefs, and less positive social influences appeared to be important factors for adolescents to omit taking a decision on registration of an organ donation preference. Further, correct knowledge about organ donation and registration procedures was significantly associated with organ donation registration and adolescents who had previously thought about organ donation and had discussed it with others, were more willing 
to register their organ donation preferences. The findings presented in part 1 of this thesis were used to develop a school-based organ donation education programme tailored to the characteristics, information needs, and beliefs of Dutch adolescents.

In accordance with general recommendations for developing educational interventions, draft intervention components were developed and tested in three pilot studies. Chapter 3 describes the findings of two studies on the development and short-term impact of two intervention components. The first study concluded that a video presentation with a group discussion was effective in increasing both the intention to register an organ donation preference and the willingness to register as a posthumous donor. In the second study, an interactive computer-tailored intervention was compared with general information on organ donation to evaluate its impact on registration intentions. The results showed that the tailored intervention did not have more impact than general information on intention to register organ donation choices or intention to become organ donor. However, the interactive computer programme was better appreciated than the extensive brochure with general organ donation information.

Chapter 4 presents the results of a Randomised Controlled Trial among 242 Dutch high school students in which practicing with completing a standard registration form was evaluated. The registration training session resulted in an increase in the likelihood to register an organ donation preference, but not in a higher willingness to register as an organ donor. Furthermore, self-efficacy beliefs with regard to completing and returning a donor registration form increased because of the training.

Chapter 5 describes the effect evaluation of the integrated schoolbased organ donation intervention conducted in 39 Dutch high schools in a randomised study among 2868 students. The study focused on the shortterm effects on registration intentions, outcome beliefs, correct knowledge, and self-efficacy expectations. The conclusions were that after exposure to the organ donation registration lessons, students were more willing to register their preferences with regard to organ donation, were more likely to register as an organ donor, and experienced less negative outcome beliefs. Furthermore, students who were exposed to the education programme had more knowledge about organ donation and registration 
procedures and experienced more positive social influences and selfefficacy beliefs regarding organ donation registration. It was concluded that because of the confirmed effectiveness, large-scale implementation of the programme in the Dutch school curriculum should be planned.

Chapter 6 deals with the process evaluation of the school-based organ donation programme and the intention of teachers to continue with using the programme in the future. Fifty teachers who had recently worked with the organ donation education programme participated in the study. It was concluded that teachers were generally positive about the school-based intervention and confident about their ability to apply the different components, which resulted in a large number of teachers intending to use the programme in the next years.

The final chapter (Chapter 7) summarises and discusses the main findings of the studies presented in this thesis. The chapter provides a theoretical reflection on the studies and its results and discusses several methodological issues. Lastly, implications for future research and practice are discussed. 


\section{Samenvatting}

In Nederland bestaat, net zoals in veel andere landen, een groot verschil tussen de vraag naar en het aanbod van donororganen en - weefsels. Ondanks de Wet op de Orgaandonatie die in 1998 van kracht werd, blijft het aantal registraties in Nederland laag. Voorlichting over orgaandonatie dient zich vooral te richten op specifieke groepen waar het registratiepercentage laag is. Dit proefschrift beschrijft de ontwikkeling en evaluatie van een lespakket over orgaandonatie en registratie dat erop gericht is jongeren te helpen een weloverwogen beslissing te nemen over orgaandonatie op hun $18^{\mathrm{e}}$ jaar en hen stimuleert om hun keuze ten aanzien van orgaandonatie te laten vastleggen in het Donorregister.

Het eerste deel van dit proefschrift (Hoofdstuk 1 en 2) toont de resultaten van een grootschalig onderzoek onder Nederlandse jongeren naar de psychosociale determinanten van orgaandonatie en registratie. Gebaseerd op de resultaten van deel 1 is in het tweede deel (Hoofdstuk 3 en 4) de ontwikkeling en evaluatie van een voorlichtingsprogramma beschreven en in het bijzonder de drie afzonderlijke componenten van deze interventie. Deel 3 (Hoofdstuk 5 en 6) beschrijft de proces- en effectevaluatie van de toepassing van het geïntegreerde lespakket onder scholieren en docenten. Het proefschrift wordt afgesloten met een algemene discussie en aanbevelingen voor toekomstig onderzoek.

Bij de ontwikkeling van een lespakket over orgaandonatie en registratie is het allereerst belangrijk te weten waarom adolescenten hun voorkeur met betrekking tot orgaandonatie niet laten registreren. Hoofdstuk 1 beschrijft de mogelijke determinanten van de bereidheid om orgaandonor te worden onder Nederlandse jongeren, die nog geen registratieformulier hebben ontvangen (leeftijd 16 tot 18 jaar), terwijl Hoofdstuk 2 de determinanten van orgaandonatie en registratie beschrijft onder jongeren van 18 en 19 jaar, die wel reeds een registratieformulier hebben ontvangen. Meer negatieve uitkomstverwachtingen, minder positieve uitkomstverwachtingen en meer negatieve sociale invloeden blijken belangrijke factoren te zijn voor het niet laten registreren van voorkeuren met betrekking tot orgaandonatie. Tevens bleek correcte kennis over orgaandonatie en registratieprocedures significant geassocieerd te zijn 
met orgaandonatieregistratie en bleken jongeren die al eerder hebben nagedacht over orgaandonatie en hier met anderen al eens over gepraat hebben, eerder bereid om hun keuze te laten vastleggen. De bevindingen gepresenteerd in deel 1 van dit proefschrift zijn vervolgens gebruikt voor de ontwikkeling van een lespakket over orgaandonatie en registratie dat is aangepast aan de kenmerken, informatiebehoeften en opvattingen van Nederlandse jongeren.

In overeenstemming met algemene aanbevelingen voor de ontwikkeling van voorlichtingsinterventies zijn interventieonderdelen ontwikkeld en getest in drie aparte deelstudies. Het derde hoofdstuk beschrijft de bevindingen van twee studies naar de ontwikkeling en korte termijn effecten van twee andere interventieonderdelen. In de eerste studie werd geconcludeerd dat een video met aansluitend een discussie in de klas effectief is in zowel het vergroten van de bereidheid om een keuze met betrekking tot orgaandonatie te laten vastleggen, als in het vergroten van de bereidheid om orgaandonor te worden. In de tweede studie werd een interactief "advies-op-maat" programma vergeleken met een brochure met algemene informatie over orgaandonatie en registratie om het effect op registratie-intenties te beoordelen. De resultaten van deze studie laten zien dat het advies-op-maat niet meer effect had op de intentie om orgaandonatievoorkeuren te laten registreren of op de bereidheid om donor te worden dan de brochure met algemene informatie over orgaandonatie en registratie. Leerlingen waardeerden echter het interactieve computerprogramma wel beter dan de brochure.

Hoofdstuk 4 beschrijft de resultaten van een onderzoek onder 242 Nederlandse middelbare scholieren waarin het oefenen met het invullen van registratieformulieren werd geëvalueerd. De registratieoefening resulteerde in een toename van de bereidheid om een orgaandonatiekeuze te laten registreren, echter niet in een hogere bereidheid om zich als orgaandonor te laten registreren. Bovendien nam de eigeneffectiviteit om een registratieformulier in te vullen en op te sturen door de oefening toe.

Hoofdstuk 5 beschrijft de effectevaluatie van het geïntegreerde lespakket over orgaandonatie en registratie dat is uitgevoerd onder 2868 leerlingen op 39 middelbare scholen in Nederland. Dit onderzoek richt zich op de korte termijn effecten van het lespakket op registratie-intenties, uitkomstverwachtingen, correcte kennis en eigeneffectiviteits- 
verwachtingen. Geconcludeerd kan worden dat leerlingen na het volgen van de lessen over orgaandonatie en registratie meer bereid waren om een orgaandonatiekeuze te laten vastleggen en om zich te laten registreren als orgaandonor en dat ze minder negatieve uitkomstverwachtingen hadden. Bovendien hadden de leerlingen die met het lespakket hadden gewerkt meer juiste kennis over orgaandonatie en registratieprocedures, ervoeren ze meer positieve sociale invloeden en achtten ze zichzelf beter in staat om een registratieformulier in te vullen. Aangezien het lespakket effectief is gebleken, wordt het landelijk ingevoerd in het Nederlandse onderwijscurriculum.

In Hoofdstuk 6 wordt de procesevaluatie van het lespakket en de intentie om het lespakket in de toekomst weer te gebruiken, besproken. In deze studie namen vijftig docenten, die recent met het lespakket hadden gewerkt, deel. De docenten oordeelden over het algemeen positief over het lespakket en hadden vertrouwen in hun bekwaamheid om de verschillende onderdelen toe te passen. Hierdoor heeft een groot aantal docenten de intentie om het lespakket de komende jaren te blijven gebruiken in hun lessen.

In het laatste hoofdstuk van dit proefschrift (Hoofdstuk 7) worden de belangrijkste resultaten samengevat en bediscussieerd. Het hoofdstuk geeft een theoretische reflectie op het onderzoek en de resultaten en bediscussieert verschillende methodologische aspecten. Tot slot worden implicaties voor toekomstig onderzoek en de praktijk besproken. 



\section{Dankwoord $\&$ Curriculum Vitae}

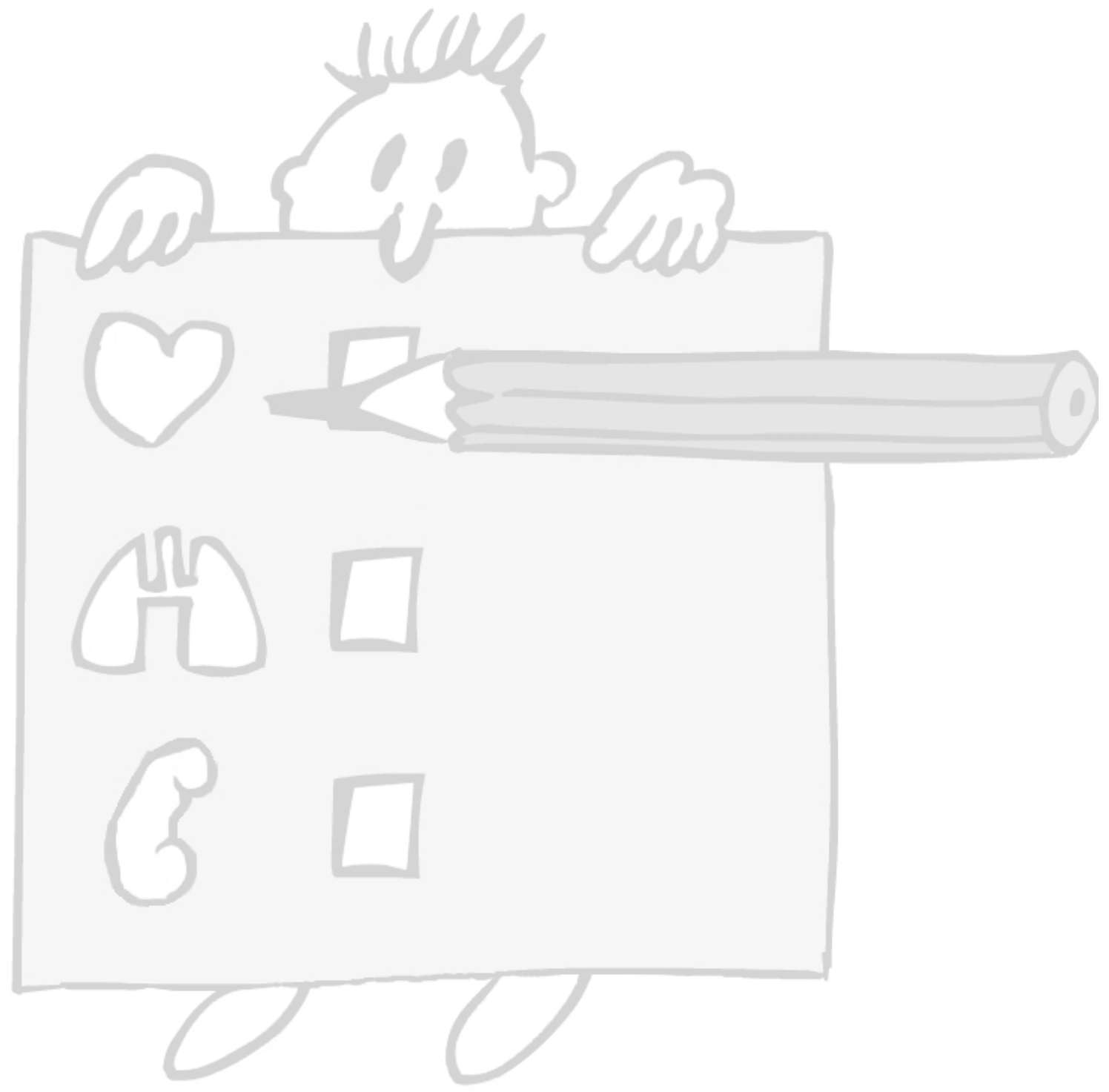




\section{Dankwoord}

De afgelopen jaren hebben veel mensen op verschillende manieren een bijdrage geleverd aan dit proefschrift. Allereerst wil ik mijn promotoren, Bart van den Borne, Hans Brug en Hans van Hooff bedanken voor de totstandkoming en begeleiding van dit project. Bart, jij bent degene geweest die mij in eerste instantie enthousiast heeft gemaakt voor het onderzoek. Bedankt hiervoor en voor al je inzet en begeleiding tijdens het project. Hans, bedankt voor de fijne gesprekken en heldere adviezen die je me altijd hebt gegeven. Jij hebt me erg geholpen en gesteund in een moeilijke periode en dat waardeer ik enorm. Hans van Hooff wil ik bedanken voor de mogelijkheden om dit onderzoek uit te voeren.

Emile Schaeken wil ik bedanken voor zijn onuitputtelijke inzet tijdens dit project, maar ook na afloop van het onderzoek. Mede dankzij jouw inzet werkt al meer dan vijftig procent van alle middelbare scholen in Nederland met het lespakket. Bedankt, ik heb veel van je geleerd. De leden van de begeleidingscommissie, J ean Servais, Riemke van Netten, Daniëlle Monté, Bert Elbertse, Rob Zeguers, Kim Schoen, en Désiree van der Heijden wil ik bedanken voor hun interesse en adviserende rol tijdens het project.

De directies, docenten en leerlingen van de deelnemende scholen wil ik bedanken voor het beoordelen van het lespakket en hun goede medewerking. Aad Reeuwijk wil ik bedanken voor het afnemen van de vragenlijsten tijdens de veldstudie, hetgeen een enorme klus is geweest. Tijdens het project heb ik veel hulp gehad van J anou Kitslaar. Bedankt voor je inzet en enthousiasme. Met veel plezier kijk ik terug op de periode dat je op de vakgroep werkte. Evelien Reinaerts en Emely de Vet, bedankt voor de leuke tijd die we tijdens jullie stage hebben gehad en voor jullie bijdrage aan dit project. De medewerkers van dataentry bureau Cendris, dank voor de vele vragenlijsten die jullie hebben ingevoerd.

De volgende mensen wil ik bedanken voor hun bijdrage aan de ontwikkeling van het lespakket. Harold Dello en Mark Lardinois wil ik bedanken voor de ontwikkeling van het tailoringprogramma. Kaspar Guyaux, bedankt voor de illustraties die je voor ons gemaakt hebt en voor de fijne samenwerking. Voor de productie van de video wil ik de audiovisuele dienst van het azM en Claudia de Leeuw bedanken. Ook dank aan de personen die in de video hun bijdrage hebben geleverd. 
Jan Klerkx en Derek Reilly bedankt voor jullie correcties van de Engelstalige publicaties. Lieve collega's en oud-collega's, ik wil jullie bedanken voor alle gezellige momenten die we de afgelopen jaren hebben gehad. Jullie zijn een grote steun voor mij. Een speciaal woord van dank voor Ciska, Froukje en Evelien voor het proeflezen van dit proefschift. Tamara, ook jij bedankt voor het proeflezen, maar vooral voor die momenten dat ik het even niet meer zag zitten. Je bent een fijne collega en vriendin. Jascha wil ik bedanken voor alle steun en de deur die altijd openstaat voor mij. Tenslotte, Marja, bedankt dat ik af en toe op je bankje mocht zitten en voor je hulp bij het afronden van mijn proefschrift.

Mijn paranimfen, Marjan Nijkamp en Yvonne Koppelman, bedankt dat jullie op deze dag naast me staan. Yvonne, ik kijk met ontzettend veel plezier op onze tijd in de Ambyerstraat terug. Marjan, wat bof ik toch met jou als kamergenootje. Je bent een geweldige meid, bedankt voor alles.

In het bijzonder wil ik mijn ouders bedanken voor alle steun en praktische hulp. Bedankt, voor het grote vertrouwen dat jullie altijd in mij hebben. Tenslotte, Michiel en Frederike bedankt dat jullie er altijd voor mij zijn. Soms is dank niet in woorden uit te drukken. 


\section{Curriculum Vitae}

Astrid Reubsaet werd geboren op 22 november 1973 te Heerlen. In 1993 behaalde ze haar VWO-diploma op het Sintermeerten College in Heerlen en in datzelfde jaar startte zij met de studie Gezondheidswetenschappen aan de Universiteit Maastricht. In september 1998 studeerde zij af met als afstudeerrichting Gezondheidsvoorlichting (GVO). Vanaf mei 1998 werkte zij als onderzoeksassistent op de capaciteitsgroep Gezondheidsvoorlichting van de Universiteit Maastricht waarna zij in september 1999 begonnen is aan haar promotieonderzoek “De ontwikkeling, implementatie en evaluatie van een voorlichtingsprogramma over orgaandonatie en registratie voor middelbare scholieren". Sinds september 2004 werkt zij als postdoc "sociale oncologie" op de capaciteitsgroep GVO in Maastricht. 